Numerical investigation of spray combustion towards HITAC conditions

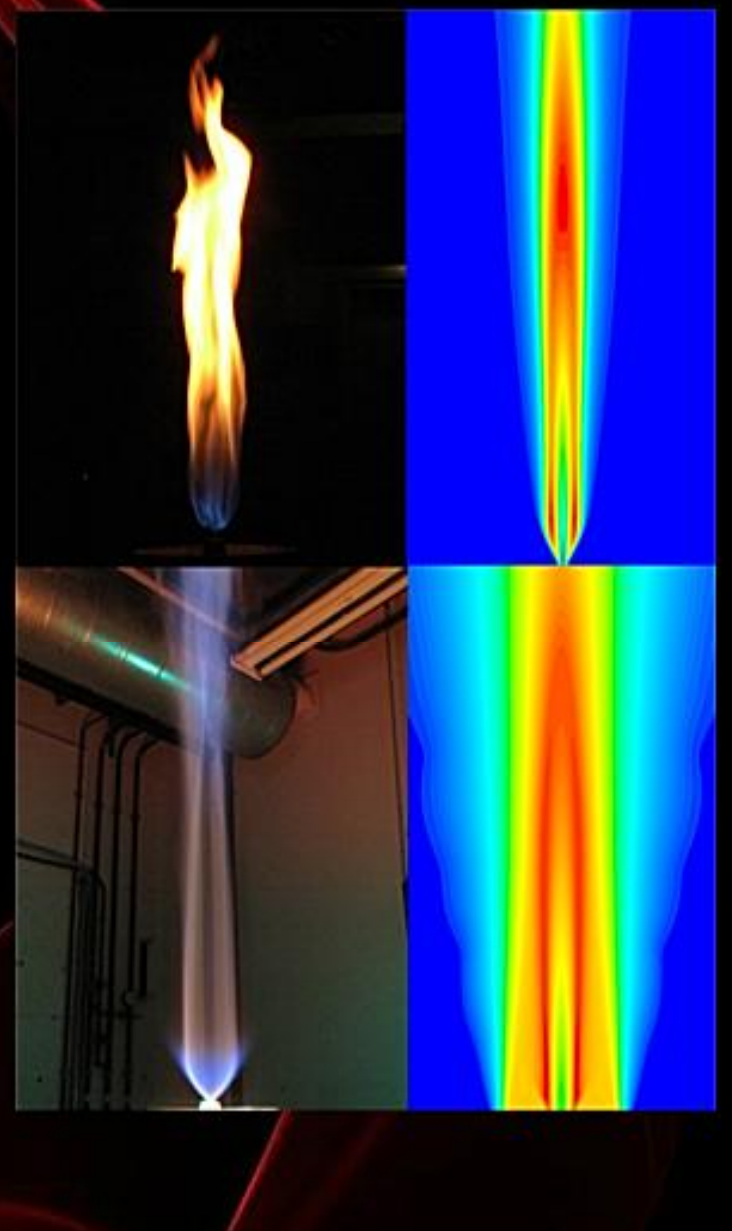

Shanglong Zhu 


\section{NUMERICAL INVESTIGATION OF SPRAY COMBUSTION TOWARDS HITAC CONDITIONS}

Shanglong Zhu 


\section{Composition of the graduation committee}

Chairman and secretary

Prof.dr. G.P.M.R. Dewulf University of Twente

Promotor

Prof.dr.ir. T.H. Van der Meer University of Twente

Co-promotor

Dr.ir. A.K. Pozarlik University of Twente

Prof.dr. D.J.E.M. Roekaerts Delft University of Technology

Members

Dr.ir. B.C.H. Venneker Stork Thermeq, Henglo

Prof.dr.ir. G. Brem University of Twente

Dr.ir. A.R. Thornton University of Twente

Prof.dr.ir. S.A. Klein Delft University of Technology

Dr.ir. L.M.T. Somers $\quad$ Eindhoven University of Technology

This research was financially supported by the Technology Foundation STW (project 10418, part of the Clean Combustion Concepts Programme).

Key wards: simulation, HiTAC, fuel oil, hot co-flow, spray combustion

Printed by: Ipskamp Printing B.V., Enschede, The Netherlands

Copyright (C) 2017 by Shanglong Zhu

ISBN: 978-90-365-4272-2

An electronic version of this dissertation is available at

https://doi.org/10.3990/1.9789036542722 


\title{
NUMERICAL INVESTIGATION OF SPRAY COMBUSTION TOWARDS HITAC CONDITIONS
}

\section{DISSERTATION}

\author{
to obtain the degree of doctor \\ at the University of Twente, on the authority of \\ the Rector Magnificus, prof.dr. T.T.M. Palstra, \\ on account of the decision of the graduation committee, \\ to be publicly defended \\ on Wednesday $8^{\text {th }}$ of February 2017 at $14: 45$
}

By

Shanglong Zhu

Born on $3^{\text {rd }}$ of December 1983

in Chaohu, Anhui, China 
The dissertation is approved by:

Prof.dr.ir. T.H. van der Meer

Promotor

Dr.ir. A.K. Pozarlik

Co-promotor

Prof.dr. D.J.E.M. Roekaerts

Co-promotor 
To my parents, my wife and my daughter.. 



\section{SUMMARY}

The improvement of combustion efficiency with low emissions has led researchers to have more interest in new combustion technology and combustion modeling in various applications in decades. The features of High Temperature Air Combustion (HiTAC), i.e. high-efficiency combustion processes creating a uniform temperature distribution with low $\mathrm{NO}_{\mathrm{X}}$ (Nitrogen oxides) and $\mathrm{CO}$ (Carbon monoxide) emissions, lend itself ideally for the combustion of all sorts of "difficult" fuels, ranging from low-calorific gases such as waste-gases, to heavy fuel-oils. However, to date most of the applications of HiTAC are for gaseous fuels and solid fuels, while little has been investigated on liquid fuel spray combustion in such combustion regimes.

The objective of the research presented in this thesis is to identify and specify the important parameters for achieving good model performance and to understand how HiTAC conditions can be achieved for spray combustion. For this purpose numerical investigations have been performed on the NIST (National Institute of Standards and Technology) methanol spray flame under a conventional condition, the DSHC (Delft Spray-in-Hot-Coflow) ethanol spray flames in both cold and hot co-flow conditions, and the heavy fuel oil spray combustion in a $9 \mathrm{MW}$ boiler with flue gas recirculation using Stork Double Register Burner (DRB).

The NIST methanol spray flame was numerically studied using an EulerianLagrangian RANS model. Experimental data and previous numerical investigations by other researchers on this flame were analysed to develop methods for more 
comprehensive model validation. The inlet boundary conditions of the spray were generated using semi-empirical models representing atomization, collision, coalescence and secondary breakup. Experimental information on the trajectory of the spray was used to optimise the parameters of the pressure-swirl atomizer model. The standard $\mathrm{k}-\varepsilon$ turbulence model was used with enhanced wall treatment. A detailed reaction mechanism of gaseous combustion of methanol was used in the frame of the steady laminar flamelet model. The radiative transfer equations were solved using the discrete ordinates method. In general, the predicted mean velocity components of the gaseous flow and the droplets, the droplet number density, and the SMD (Sauter Mean Diameter) of the droplets at various heights in the present study show better agreement with the experiment than previous numerical studies. Special attention is paid to the relative merits of the employed method to set inlet boundary conditions compared to the alternative method of using a measured droplet size and velocity distribution.

In the simulation of DSHC flames, we extended the limited co-flow conditions of experiment to a series of combinations of temperatures $(300 \mathrm{~K}, 600 \mathrm{~K}, 900 \mathrm{~K}, 1200 \mathrm{~K}$ and $1500 \mathrm{~K})$ and $\mathrm{O}_{2}$ concentrations $(21 \%, 18 \%, 15 \%, 12 \%, 9 \%$ and $6 \%$ vol). The same methods and models as introduced in the simulation of the NIST flame were used. The results showed that with constant co-flow velocity, although the increased temperature leads to a lowered density of the co-flow which then enlarges the flame zone, the increased enthalpy input still results in a high peak temperature in the flame and thus leads to more thermal $\mathrm{NO}_{\mathrm{x}}$ formation. A low $\mathrm{O}_{2}$ concentration is considered as the key to lead to a low peak temperature in the flame and reduced consumption rate of fuel. Both in return slow down the evaporation process of droplets. 
The cold co-flow case $\left(300 \mathrm{~K}\right.$ and $21 \%$ vol $\mathrm{O}_{2}$ concentration) and the hot co-flow case $\left(1500 \mathrm{~K}\right.$ and $6 \%$ vol $\mathrm{O}_{2}$ concentration) were compared with the experimental data under the similar co-flow conditions. The flame profiles and SMD at various elevations showed good agreements. Some deviations were attributed to limitations of either the experiment or models used in simulation. This has been discussed with the comparison of results from other researchers. The conditional droplet injection model employed in work of Ma et al. leading to a good match between experimental data and simulation results has been introduced and discussed as well. This model is tuned based on a large amount of measured data and preliminary predictions of droplets from simulation to count for the droplets not captured in the experiment and evaporated at low elevations. In general the models and methods used in the present study are considered effective and efficient for a comparative study to investigate the influences of co-flow conditions on spray flames in the reaction zone. However, for proper model validation multiple cases are required to obtain a convincing and transferable modeling approach.

Heavy fuel-oil combustion in a 9MW boiler was numerically investigated with the Euler-Lagrange method as well. Due to the complexity of geometry and inlet conditions, a method of staged simulation employing the second order upwind scheme was used. For combustion model, since detailed reaction mechanisms of heavy fuel oils are not available yet, the Eddy Dissipation (ED) model with a two-step global reaction mechanism was used instead.

The results showed that a more uniform temperature distribution in the boiler can be achieved by diluting the primary and secondary air flow with flue gas recirculation. In 
this way the thermal $\mathrm{NO}_{\mathrm{x}}$ can be effectively reduced, while the remained fuel $\mathrm{NOx}$ formation is mainly dependent on the local combustion characteristics and the initial concentration of nitrogen-bound compounds. The contribution of fuel bound nitrogen to $\mathrm{NO}_{\mathrm{X}}$ formation and its reduction requires further investigation supported by the detailed reaction mechanism. Besides, soot formation should be included in the simulation since it shows considerable influence on peak temperature and $\mathrm{NO}_{\mathrm{X}}$ formation. It is also concluded that the realization of HiTAC-like conditions in heavy fuel-oil combustion depends on the possibility to guarantee a sufficiently high level of flue gas recirculation flow into the evaporating spray jet. 


\section{SAMENVATTING}

De efficiëntie van een verbrandingsproces met lage emissies heeft er voor gezorgd dat onderzoekers meer dan ooit interesse hebben in nieuwe verbrandingstechnologie en verbrandingsmodellen in verschillende toepassingen. "High Temperature Air Combustion" (HiTAC) is een zeer efficiënt verbrandingsproces, dat zorgt voor een uniforme temperatuurdistributie met lage $\mathrm{NOx}$ (Nitrogen oxides) en $\mathrm{CO}$ (Carbon monoxide) emissies. HiTAC leent zich ideaal voor het verbranden van verscheidene "moeilijke" brandstoffen, variërend van laagcalorische gassen zoals afval-gassen tot zware stookolie. Echter, tot op heden zijn de meeste toepassingen van HiTAC voor gasvormige brandstoffen en vaste brandstoffen, terwijl er weinig onderzoek is gedaan naar de verbranding van vloeibare brandstof in dit verbrandingsregime.

Het doel van het onderzoek, gepresenteerd in deze scriptie, is het identificeren en specificeren van de belangrijke parameters voor een goede modellering van HiTAC en om kennis te krijgen hoe HiTAC condities kunnen worden bereikt voor olievlammen. Met dit doel voor ogen, zijn simulaties uitgevoerd van de NIST (National Institute of Standards and Technology) methanol spray vlam onder conventionele omstandigheden, de DSHC (Delft Spray-in-Hot-Coflow) ethanol spray vlammen in koude en hete co-flow condities en de zware stookolie spray verbranding in een 9MW boiler met rookgas recirculatie, gebruik makend van de Stork Double Register Burner (DRB).

De NIST methanol spray vlam was numeriek bestudeerd gebruikmakend van een 
Eulerian-Lagrangian RANS model. Experimentele data en voorgaande numerieke simulaties, uitgevoerd door andere onderzoekers op deze vlam, zijn geanalyseerd om methodes te ontwikkelen voor een uitgebreidere model validatie. De inlaat randvoorwaarden voor de spray zijn gegenereerd, gebruikmakend van semi-empirische modellen welke de atomisering, botsing, coalescentie en secondaire break-up representeren. Experimentele informatie over het traject van de spray is gebruikt om de parameters van het "pressure-swirl atomizer" model te optimaliseren. Het standaard k- $\varepsilon$ turbulentie model is gebruikt met een "enhanced wall treatment". Een gedetailleerd chemisch reactie mechanisme van de gasvormige verbranding van methanol is gebruikt in het raamwerk van het stationaire laminaire flamelet model. De vergelijkingen voor warmteoverdracht door straling zijn opgelost gebruikmakend van de "discrete ordinate method". In het algemeen laten de voorspelde gemiddelde snelheden van de gasvormige stroming, de snelheden van de druppels, de verdeling van de druppels, en de SMD (Sauter Mean Diameter) van de druppels op verschillende niveaus in het huidige onderzoek, een betere overeenkomst zien met het experiment dan voorgaande simulatie studies. Er is speciale aandacht besteed aan de relatieve verdiensten van de aangenomen methode om de inlaat randvoorwaarden in te stellen in relatie met de alternatieve methode gebruikmakend van een gemeten druppelgrootte en snelheidsdistributie.

In de simulaties van DSHC vlammen hebben we de beperkte co-flow condities van het experiment uitgebreid naar een combinatie van temperaturen $(300 \mathrm{~K}, 600 \mathrm{~K}, 900 \mathrm{~K}$, $1200 \mathrm{~K}$ en $1500 \mathrm{~K})$ en $\mathrm{O}_{2}$ concentraties $(21 \%, 18 \%, 15 \%, 12 \%, 9 \%$ en $6 \%$ vol). Dezelfde methoden en modellen zoals geïntroduceerd in de simulaties van de NIST vlam zijn gebruikt. De resultaten lieten zien dat bij constant co-flow snelheid de verhoogde 
enthalpie in de co-flow resulteert in een hogere maximale temperatuur in de vlam en dus tot meer thermische NO-formatie. Dit ondanks de lagere dichtheid van de co-flow, hetgeen resulteert in een grotere vlamzone. Een lage $\mathrm{O}_{2}$ concentratie zal leiden tot een lage piek temperatuur in de vlammen en tot een reductie van het brandstofverbruik. Daar staat tegenover dat het verdampingsproces wordt vertraagd.

De koude co-flow situatie ( $300 \mathrm{~K}$ en $21 \%$ vol. $\mathrm{O}_{2}$ concentratie) en de hete co-flow situatie $\left(1500 \mathrm{~K}\right.$ en $6 \%$ vol. $\mathrm{O}_{2}$ concentratie) werden vergeleken met de experimentele data met vergelijkbare co-flow condities. De vlamprofielenen en SMD bij verschillende vlamhoogtes lieten goede overeenkomsten zien. Afwijkingen zijn te wijten aan de beperkingen van het experiment of aan de modellen die gebruikt zijn in de simulatie. Een vergelijking van de resultaten met die van andere onderzoekers is gemaakt. Het conditionele druppel injectie model gebruikt in het onderzoek van Ma et al., leidend tot een goede match tussen de experimenten en simulaties, is geïntroduceerd en ook bediscussieerd. Dit model is gebaseerd op een grote hoeveelheid gemeten data en preliminaire voorspellingen van druppels uit simulaties en houdt rekening met druppels die niet kunnen worden waargenomen in de experimenten en zijn verdampt op lage hoogtes. In het algemeen zijn de modellen en methodes, die gebruikt zijn in de huidige studie, effectief en efficiënt voor een vergelijkende studie om de invloeden van co-flow condities op spray vlammen in de reactie zone te onderzoeken. Echter, voor een definitieve model validatie zijn meerdere casussen nodig om een overtuigende en overdraagbare modeleringsaanpak te verkrijgen.

De verbranding van zware stookolie in een 9MW boiler is gesimuleerd met de Euler- 
Lagrange methode. Vanwege de complexiteit van de geometrie en de inlaat condities, is een methode voor trapsgewijze simulatie ingezet. Er is gebruik gemaakt van het "second order upwind" schema. Als verbrandingsmodel is het Eddy Dissipation (ED) model met een 2-staps globaal reactie mechanisme gebruikt, aangezien een gedetailleerde reactiemechanisme van zware stookolie nog niet beschikbaar is.

De resultaten lieten zien dat een meer uniforme temperatuurverdeling in de boiler bereikt kan worden door het verdunnen van de primaire en secundaire luchtstroming met rookgas recirculatie. Op deze manier kan de thermische NOx productie effectief gereduceerd worden, terwijl de overgebleven brandstof NOx productie grotendeels afhankelijk is van de lokale verbrandingskarakteristieken en de initiële concentratie van stikstof gebonden componenten. De bijdrage van brandstof gebonden stikstof aan de NOx productie en de vermindering hiervan dient verder onderzocht te worden met behulp van een gedetailleerd reactie mechanisme. Overigens zou de productie van roet meegenomen moeten worden in de simulatie, omdat dit een aanzienlijke invloed op de piek temperatuur en op de $\mathrm{NO}_{\mathrm{x}}$ productie heeft. Verder kan geconcludeerd worden dat de realisatie van HiTAC-achtige condities in stookolie verbranding afhangt van de mogelijkheid om voldoende rookgas recirculatie in de verdampende spray jets te bereiken. 


\section{CONTENTS}

$\begin{array}{ll}\text { Summary } & \text { i }\end{array}$

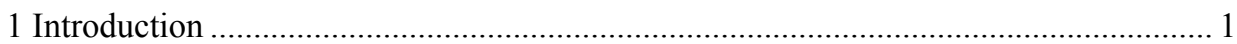

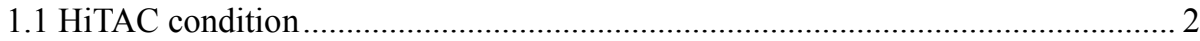

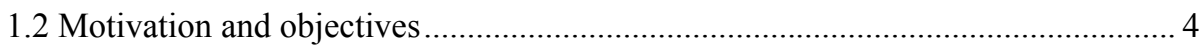

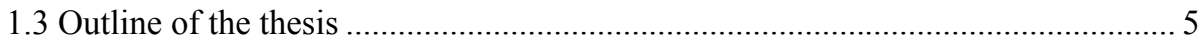

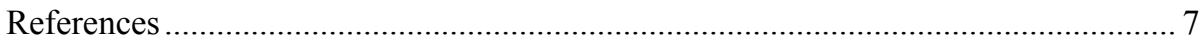

2 Numerical study of the nist turbulent methanol spray flame ..................................... 9

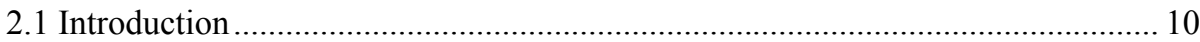

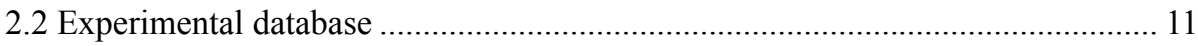

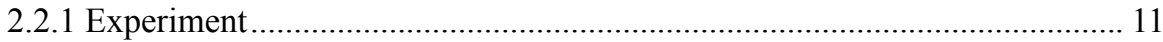

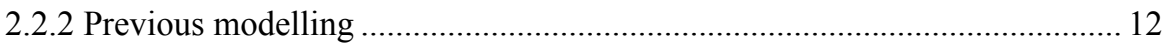

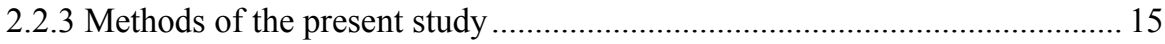

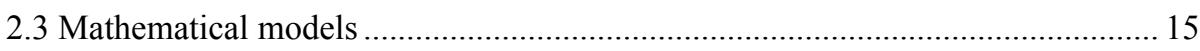

2.3.1 Computational domain, grid and turbulence model ................................. 15

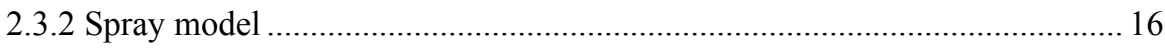

2.3.2.1 Model for droplet diameter distribution ....................................... 16

2.3.2.2 Model for spray evolution ...................................................... 19

2.3.3 Radiation and combustion model .......................................................... 21

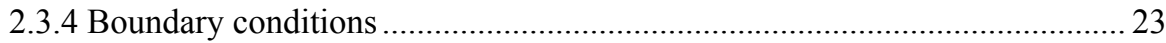

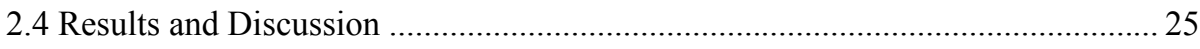

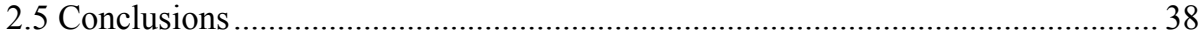




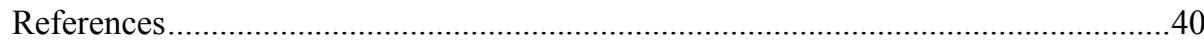

3 Numerical investigation of ethanol spray flames towards HiTAC conditions .............43

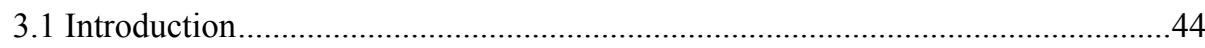

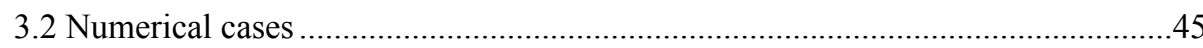

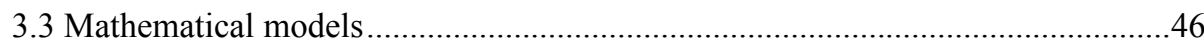

3.3.1 Computational grid, near-wall treatment and turbulence model ....................47

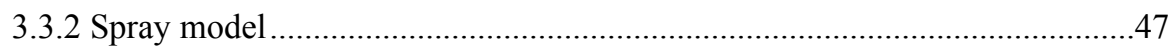

3.3.3 Radiation and combustion model ................................................................48

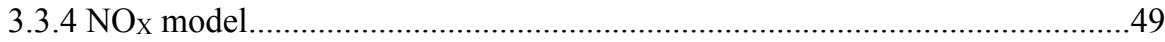

3.4 Boundary conditions for modelling .................................................................52

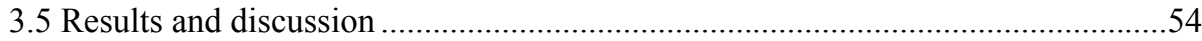

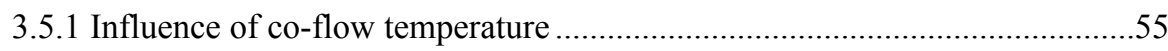

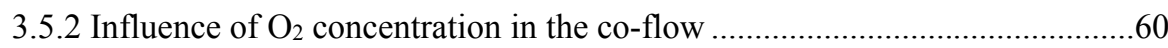

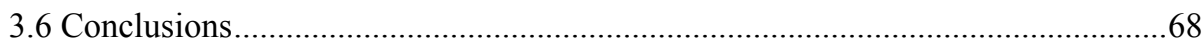

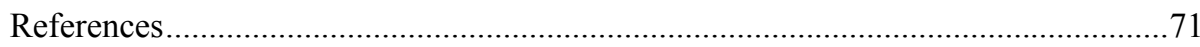

4 Validation and discussion of spray combustion under various co-flow conditions......73

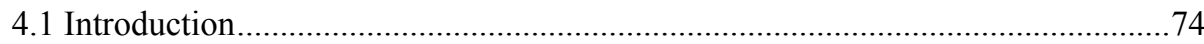

4.2 Validation with models in the previous chapter....................................................74

4.3 Validation from other researchers and discussion .............................................79

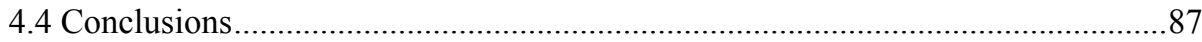

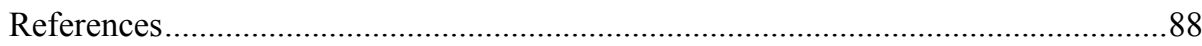

5 Numerical investigation towards a HiTAC condition in a 9mw heavy fuel oil boiler 89

5.1 Introduction .90 


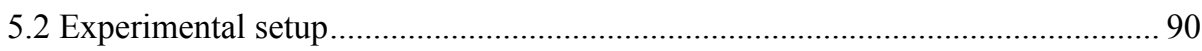

5.3 Mathematical models and boundary conditions ................................................. 93

5.3.1 Computational domain, grid and turbulence model ………......................... 93

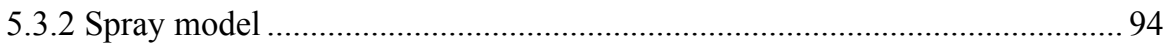

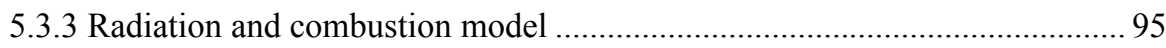

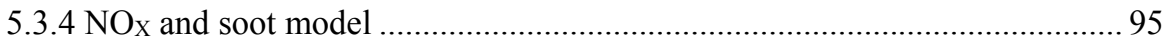

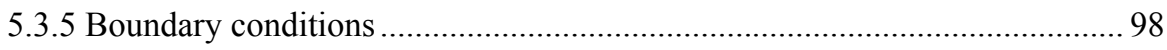

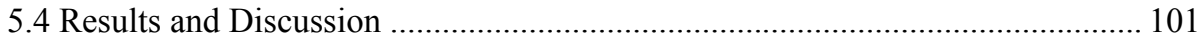

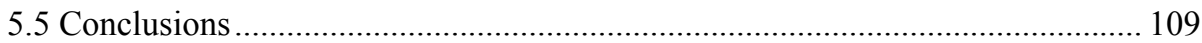

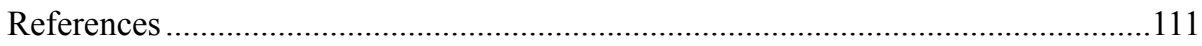

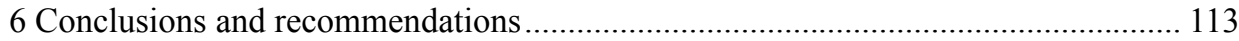

6.1 Main conclusions and model development....................................................... 114

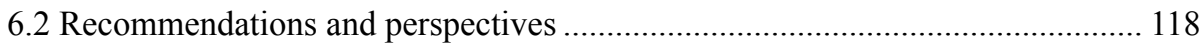

Appendix A: Summary of models used in the current study........................................ 121

Appendix B: Comparison of ED model vs. steady laminar flamelet model for the DSHC

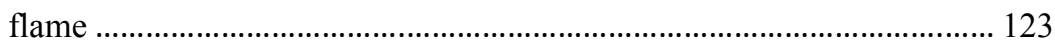




\section{CHAPTER 1.}

\section{INTRODUCTION}

In this chapter, the High Temperature Air Combustion (HiTAC) technology and spray combustion are briefly introduced, together with the difficulties in creating and modeling HiTAC conditions for spray combustion. Motivation and objectives are clarified and the outline of this thesis is described. 


\subsection{HiTAC condition}

Chemical reaction through combustion still contributes to most of the power generated nowadays. The demand of energy is dramatically increasing due to the growth of the world's population and substantial economic development, while about $80 \%$ of these energy needs are fulfilled by fossil fuel $[1,2]$. Besides, the pollution from conventional combustion processes is linked with global warming and other associated changes such as abnormal weather patterns, rise in ocean levels and melting of ice the North and South Poles, etc.

In the past decades, the improvement of combustion efficiency with low emissions has led researchers to have more interest in new combustion technology and combustion modeling in various applications. One of the advanced methods is to create a combustion regime, in which oxygen/fuel stream is diluted by a substantial amount of hot inert flue gases before it reacts with the fuel/oxygen. This results in a more uniform temperature distribution and a lower $\mathrm{NO}_{\mathrm{x}}$ emission than in case of conventional combustion (see Fig.1). This regime was firstly developed in Japan around 1990 [3] by preheating air, and it was then named "High temperature air combustion (HiTAC)" technology. With many experimental and industrial applications, it was further found that increasing the air temperature by preheating systems (e.g. via regenerators) is not the only way to achieve this combustion regime. The technology was further developed and reported as "moderate or intense low oxygen dilution (MILD) combustion", "flameless oxidation (FLOX)", or “colorless distributed combustion (CDC)" [4,5,6,7,8,9,10,11]. In FLOX or MILD the inlet temperature of the main reactant flow is higher than mixture auto-ignition temperature and the maximum allowable temperature increase during combustion is lower than mixture auto-ignition temperature, due to dilution. The common key feature to achieve CDC mode is the separation and controlled mixing of high momentum air jet and the low momentum fuel jet, large amount of gas recirculation and high turbulent mixing rates to achieve spontaneous ignition of the fuel to provide distributed combustion reactions [12]. 

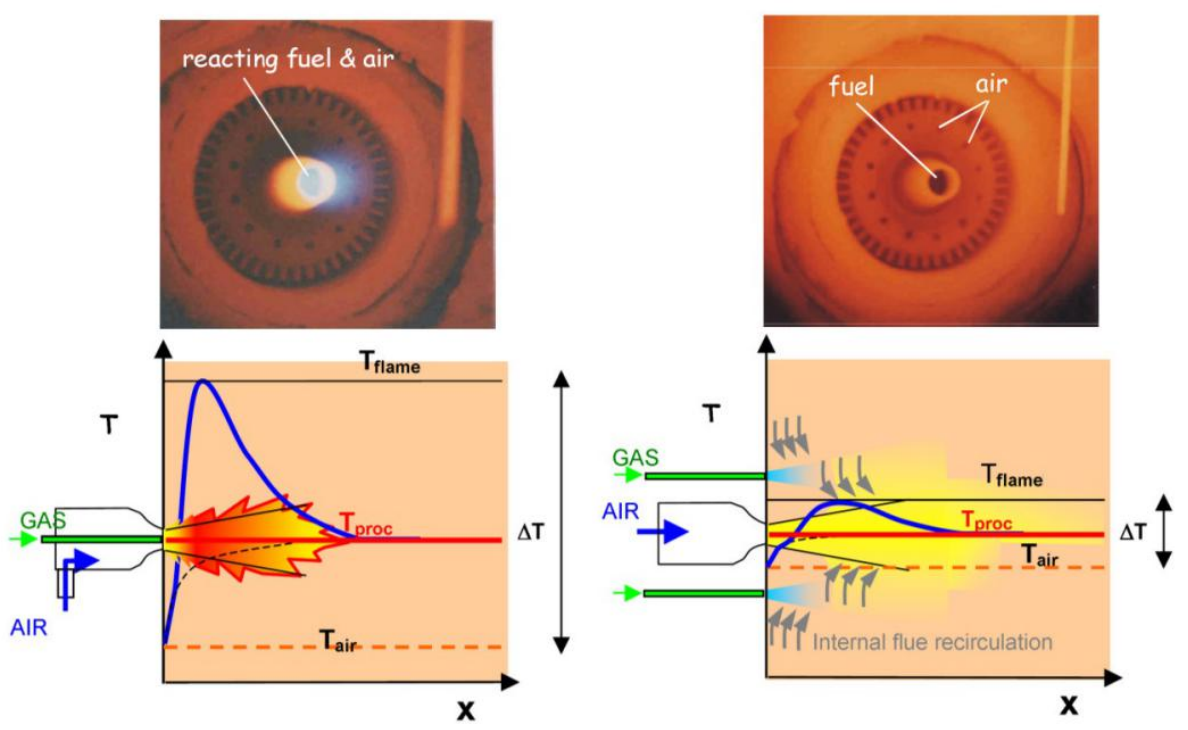

Figure 1. Conventional combustion (left) and HiTAC (right) [13]

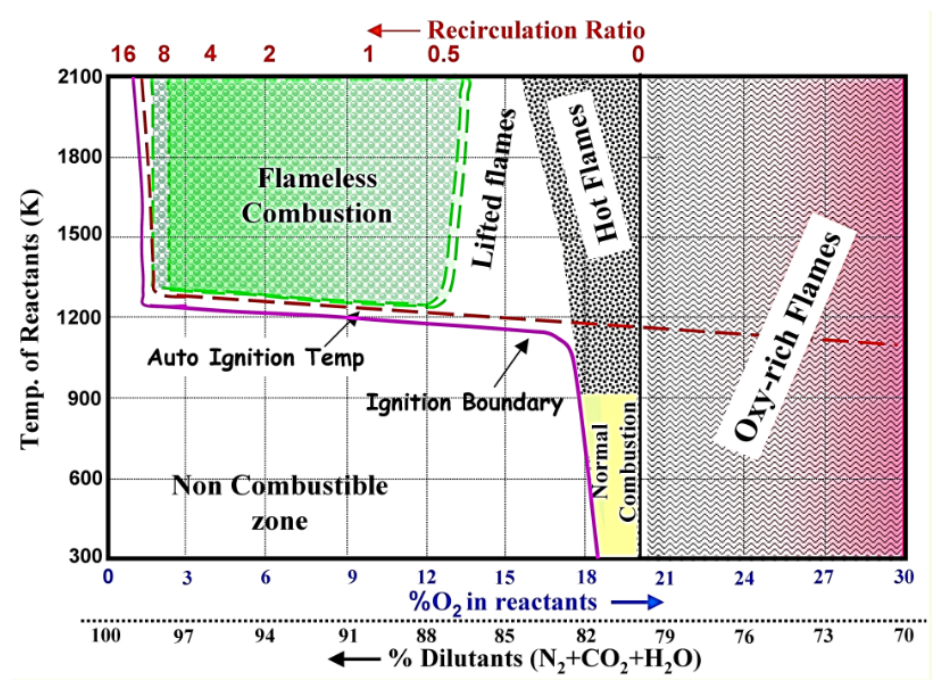

Figure 2. Combustion regimes in relation to the dilution and reactants' temperature [14]

In general, the principle of those combustion processes is the same, i.e. to achieve the above mentioned combustion regime in order to reduce the peak temperature in the flame and hence the $\mathrm{NOx}$ emission while the average temperature is still high enough to 
effectively consume the remained fuel such as CO. Fig.2 shows the combustion regimes in diluted combustion, and the temperature and $\mathrm{O}_{2}$ concentration of the reactants are considered as two important parameters to create the "flameless" condition.

In the present study we aim to extend this combustion process to spray combustion, and investigate the important parameters for both: modelling and achieving of the abovementioned combustion regime. Since for spray combustion the flame may have more uniform temperature distribution while the appearance of the flame is not yet "flameless" but just "flame-less", in this thesis we call it "HiTAC condition".

\subsection{Motivation and objectives}

The features of HiTAC lend itself ideally for the combustion of all sorts of "difficult" fuels, ranging from low-calorific gases such as waste-gases, to heavy fuel-oils. Especially for heavy fuel-oils, expectations are that in combination with HiTAC these can be utilized for steam generation with very low harmful emissions such as $\mathrm{NO}, \mathrm{CO}$ and particulates. The key features of this high-efficiency combustion process can be utilized to lead to simpler, cheaper and more reliable designs of boilers, with very low emissions of harmful species.

However, to date most of the applications of HiTAC are for gaseous fuels $[6,7,8]$ or solid fuels $[15,16]$, but little is known about spray combustion under HiTAC condition [4,17]. H.Tsuji et al. [4] introduced the historical background of HiTAC technology, and described its development and practical application to different kinds of furnaces of importance in industry. Besides the gaseous and solid fuels, they investigated experimentally kerosene spray flames and reported qualitatively with photographs the states of spray flame combustion in the high temperature preheated diluted air (523K to $1373 \mathrm{~K})$, when the $\mathrm{O}_{2}$ concentration is changed (13\% to $\left.3 \%\right)$. Although it was concluded that $\mathrm{NO}_{\mathrm{X}}$ emissions reduce in the same manner as gaseous fuel, cases when the $\mathrm{O}_{2}$ concentration in highly preheated air is lower than $15 \%$ were not further discussed. Moreover, the experimental results from NKK Keihin [4] using heavy oil ' $A$ ' did not show a clear trend. This can be explained by the complexity of spray combustion and many unclear fundamental aspects involved in spray combustion, and in particular 
turbulent spray combustion. Modeling of turbulent spray combustion however, although challenging provides a deep understanding of various phenomena involved in the processes. In a real turbulent spray flame, dispersion, continuous phase turbulence modification, dispersed phase inter-particle collisions, evaporation, mixing and combustion occur simultaneously. Dealing with all these complexities and their interactions poses a tremendous modeling task [17].

In order to generate the knowledge required to achieve the HiTAC condition for fuel oil, experimental and computational investigations of light oil spray flame under HiTAC conditions, are needed due to the complexity of heavy fuel oil spray combustion and feasibility of both numerical models and experimental tools. Moreover, since little is known about spray combustion under HiTAC condition, validation of models and methods for light oil spray combustion under conventional conditions is essential to find out what is necessary and important for the modeling of heavy fuel oil spray combustion.

\subsection{Outline of the thesis}

With the focus on development and achieving the HiTAC conditions for spray combustion, this thesis is structured in six chapters as following:

The current chapter introduces the background of the HiTAC condition and the difficulties in creating and modeling HiTAC conditions for spray combustion. It also clarifies the motivation and objectives of the investigations that are conducted in this thesis and draws the overall picture.

In chapter 2, the models and methods involving turbulence, atomization, evaporation, combustion, radiative heat transfer, etc. have been numerically studied, and validated against a conventional methanol spray flame in a chamber at the National Institute of Standards and Technology, which is also called "the NIST flame". Previous simulations of the NIST flame are studied and the features of this flame, including the boundary conditions of the inlet air and the spray, are analyzed to relate the experiment and simulations. The simulation is performed in ANSYS Fluent with the steady laminar flamelet model in order to include detailed chemistry and the influence of the evaporation on mixture fraction variance was investigated. Predictions of the mean velocity 
components of air flow and droplets, droplet number density, and Sauter Mean Diameter (SMD) at various heights were compared with the experimental data and they showed good agreements. Besides, the findings regarding necessary and important parameters in spray combustion modeling, boundary conditions and validation are suggested for the establishment of the experimental set-up.

Chapter 3 introduces the turbulent ethanol spray flame for the HiTAC condition, which is also called "Delft-Spray-in-Hot-Coflow" flame. The models and methods validated by the conventional NIST spray flame are then employed in order to comparatively investigate the influence of various co-flow conditions on the combustion characteristics, due to the limitations in the experiments discussed in this chapter.

Chapter 4 discussed the preliminary validation using the models and methods developed by the author and other researchers. Simulation results are compared with the experimental data and discussed.

In chapter 5, based on a thorough understanding of the influences of the temperature and $\mathrm{O}_{2}$ concentration on light fuel oil spray combustion in previous investigations, 3D simulations of heavy fuel oil combustion in a 9MW boiler using the Stork Double Register Burner are conducted in order to further investigate the influence of flue gas recirculation on the temperature distribution and emissions. Oil gun with an industrial steam-blast atomizer is used. The atomizer is surrounded by separated air flow, primary air and secondary air. The available field test results are used to validate the simulation results.

In the last chapter, the main conclusions and findings of this study are summarized. Recommendations and prospective have been made for future studies. 


\section{References}

[1] IEA/OECD 2009 World Energy Outlook (WEO), Int. Energy Agency, IEA, Paris.

[2] A. Maczulak. Renewable energy: sources and methods. Green Technology. New York, NY: Facts on File, 2010.

[3] I. Nakamachi, K. Yasuzawa, T. Miyahara, and T. Nagata, Apparatus or method for carrying out combustion in a furnace, US patent 4.945 .841 (1990).

[4] H. Tsuji, A. Gupta, T. Hasegawa, et al., High temperature air combustion: from energy conservation to pollution reduction, CRC Press, Boca Raton, 2002.

[5] A. Cavaliere, M. de Joannon, Mild combustion, Prog. Energy Combust. Sci., 30-4 (2004): 329-366.

[6] L. Blarino, M. Fantuzzi, E. Malfa, U. Zanusso, Tenova Flexytech burners: flamesless combustion for very low NOx reheating furnaces, In: Proceedings of the HITAC Conference, Thailand (2007).

[7] J. A. Wünning and J. G. Wünning, Flameless oxidation to reduce thermal NO-formation, Progress in Energy and Combustion Science, Vol. 23, No. 1 (1997): 81-94.

[8] V. K. Arghode and A. K. Gupta, Development of high intensity CDC combustor for gas turbine engines, Applied Energy, Vol. 88, No. 3 (2011): 963-973.

[9] W. Blasiak, W. Yang, Volumetric combustion of coal and biomass in boilers, In: Proceedings of the HITAC Conference, Thailand (2007).

[10] Y. Kunio, R\&D Commercialization of innovative waste-to-energy technologies, In: Proceedings of the HITAC Conference, Thailand (2007).

[11] R. Weber, J. P. Smart, W. vd Kamp, On the (MILD) combustion of gaseous, liquid, and solid fuels in high temperature preheated air, Proceedings of the Combustion Institute 30 (2005): 2623-2629.

[12] V. K. Arghode, A. K. Gupta, K. M. Bryden, High intensity colorless distributed combustion for ultra low emissions and enhanced performance, Applied Energy, Vol. 92 (2012): 822830.

[13] M. Khosravy el_Hossaini, Review of the new combustion technologies in modern gas turbines, Process in Gas Turbine Performance (2013): 978-953. 
[14] A. G. Rao and Y. Levy, A new combustion methodology for low emission gas turbine engines, in 8th HiTAC conference (2010).

[15] N. Schaffel-Mancini, et al., Novel conceptual design of a supercritical pulverized coal boiler utilizing high temperature air combustion (HTAC) technology, Energy, Vol. 35, No. 7 (2010): 2752-2760.

[16] H. Zhang, et al., Development of high temperature air combustion technology in pulverized fossil fuel fired boilers, Proceedings of the Combustion Institute, Vol. 31, No. 2 (2007): $2779-2785$.

[17] P. Jenny, D. Roekaerts, and N. Beishuizen, Modeling of turbulent dilute spray combustion, Prog. Energy Comb. Sci. 38 (2012): 846-887. 


\section{CHAPTER 2.}

\section{NUMERICAL STUDY OF THE NIST TURBULENT METHANOL SPRAY FLAME*}

In this chapter, a methanol spray flame in a combustion chamber of the NIST was simulated using an Eulerian-Lagrangian RANS model. Experimental data and previous numerical investigations by other researchers on this flame were analysed to develop methods for more comprehensive model validation. In general, the predictions at various heights in the present study show better agreement with the experiment than previous numerical studies. Special attention is paid to the relative merits of the employed method to set inlet boundary conditions compared to the alternative method of using a measured droplet size and velocity distribution.

\footnotetext{
${ }^{*}$ Content in this chapter has been published in the following paper:

S.Zhu, D.J.E.M.Roekaerts, A.Pozarlik, T.H.van der Meer, Eulerian-Lagrangian RANS model simulations of the NIST turbulent methanol spray flame, Combustion Science and Technology, 187(7):1110-1138.
} 


\subsection{Introduction}

Turbulent spray combustion plays an important role in industrial furnaces, gas turbines, internal combustion engines, oil gasifiers, etc. The combustion efficiency, stability, and pollutant formation strongly depend on the characteristics of the turbulent spray combustion. A better understanding of the fundamental mechanisms together with improved modelling capabilities would help to enhance the efficiency and lead to a cleaner and safer environment [1].

Numerical simulations have been attractive for many years because they provide an easier and safer way to understand the characteristics of combustion in detail compared to experiments. However, the modelling and simulation of the turbulent spray is particularly challenging because complex processes involving turbulence, atomization, evaporation, combustion and radiative heat transfer are included and they are strongly coupled. To improve the reliability of the spray combustion simulation, it is necessary to validate mathematical models with experimental data.

As described in [1], often light fuel-oils are used [2,3,4,5] to get a better understanding of the turbulent spray combustion because their properties and reaction mechanisms have been well investigated and are readily available. The reported experiment carried out by Widmann and Presser [4] at the National Institute of Standards and Technology (NIST) led to the creation of a database of a methanol spray flame [6]. As Presser reported in [7], the predicted spray characteristics are sensitive to the model representation of the spray inlet boundary conditions. Compared to other flames, a relative advantage of the NIST flame is that a lot of attention was paid to accurate measurement of the droplet size and velocity distributions close to the injector in order to provide good boundary conditions for the simulation. Three gas velocity components were obtained from the PIV (Particle Image Velocimetry) measurements at three heights within the chamber for the cases with non-burning and with burning spray (cold and hot states). Droplet size distributions, Sauter Mean Diameter (SMD), droplet mean axial and radial velocities, and droplet number density were measured at various axial locations downstream of the nozzle exit. The combination of accurate boundary conditions and relatively large amount of data make this database very valuable for validation. 
Several research groups $[8,9,10]$ have used this database for the validation of their simulations. Their modelling approaches are all based on RANS, since LES and DNS are computationally too expensive due to their high spatial and temporal resolution requirements for this flame. Crocker et al. [8] and J. Collazo et al. [10] carried out Eulerian-Lagrangian RANS simulations while De Jager [9] employed an EulerianEulerian RANS simulation. Some agreements with the experiment were found in their simulation results. However, as it will be discussed in the following, either only a limited part of this database was used for validation or boundary conditions of the NIST flame were not analysed in detail. We will follow the line of modelling with RANS simulations and simulate the NIST flame based on the analysis of boundary conditions and above mentioned numerical studies in order to handle accurately important aspects of turbulence modulation, evaporation, mixing and detailed chemistry.

\subsection{Experimental database}

\subsubsection{Experiment}

The NIST flame experiment was carried out in a combustion chamber, a drawing of which is shown in Fig.1. The chamber height is $1.2 \mathrm{~m}$ and the inner diameter is $0.8 \mathrm{~m}$. The flame is fired vertically upwards. The exhaust channel is off-axis to permit direct probing of the flame from above. Swirling combustion air generated by a movable 12vane swirl cascade passes through the outer annulus passage, with a flow rate of $0.01575 \pm 0.0005 \mathrm{~m}^{3} / \mathrm{s}$ at ambient pressure and temperature. The inner and outer diameters of the annulus are $34.9 \mathrm{~mm}$ and $101.6 \mathrm{~mm}$, respectively. A pressure-jet nozzle forms a hollow-cone methanol spray with a nominal $60^{\circ}$ full cone angle at ambient temperature and it is surrounded by the annulus passage. The nominal upstream pressure of the liquid fed to the nozzle is maintained at $690 \mathrm{kPa}$ and the flow rate is kept at $0.00083 \pm 0.000006 \mathrm{~kg} / \mathrm{s}$. More details regarding the set-up of the configuration can be found in [4]. 


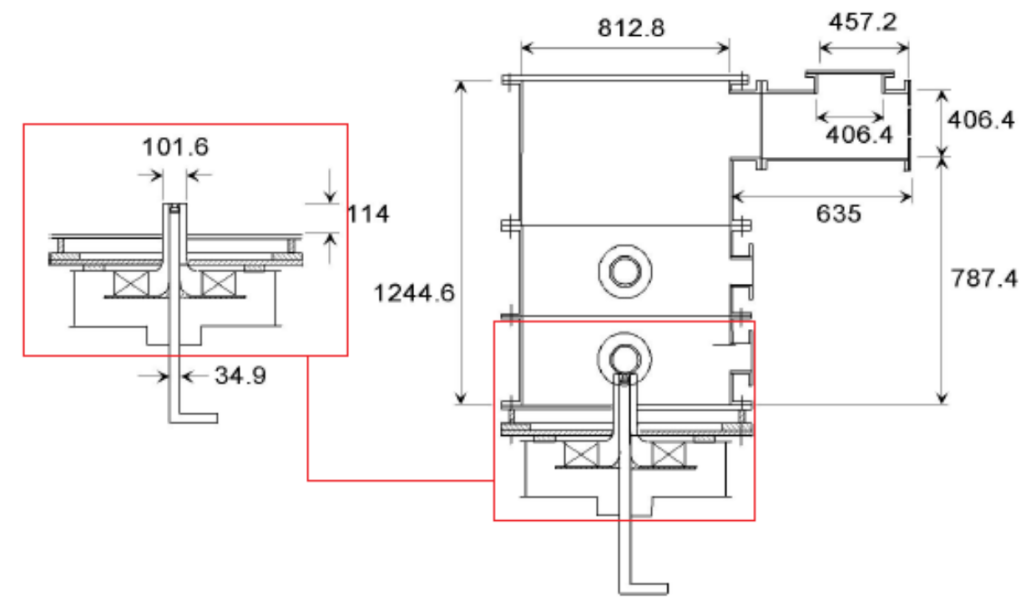

Fig.1. Sketch and dimensions $(\mathrm{mm})$ of the NIST reference spray combustor

By using a PIV system, the gas phase axial, radial and tangential velocities at various heights $(1.4 \mathrm{~mm}, 9.5 \mathrm{~mm}$ and $17.6 \mathrm{~mm}$ from the nozzle exit) were measured. The axial and radial particle velocities and the diameter of the droplets were obtained using a Phase Doppler Interferometer (PDI) along cross-section at seven heights in the range from 5 $\mathrm{mm}$ to $65 \mathrm{~mm}$. Sheathed K-type thermocouples were used to measure the wall temperatures at various elevations and gas temperatures at the exit. Concentrations of $\mathrm{CO}_{2}, \mathrm{CH}_{3} \mathrm{OH}$ and $\mathrm{CO}$ were measured at the exit of the exhaust channel. No minor components or reaction intermediates were identified. More details are available in [6].

\subsubsection{Previous modelling}

As mentioned above, several investigations of the NIST flame have been made before. In order to obtain a better understanding of the NIST flame and the corresponding simulation aspects, it is necessary to review and analyse the previous simulations, and the predictions in the present study will be discussed and compared in relation to previous results.

With a 2D axisymmetric Eulerian-Lagrangian RANS simulation using CFD-ACE, Crocker et al. [8] computed the NIST flame for both non-reacting and reacting cases. The RNG k- $\varepsilon$ model was used for turbulent gas flow and combustion was modelled using a 
one-step, finite-rate reaction with equilibrium products of $\mathrm{CO}_{2}, \mathrm{H}_{2} \mathrm{O}, \mathrm{CO}, \mathrm{H}_{2}, \mathrm{OH}$ and $\mathrm{O}$, proposed by Westbrook and Dryer (1981). The measured velocity profiles at height $\mathrm{z}=1.4$ $\mathrm{mm}$ in the cold state were assumed to be the initial conditions of the inlet air, and the measured droplet diameter and velocity components of the droplets at height $\mathrm{z}=5 \mathrm{~mm}$ were analysed for obtaining the initial boundary conditions of the spray in the simulation. The fuel-oil was then assumed to be injected at height $\mathrm{z}=5 \mathrm{~mm}$ as droplet parcels at 30 radial locations, with 20 different droplet sizes, 5 different velocity magnitudes, and 7 different angles (directions) at each radial location. The spray volume flux, spray velocity components, and droplet SMD were compared with the experimental data, and they showed good agreements. However, due to the very low measured spray flux in the nearnozzle region, the measured data of droplets at height $\mathrm{z}=5 \mathrm{~mm}$ was considered to be insufficient to describe the initial conditions of the droplets. Data of the droplets were further modified to some specific values in the simulation in order to fit one subset of the measured data while other subsets were found difficult to fit. Since the droplets were injected from height $\mathrm{z}=5 \mathrm{~mm}$ in the investigation of Crocker et al., the secondary breakup process was not included. Predictions of velocity components of the gaseous phase were not compared with the experimental data in detail in Ref. [8] and the evaporation process of the droplets was not discussed either. An aspect worthy to note is that as a result of the estimation of the spray trajectories for the initial boundary condition of the spray, the predicted spray velocity components and SMD of droplets with low number densities showed good agreement with measured data. It will be discussed and compared with the predictions from the present study later.

De Jager [9] employed an Eulerian-Eulerian approach and introduced a CFI model for the composition of the gaseous phase, in which $\mathrm{C}, \mathrm{F}$ and I represent a reaction progress variable, the mixing scalar and enthalpy scalar, respectively. The fluctuations are described by a $\beta$-PDF for $\mathrm{C}$ and $\mathrm{F}$, and the $\delta$-PDF for the normalized enthalpy loss $\mathrm{i}$. The predicted velocity components of the combustion air at heights $\mathrm{z}=9.5 \mathrm{~mm}$ and $\mathrm{z}=17.6 \mathrm{~mm}$ were compared with the experimental data at both non-burning and burning conditions. Significant discrepancies of radial and tangential velocities of the gaseous phase between simulation and experiment were found. The author indicated that turbulence is modelled poorly using the k- $\varepsilon$ model, and the proposed spray model in its current form with the 
Eulerian-Eulerian approach is limited and needs further improvement. The interaction between spray and combustion air needs more attention, especially in the near nozzle region. The suggestion was given by the author that it would be beneficial to implement spray effects in simulations with a Lagrangian description of the droplets, to represent the effects of coalescence and secondary break-up, to reach a more accurate prediction of the SMD.

Collazo et al. [10] presented results of Eulerian-Lagrangian RANS simulations with a 3D geometry. The interaction processes between droplets and continuous phase were simulated by use of the Dispersed Phase model, and the Linearized Instability Sheet Atomization (LISA) model of Schmidt et al. [11]. The standard k- $\varepsilon$ model was used to simulate the turbulence. For combustion, the Eddy Dissipation Concept (EDC) model proposed by Magnussen [12] was applied with a two-step reaction of methanol with oxygen, including carbon monoxide. Predictions of droplet diameters, droplet trajectories, temperatures and gas concentrations were presented and compared with the NIST database [4]. The prediction of droplet properties showed some discrepancies, and the authors deduced that the initial spray angle should be higher than $60^{\circ}$. Temperatures and carbon dioxide concentration at the exhaust of the system were well predicted in the simulation of [10], while the peak temperature of the flame was overestimated and the concentration of intermediate species was relatively inaccurate. Since neither the results of the velocities of air or droplets were presented, the turbulence model was not validated in this paper.

In both simulations of De Jager and Collazo et al., the SMD of the droplets and the droplet number density at various heights were compared with the experimental data. However, their results from the simulations were all studied under cold state without combustion while the reported spray measurements were conducted in the reacting flow in the experiment. This was confirmed in a private communication by Presser (one of the authors of the NIST experiment [4]). In the present study, simulation of the NIST flame and its validation is done for both gaseous phase and spray, based on the analysis of features of the burning flame and experience obtained from previous simulations. 


\subsubsection{Methods of the present study}

Based on the analysis of previous simulations of the NIST flame, in the present study, an Eulerian-Lagrangian RANS approach with modelling of droplet collision and secondary break-up is used to obtain an improved prediction of the spray. The exhaust channel is omitted in the simulation since it is shown in [8] that it has little influence on the simulation in the near-nozzle region. The measured velocity components of the gaseous phase at height $\mathrm{z}=1.4 \mathrm{~mm}$ under hot state are used for the boundary condition of the inlet air $(\mathrm{z}=0 \mathrm{~mm})$, and the corresponding predicted velocity components of the gaseous phase at height $\mathrm{z}=1.4 \mathrm{~mm}$ are compared with the measured data to test the validity of this method. Attention is paid to the analysis of the spray trajectories in order to obtain an accurate boundary condition of the spray. The numerical simulation is performed with the steady laminar flamelet model in order to include detailed chemistry and the influence of the evaporation on mixture fraction variance is investigated. Predictions of the mean velocity components of air flow and droplets, droplet number density, and SMD is compared with the experimental data and previous predictions mentioned above in order to get a better understanding of this turbulent spray flame.

\subsection{Mathematical models}

\subsubsection{Computational domain, grid and turbulence model}

For the simulation of the NIST flame, as we discussed above, the influence of the exhaust channel on the simulation of the near-nozzle region is negligible and it can be omitted in the geometry, considering the end of the combustion chamber as an open boundary. As a result, the $2 \mathrm{D}$ axisymmetric simulation with swirl is employed in the present study. 


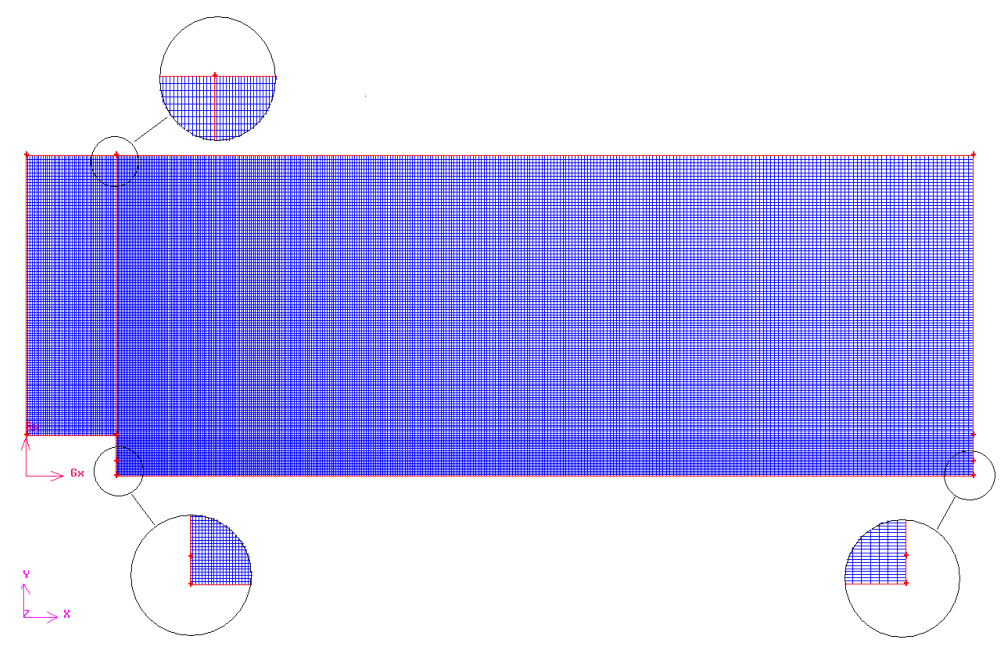

Fig.2. 2D mesh with about 46000 quadrilateral cells

The grid independence was tested by introducing a series of different cell sizes with the same axial/radial aspect ratio of 3 . The role of the near-wall treatment for this swirling flow was analysed. As a result a 2D mesh with about 46000 quadrilateral cells (as shown in Fig.2) in combination with the second order upwind scheme was found suitable for this study. A standard k- $\varepsilon$ turbulence model with the enhanced wall treatment is employed based on the comparative analysis. The use of the enhanced wall treatment can possess the accuracy of the standard two-layer (a viscosity affected region and a fully-turbulent region) approach for fine the near-wall mesh and at the same time, not to reduce accuracy for the wall-function mesh. Its application is dependent on both the grid and flow characteristics, and we found that this is particularly of significance for the prediction of the profile of radial velocity of the gaseous phase.

\subsubsection{Spray model}

\subsubsection{Model for droplet diameter distribution}

The atomization process of light oil sprays is commonly modelled using a wave growth or aerodynamic theory that predicts spray parameters such as the spray angle and the drop diameter. The surface wave instability model proposed by Reitz [13], the KelvinHelmholtz/Rayleigh-Taylor (KHRT) instability model by Patterson and Reitz [14] and 
the Taylor Analogy Breakup (TAB) model by O'Rourke and Amsden [15] are widely used atomization models. However, their coupling with the nozzle effects and the primary breakup is largely unknown and is usually represented by an arbitrary nozzle-dependent constant.

For the pressure swirl atomizer in the NIST flame, we employ the LISA model [11]. It assumes that Kelvin-Helmholtz waves grow on the sheet and eventually break the liquid into ligaments. It is then assumed that the ligaments break up into droplets due to varicose instability. Once the liquid droplets are formed, the spray evolution is determined by drag, collision, coalescence and secondary breakup.

For film formation, the relationship between the thickness of this film, $\mathrm{t}$, and the mass flow rate is as follows:

$$
\dot{m}_{e f f}=\pi \rho u t\left(d_{i n j}-t\right)
$$

where $d_{i n j}$ is the injector exit diameter, $\dot{m}_{e f f}$ is the effective mass flow rate, and $u$ is the mean axial component of velocity at the injector exit. Because $u$ depends on internal details of the injector and is difficult to calculate from first principles, the approach of Han et al. [16] is used and the velocity magnitude is assumed to be related to the injector pressure by:

$$
U=k_{v} \sqrt{\frac{2 \Delta P}{\rho_{l}}}
$$

where $k_{v}$ is a dimensionless velocity coefficient and a function of the injector design and injection pressure [17]. If $\Delta P$ is known, $u$ can be calculated as

$$
u=U \cos \theta
$$

where $\theta$ is the spray angle.

The pressure-swirl atomizer model for sheet breakup and atomization includes the effects of the surrounding gas, liquid viscosity and surface tension on the breakup of the liquid sheet. It is based upon the growth of sinusoidal waves on the liquid sheet. For waves that are long compared with the sheet thickness, ligaments are assumed to be formed from 
the sheet breakup process once the unstable waves reach a critical amplitude. If the surface disturbance has reached a value of $\eta_{b}$ at a breakup time $\tau$, the sheet breaks up and ligaments will be formed at a length given by:

$$
L_{b}=U_{\tau}=\frac{U}{\Omega} \ln \left(\frac{\eta_{b}}{\eta_{O}}\right)
$$

where $\Omega$ is the maximum growth rate, and $\ln \left(\eta_{b} / \eta_{O}\right)$ is an empirical sheet constant for which a default value of 12 was obtained theoretically by Weber [18] for liquid jets. Dombrowski and Hooper [19] also showed that a value of 12 for the sheet constant agreed favourably with experimental sheet breakup lengths over a range of Weber numbers from 2 to 200 .

Thus the diameter of the ligaments formed at the point of breakup can be obtained from a mass balance. If it is assumed that the ligaments are formed from tears in the sheet twice per wavelength, the resulting diameter is given by:

$$
d_{L}=\sqrt{\frac{8 h}{K_{S}}}
$$

where $K_{S}$ is the wave number corresponding to the maximum growth rate, and the film thickness can be calculated from the breakup length and the radial distance from the centre line to the mid-line of the sheet at the atomizer exit $r_{0}$ :

$$
h_{\text {end }}=\frac{r_{0} h_{0}}{r_{0}+L_{b} \sin \left(\frac{\theta}{2}\right)}
$$

For waves that are short compared to the sheet thickness, this mechanism is not used. The ligament diameter is assumed to be linearly proportional to the wavelength that breaks up the sheet:

$$
d_{L}=\frac{2 \pi C_{L}}{K_{S}}
$$

where $C_{L}$ is the ligament constant equal to 0.5 . 
In either the long-wave or the short-wave case, the breakup from ligaments to droplets is assumed to behave according to Weber's analysis for capillary instability [18]. So the most probable diameter for droplet diameter distribution, $d_{0}$, is determined from:

$$
d_{0}=1.88 d_{L}(1+3 O h)^{1 / 6}
$$

where $O h$ is the Ohnesorge number which is a combination of the Reynolds number and the Weber number.

Once this most probable droplet size for a Rosin-Rammler distribution has been determined, with a spread parameter and a dispersion angle, which are equal to 3.5 and $6^{\circ}$ based on past modelling experience [20], respectively, the droplet diameter distribution is determined.

\subsubsection{Model for spray evolution}

In the simulation, the fuel is assumed to be injected into the chamber as a fully atomized spray consisting of spherical droplets of various sizes. The motions of the droplets in the turbulent combustion flow field are calculated using a stochastic method in which the momentum, mass, and energy exchange between the droplets and the gas phase is simulated while tracking a large number of droplets.

The equation of motion for a droplet is:

$$
\frac{d u_{p, i}}{d t}=\frac{18 \mu}{\rho_{p} D_{p}^{2}} \frac{C_{D} \operatorname{Re}}{24}\left(U_{i}-u_{p, i}\right)+\frac{g_{i}\left(\rho_{p}-\rho\right)}{\rho_{P}}+F_{i}
$$

In this equation, $u_{p, i}$ is the velocity of droplet (particle) $i, U$ is a sampled gas velocity, $\mu$ is the molecular viscosity of the fluid, $\rho$ is the fluid density, $\rho_{p}$ is the density of the particle, $D_{p}$ is the particle diameter, Re is the relative Reynolds number based on slip velocity and particle diameter, and the drag coefficient $C_{D}$ is a function of the particle Reynolds number. $F_{i}$ is a possible additional acceleration term. In practice a number of 'parcels', each representing a set of identical droplets, is tracked. 
For secondary breakup, the Taylor Analogy Breakup (TAB) model, which is based upon Taylor's analogy [21] between an oscillating and distorting droplet and a spring mass system, is employed since the investigated case has relative low Weber number injections (Weber number less than 100) and the TAB model is well suited for low-speed sprays into a standard atmosphere [19].

For droplet collision and coalescence, the algorithm of O'Rourke [22] is employed. It uses the concept of a collision volume to calculate the probability of collision. In general, once two parcels are supposed to collide, the outcome tends to be coalescence if they collide head-on, and bouncing if the collision is more oblique. The probability of coalescence can be related to the offset of the collector droplet centre and the trajectory of the smaller droplet. The critical offset is a function of the collisional Weber number and the relative radii of the collector and the smaller droplet.

The rate of vaporization is governed by gradient diffusion, with the flux of droplet vapour into the gas phase related to the difference in vapor concentration at the droplet surface and the bulk gas:

$$
N_{i}=k_{c}\left(C_{i, s}-C_{i, \infty}\right)
$$

where $N_{i}$ is the molar flux of vapour, $C_{i, s}$ is the vapour concentration at the droplet surface, and $C_{i, \infty}$ is the vapour concentration in the bulk gas. $k_{c}$ is the mass transfer coefficient calculated from the Sherwood number correlation [23,24], defined as:

$$
S h_{A B}=\frac{k_{c} D_{p}}{D_{i, m}}=2.0+0.6 \mathrm{Re}^{1 / 2} S c^{1 / 3}
$$

where $D_{i, m}$ is the diffusion coefficient of vapour in the bulk, $S c$ is the Schmidt number. The concentration of vapour at the droplet surface is evaluated by assuming that the partial pressure of vapour at the interface is equal to the saturated vapour pressure, $P_{\text {sat }}$, at the droplet temperature, $T_{P}$ : 


$$
C_{i, s}=\frac{P_{s a t}\left(T_{P}\right)}{R T_{P}}
$$

where $R$ is the universal gas constant.

\subsubsection{Radiation and combustion model}

By comparison of the predictions with and without the radiation model, it was found that radiative heat transfer cannot be neglected in the simulation of the NIST flame. The difference of the peak temperature can be as high as about 200K. Therefore, in this study, the Discrete Ordinates (DO) radiation model with a variable absorption coefficient, weighted-sum-of-gray-gases model (WSGGM) is employed.

As combustion model, a one-step global reaction mechanism with the Eddy Dissipation Model (ED) is often used in spray combustion simulations. However, this model often leads to overestimated temperature predictions, and sometimes detailed chemistry is also necessary for the prediction of ignition and extinction processes, as well as the pollutant formation. According to the relative fast chemistry of methanol, the laminar flamelet method provides a feasible way here to include detailed chemical reactions in turbulent combustion simulations without a considerable increase in computational time. It assumes that in the gaseous phase combustion, the diffusion coefficients for all species are equal, and then the species mass fraction and temperature are mapped from physical space to mixture fraction space and can be uniquely described by two parameters: the mixture fraction $\xi$ and the scalar dissipation $\chi$. Figure 3 shows results contained in the look-up table. The Favre-averaged values of quantities in the turbulent flame are then obtained through the use of Favre-averaged probability density function, $\tilde{f}(\xi, \chi)$ :

$$
\tilde{\Phi}=\int_{0}^{\infty} \int_{0}^{1} \Phi(\xi, \chi) \tilde{f}(\xi, \chi) d \xi d \chi
$$


The detailed reaction mechanism for methanol employed in the present study was developed by Lindstedt and Meyer [25] and provided by Lindstedt and Chen [26] with a Chemkin compatible reduced mechanism. It comprises 32 species and 167 reactions.

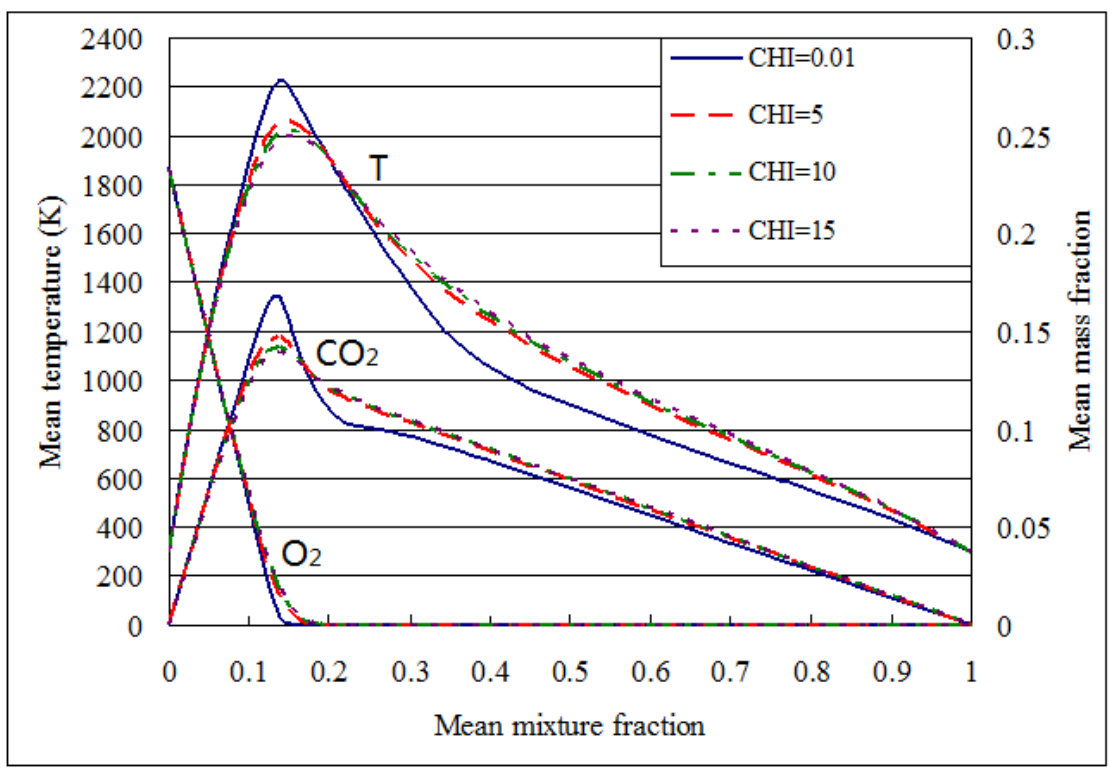

Fig.3. Steady flamelet profiles stored in the look-up table $\left(\mathrm{CHI} \equiv \tilde{\chi}\left[\mathrm{s}^{-1}\right]\right)$

In the model, the heat gain/loss to the system is assumed to have a negligible effect on the species mass fractions, and adiabatic mass fractions are used [27,28]. The flamelet profiles are then convoluted with the assumed $\beta$-function-shape PDFs as in Equation (13), and then tabulated for look-up. The equations for the mean mixture fraction, mixture fraction variance, and mean enthalpy are solved. The scalar dissipation field is calculated from the turbulence fields $\tilde{k}, \tilde{\varepsilon}$ and the mixture fraction variance $\tilde{\xi}^{\prime \prime 2}$ as follows:

$$
\tilde{\chi}=\frac{C_{\chi} \tilde{\varepsilon} \tilde{\xi}^{\prime \prime 2}}{\tilde{k}}
$$

where $C_{\chi}$ is set to the standard value 2 .

The mean values of temperature, density, and species mass fraction are obtained from the PDF look-up table. 
Furthermore, in order to investigate the influence of a source term, $\overline{\dot{\rho}}_{s} \tilde{\xi}^{\text {"2 }}(1-2 \tilde{\xi}) \tilde{\xi}$ due to evaporation in the mixture fraction variance equation, see [29], calculations were made with and without this source term included.

\subsubsection{Boundary conditions}

An accurate representation of the boundary conditions is essential to carrying out a successful simulation [7]. With respect to the air inlet conditions, the mass flow and the temperature for the simulation are shown in Tab.1. The air velocity components at height $\mathrm{z}=1.4 \mathrm{~mm}$ near the air inlet both with and without the spray are measured in the experiment. Based on the previous simulations and analysis, the velocity components at this elevation can represent the inlet conditions, and the data measured when the spray flame is present are supposed to be a better assumption for the simulation of the spray combustion. This will be discussed in the next section.

Tab.1. Inlet conditions of air and fuel

\begin{tabular}{|l|c|}
\hline Air flow rate $\left(\mathrm{m}^{3} / \mathrm{h}\right)$ & $\sim 56.7^{*}$ \\
\hline Air temperature $(\mathrm{K})$ & 298 \\
\hline Fuel flow rate $(\mathrm{kg} / \mathrm{h})$ & 3.0 \\
\hline Fuel temperature $(\mathrm{K})$ & 298 \\
\hline Injection pressure $(\mathrm{Pa})$ & 690000 \\
\hline Spray angle $\left({ }^{\circ}\right)$ & 60 \\
\hline
\end{tabular}

*: interpolated data within $5 \%$ relative error

With regard to the spray, the mass flow rate, temperature of methanol, the injector pressure and spray angle for the simulation based on the experiment are shown in Tab.1. However, the injector exit diameter, $d_{i n j}$ in Equation (1) and the parameters for the droplet diameter distribution in the LISA model are not well defined and we have to 
deduce them from the experimental data in order to obtain a relative accurate spray trajectory.

The droplet number density at seven axial locations downstream of the nozzle exit ( $\mathrm{z}$ $=5,15,25,35,45,55$, and $65 \mathrm{~mm}$ ) from the experiment [4] was analysed to estimate the injector exit diameter, as shown in Fig.4. The short dashed line represents the trajectory obtained in the experiment by linking the location of the peak number density at each elevation. The long dashed line represents the trajectory from the point of origin with the spray angle of $60^{\circ}$. As we can see from Fig.4, at large radii, the trajectory of the spray in the experiment is already influenced by the co-flow and thus the spray angle is less than $60^{\circ}$. Therefore, to estimate the initial trajectory of the spray, we kept the spray angle of $60^{\circ}$ and used the data of locations where the spray is less influenced by the co-flow.

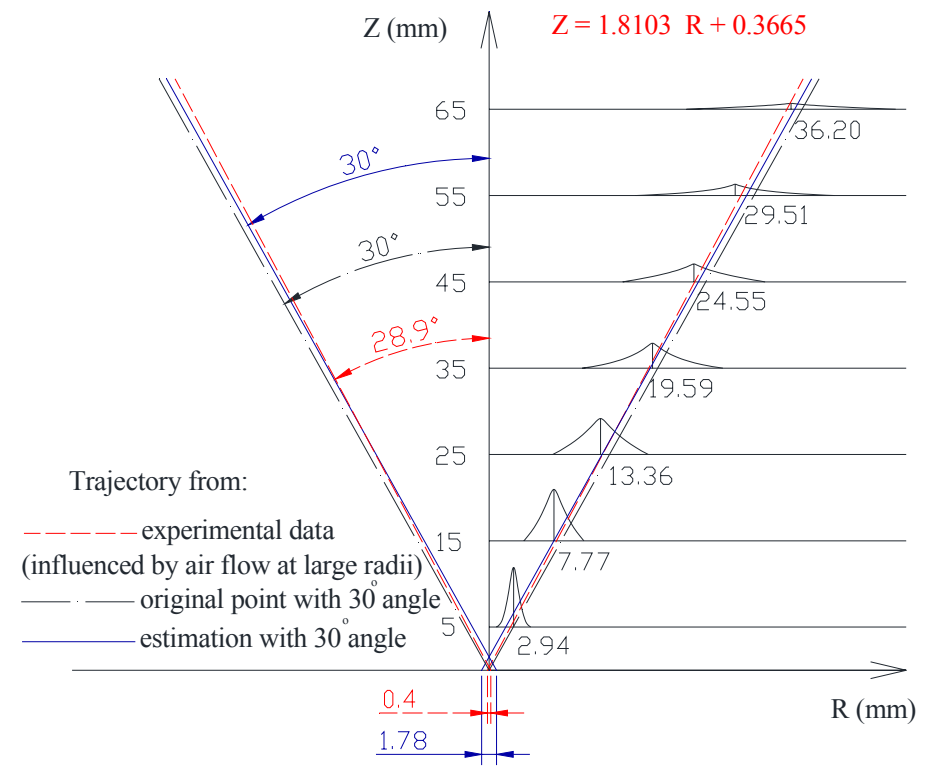

Fig.4. Estimation of the spreading angle of the spray

As a result, the trajectory of the spray was estimated as shown in Fig. 4 with the solid line. The injector exit diameter in Equation (1) is then set to be $1.78 \mathrm{~mm}$. Furthermore, the influence of the dispersion angle, sheet constant and ligament constant on the predicted results were investigated, and a combination of a dispersion angle of $10^{\circ}$, a sheet constant of 12 and a ligament constant of 0.5 was employed in our simulations. 
For the walls, a convection coefficient with the ambient air of $12 \mathrm{Wm}^{-2} \mathrm{~K}^{-1}$ and a surrounding temperature of $298 \mathrm{~K}$ (also used in work of Collazo et al. [10]) were adopted.

\subsection{Results and Discussion}

Numerical and experimental data of air mean velocity components at height $\mathrm{z}=1.4$ $\mathrm{mm}$ are presented in Fig. 5. The uncertainty of the experimental measurements is represented by error bars. The experimental data at this height are used as inlet boundary conditions at height $\mathrm{z}=0 \mathrm{~mm}$ for the combustion air flow in the simulation. The corresponding computational predictions at height $\mathrm{z}=1.4 \mathrm{~mm}$ are very close to the measured data. Neither influence of flue gas entrainment nor radiation from the flame is observed, suggesting that the measured velocity components at height $\mathrm{z}=1.4 \mathrm{~mm}$ at hot state are accurate enough to be used as inlet boundary conditions for the combustion air.

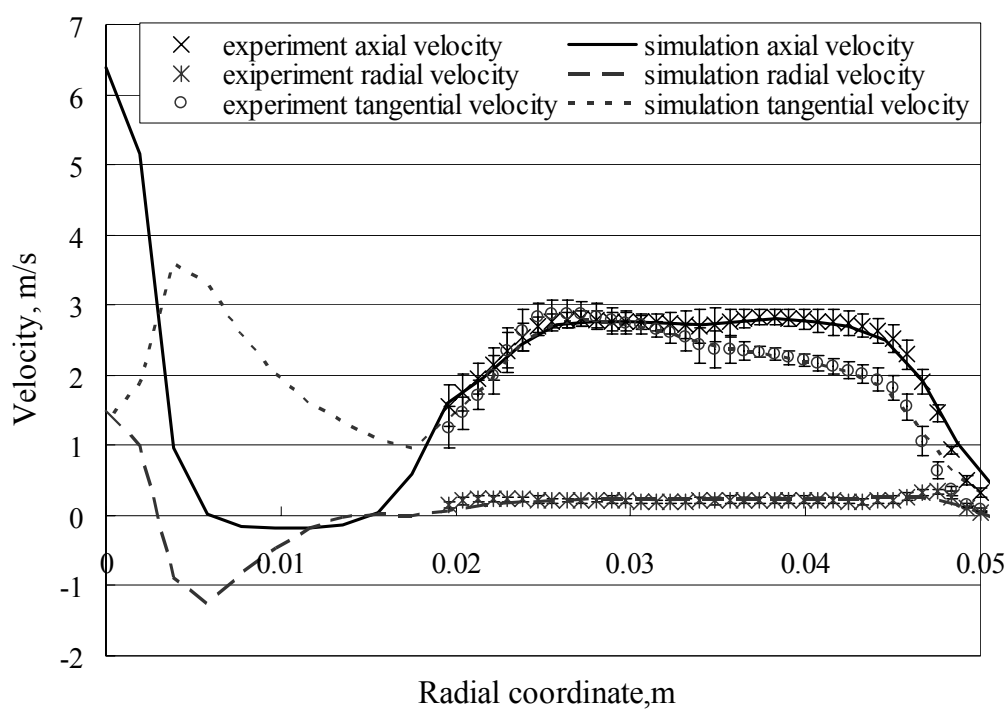

Fig. 5 Predicted mean velocity components at $\mathrm{z}=1.4 \mathrm{~mm}$ compared with experiment 

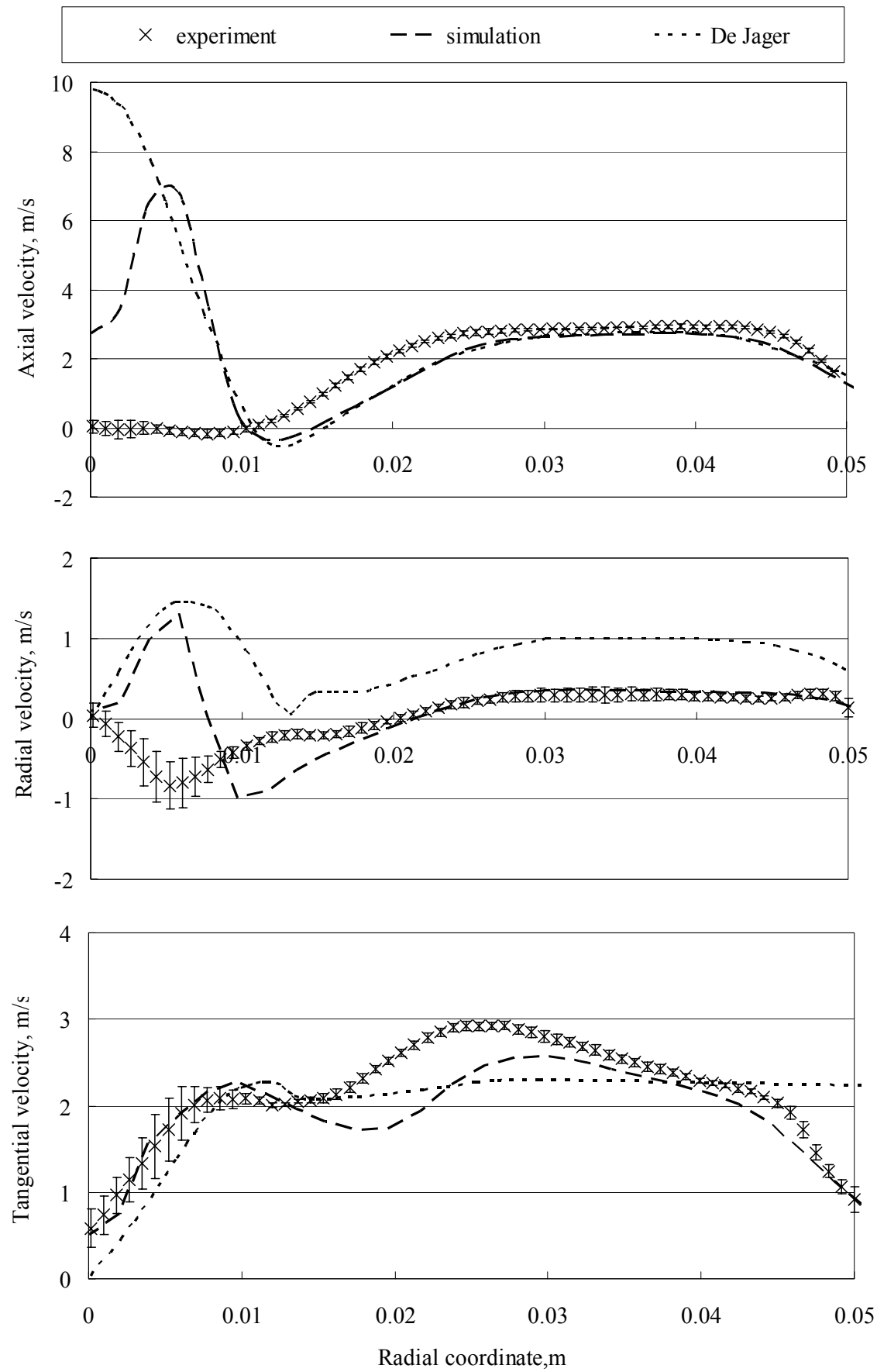

Fig.6 Predicted mean velocity components at $\mathrm{z}=9.5 \mathrm{~mm}$ compared with De Jager's results and the experiment 

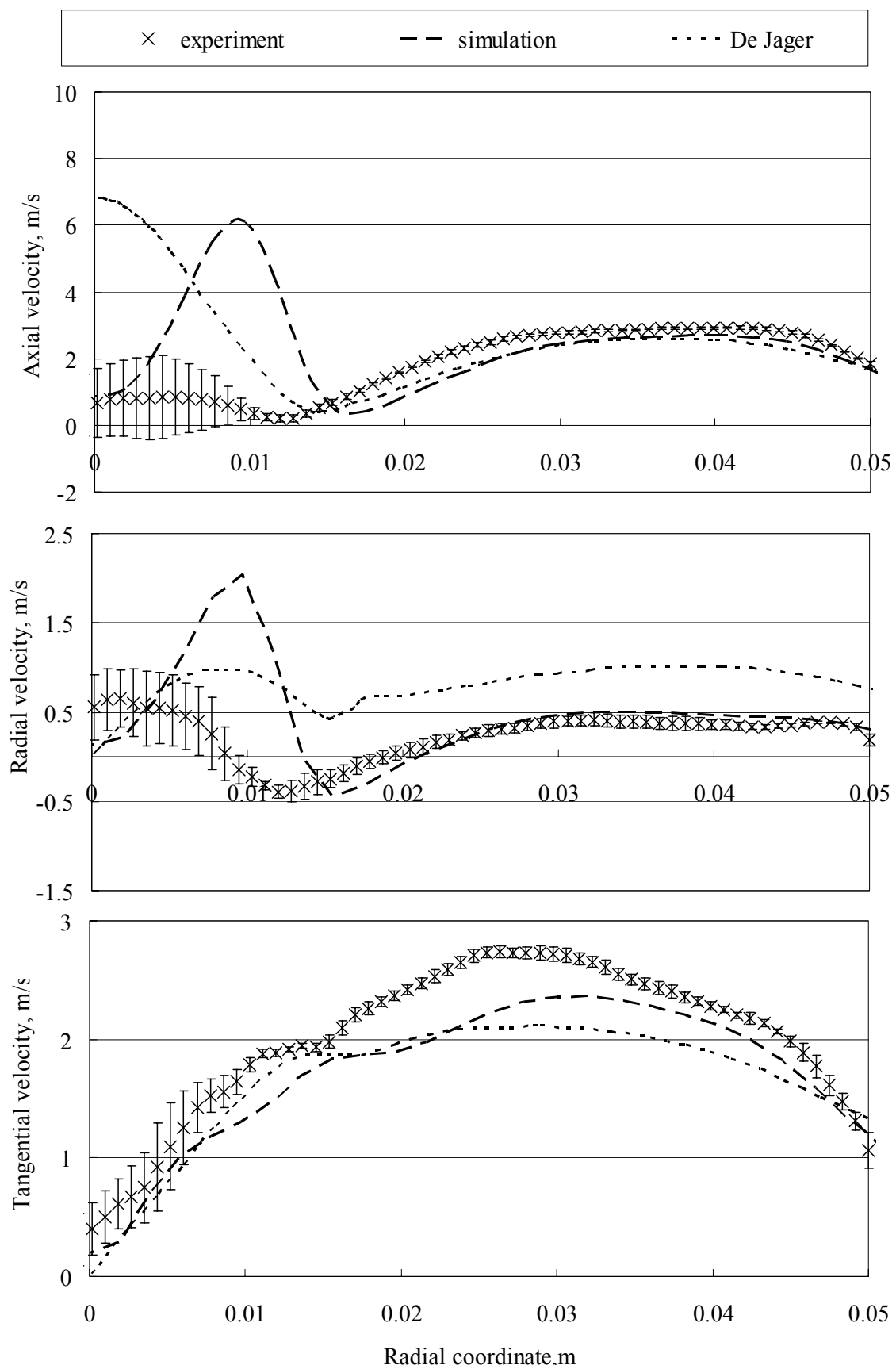

Fig.7 Predicted mean velocity components at $\mathrm{z}=17.6 \mathrm{~mm}$ compared with De Jager's results and the experiment 
Fig. 6 and Fig. 7 show the computed mean gas velocity components at heights $z=9.5$ $\mathrm{mm}$ and $\mathrm{z}=17.6 \mathrm{~mm}$, respectively. These data are compared with De Jager's predictions [9] and the experiment [4]. At large radii (larger than the inner radius of the combustion air inlet), where the flow field is dominated not by the spray but by the air flow, the present study shows good agreement with experimental data for mean gas velocity components. The deviations at large radii for the tangential velocity at $\mathrm{z}=9.5 \mathrm{~mm}$ and $\mathrm{z}=17.6 \mathrm{~mm}$ seem to be remarkable. However, taking into account the influence of the measurement errors of the data at $\mathrm{z}=1.4 \mathrm{~mm}$ shown in Fig. 5 which affects the inlet conditions, the deviations are still minor. For small radii, major deviations from the experimental data for axial and radial velocities can be observed. This is also visible in work of De Jager. This can be an effect of an overestimation of the interaction between the droplets and the continuous phase. However, because the acceleration of the continuous phase by the spray and thermal expansion of the continuous phase result in the enhanced velocity components, an alternative more probable explanation can be found, i.e. it is difficult to measure velocity components of a gaseous phase in a region where a dispersed phase is present in high concentration. For the tangential velocity, the predicted results at small radii resemble the experimental data well because the tangential velocity is not accelerated by the spray.

Due to the assumptions of pre-evaporated fuel used in De Jager's simulation [9], the predicted axial velocity profile observed in his results has a peak value of $9.7 \mathrm{~m} / \mathrm{s}$ at the central line $(z=9.5 \mathrm{~mm})$. In the present study a peak value of $6.9 \mathrm{~m} / \mathrm{s}$ occurs at a radial position about $5 \mathrm{~mm}$ away from the central line, which means the gaseous phase is dragged by the spray along the injection trajectory. This is also observed in the simulation results of Crocker et al. [8] with a narrow region of accelerated flow near the nozzle tip caused by liquid spray entrainment. Large discrepancies between predicted radial and tangential velocities from De Jager's simulation and the experimental data can be observed. That is most likely attributed to the near-wall treatment introduced in the turbulence model. In this case, the heights at which data were measured are close to the nozzle, and the influence of the tip of the atomizer needs to be taken into account. According to the $\mathrm{y}+$ value in the near-wall region, more accurate prediction can be obtained by using the enhanced wall treatment [30], instead of the wall function used by De Jager. 


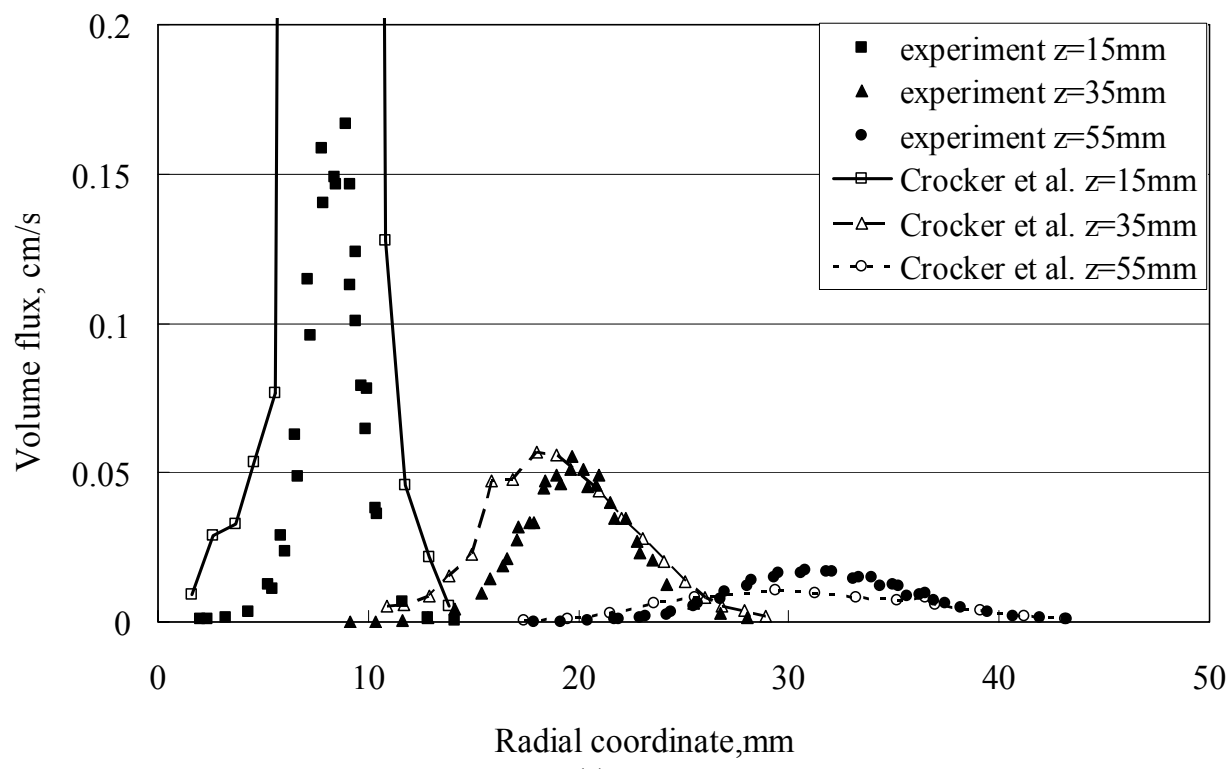

(a)

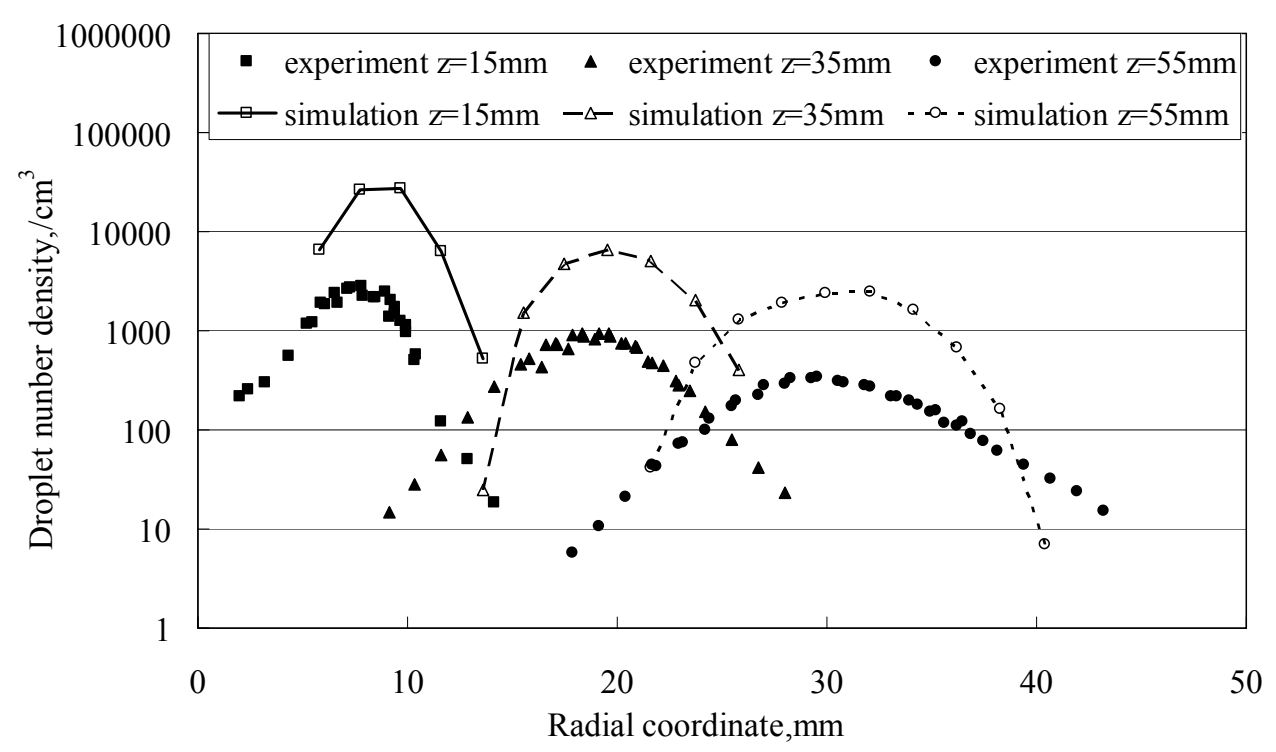

(b) 


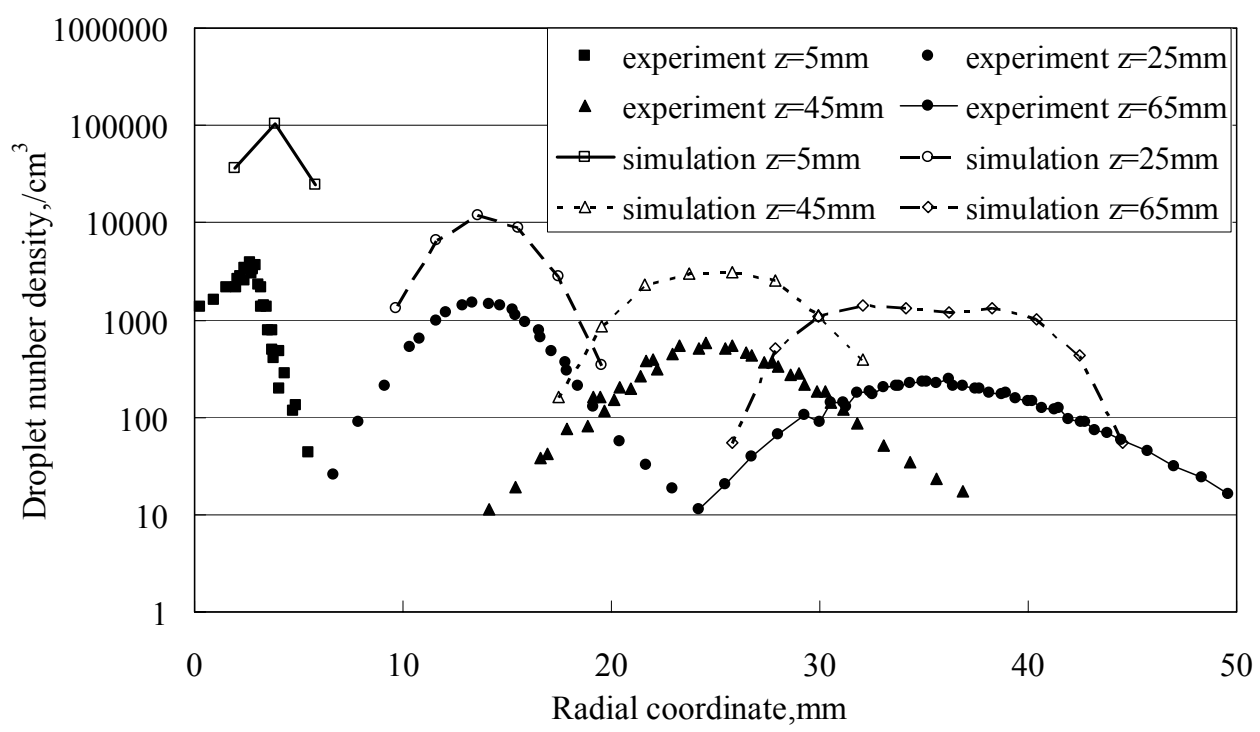

(c)

Fig.8. Predicted spray volume flux/ droplet number density at different heights compared with results from Crocker et al. and the experiment

Fig.8 (a) shows the spray volume flux at different heights from simulation of Crocker et al. [10] compared with the experiment [4]. The magnitude of the peak at height $\mathrm{z}=15$ $\mathrm{mm}$ is predicted to be significantly higher than the experimental data. This phenomenon is also observed in the present study, see Fig.8 (b) for comparison of droplet number density between numerical and experimental data. At further downstream locations, i.e. heights $z=35 \mathrm{~mm}$ and $\mathrm{z}=55 \mathrm{~mm}$, peak magnitudes of spray volume fluxes from the simulation of Crocker et al. occur at different radial location from the experimental. Therefore it was proposed by the authors to increase all of the initial spray angles by $3^{\circ}$ in order to better evaluate the sensitivity of the spray flux location to the initial spray angle. Since the predicted droplet velocity and SMD in the work of Crocker et al. show good agreement with the experiment without adjustment of initial spray angles, this modification may entail more significant discrepancy in both profiles. In the present study, an increased dispersion angle of $10^{\circ}$ is introduced instead of the initial spray angle, resulting the peak positions and trends are all in good agreement with the experimental data. This behaviour is observed not only at $\mathrm{z}=15,35$ and $55 \mathrm{~mm}$ heights, but also at four other elevations shown in Fig.8 (c). The main difference here is that the simulation of the 
present study provides higher droplet number density than the experiment. Closer to the atomizer, at heights $5 \mathrm{~mm}$ and $15 \mathrm{~mm}$, the predicted number of droplets increases leading to more significant overestimation there between numerical and experimental data. This is reasonable because accurate measurements of droplet number density in the high number density region close to the nozzle are very difficult. That is why it is suggested by Widmann and Presser to use the information about the droplet number density in a qualitative way rather than quantitatively [4].

Fig.9 shows the predicted SMD of the droplets in comparison with results of Crocker et al. and experimental data. In view of the uncertainties related to measurements and calculations of the SMD from captured droplets, the results obtained in the present study are very satisfactory. It is observed that at height $\mathrm{z}=5 \mathrm{~mm}$ the SMD has higher deviations than at other heights. That might be because in the simulation at the nozzle exit the spray is directed towards the symmetry axis. In a $2 \mathrm{D}$ simulation all droplets then travel through the axis and the coalescence is overestimated according to the algorithm of O'Rourke [15] and causes the droplet diameters to be more narrowly distributed. It has to be noted that the simulation does not predict any SMD in the inner region of the cone because no droplets reach that region, and this is in contrast with the experiment. In results of Crocker et al. shown in Fig.9 (a), because the droplets are injected at height $\mathrm{z}=5 \mathrm{~mm}$ and the initial droplet size distribution at each radial position is taken directly from the measured data with 21,000 parcels of droplets, the predicted SMD shows better agreement with the experiment in regions with low droplet number density (aside of the main spray trajectory) than the present study. This behaviour is visible especially at height $\mathrm{z}=15 \mathrm{~mm}$. Large discrepancies between simulation of Crocker et al. and the experiment can be observed at further downstream position. They proposed to use seven equally weighted parcels with a $1.5^{\circ}$ interval centred on the mean angle, in order to fit the measured SMD. However, this action may also influence other predictions leading finally to significant discrepancy from experiment. 


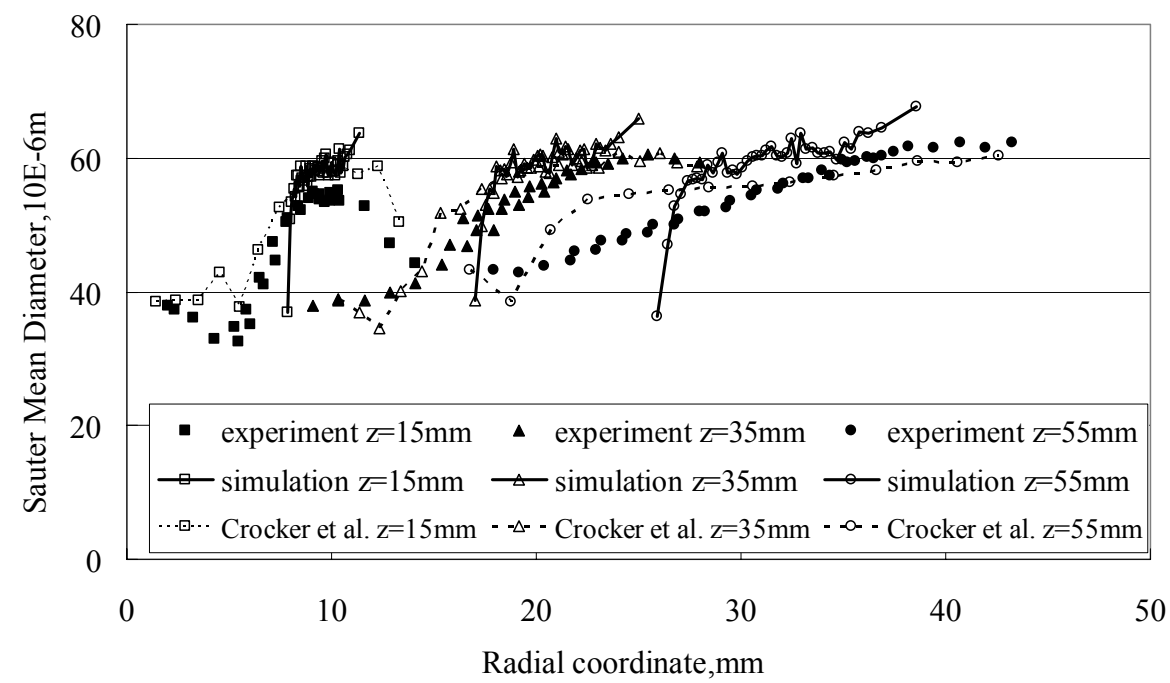

(a)

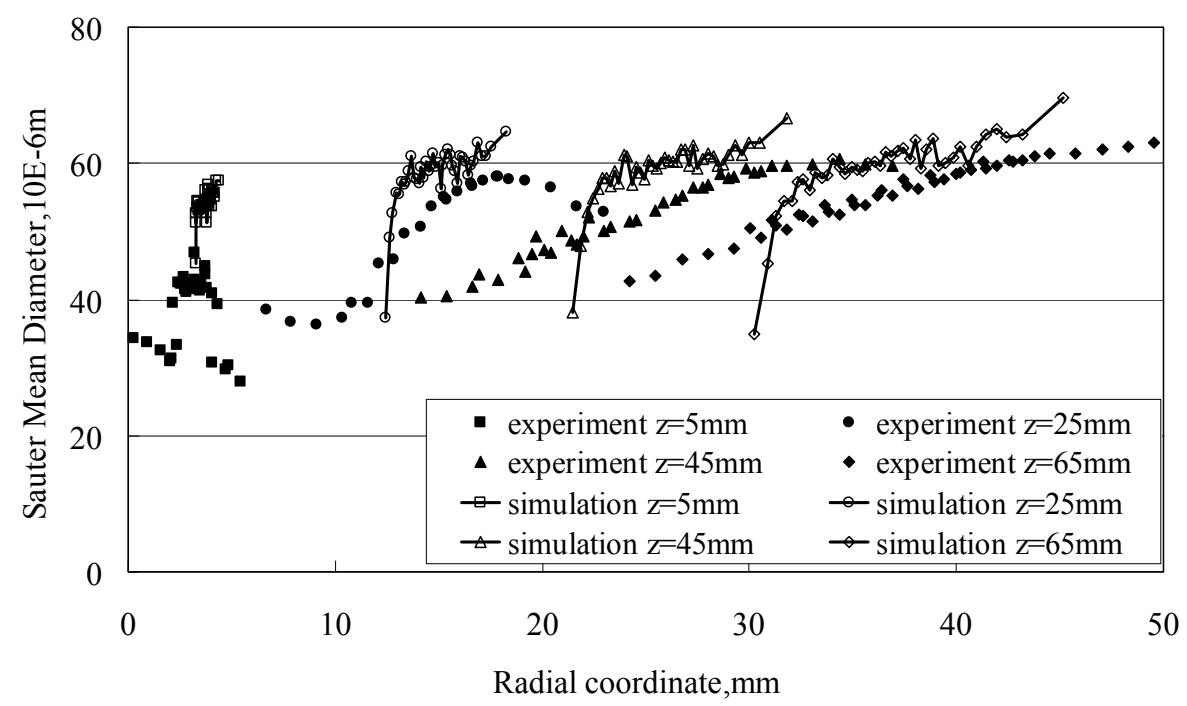

(b)

Fig.9. Predicted SMD of the droplets at different heights compared with results from Crocker et al. and the experiment

The computed mean axial and radial velocities of the droplets are compared with results from Crocker et al., and with the experimental data in Fig.10. The predictions from the present study are in good agreements with the experiment in regions of significant importance, i.e. regions with high droplet number density (along the main spray trajectory), see Fig.10 (a) and Fig.10 (b). In the region with low droplet number density, 
there are some discrepancies similar as found in the comparison of the SMD. In simulation of Crocker et al., the axial velocities are slightly under predicted. Therefore it was proposed to shift the initial droplet size to an even larger size. That would again lead to difficulties in other predictions.
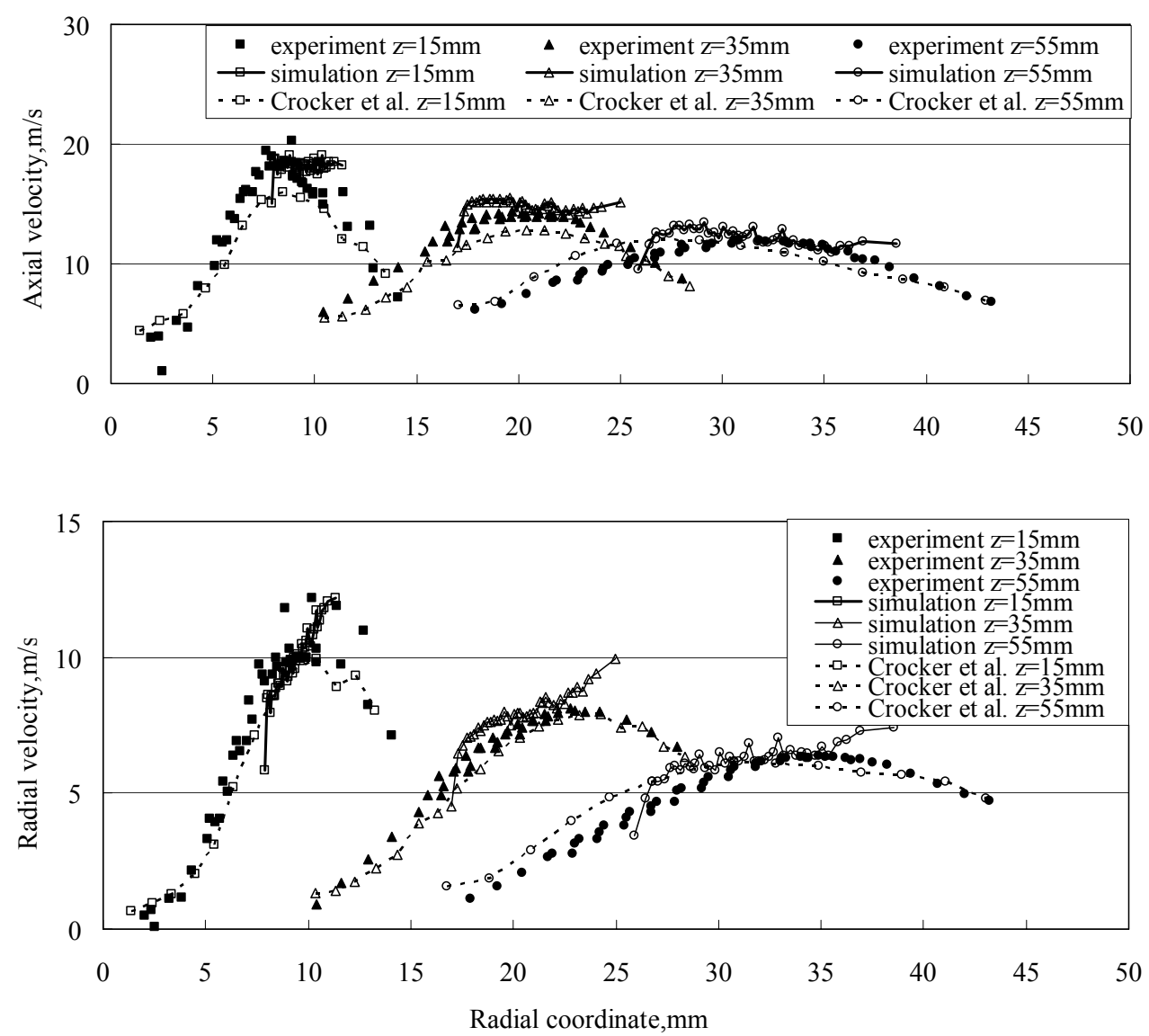

Fig.10 (a). Predicted mean axial and radial velocities of the droplets at different heights $(z=15,35$ and $55 \mathrm{~mm}$ ) compared with results from Crocker et al. and the experiment 

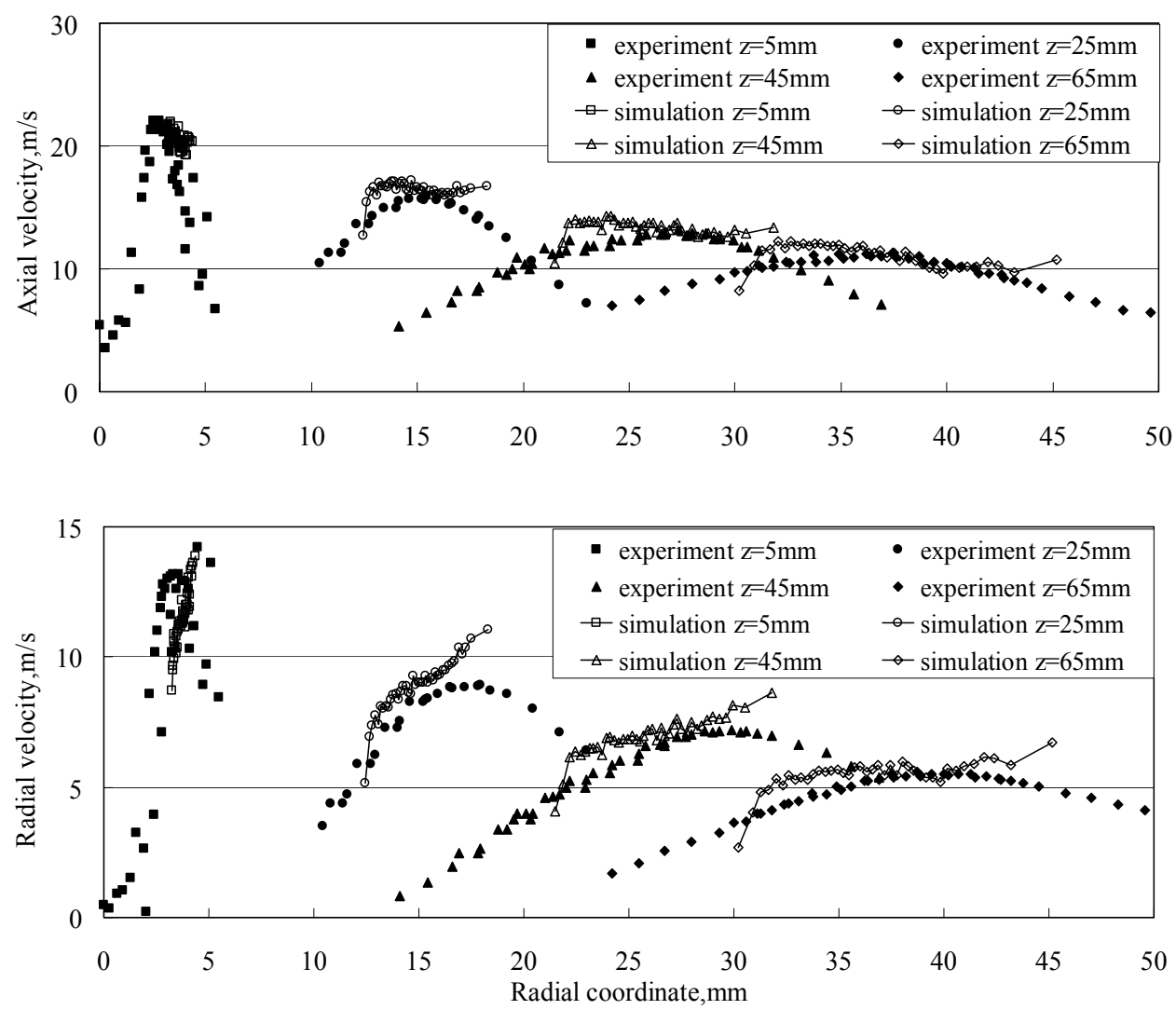

Fig.10 (b). Predicted mean axial and radial velocities of the droplets at different heights $(z=5,25,45$ and $65 \mathrm{~mm}$ ) compared with results from Crocker et al. and the experiment

In general, it is a feasible and effective approach to use the measured data of droplets, i.e. droplet size distribution and velocity components, as the initial boundary condition of the spray. In this way, the modelling of primary breakup process, which is not wellunderstood yet, can be avoided. Furthermore, since the data are usually measured at downstream positions i.e. at least $5 \mathrm{~mm}$ away from the atomizer, the droplet coalescence, collision and secondary breakup processes are mostly completed, and can be avoided in the simulation. As a result, the more accurate data we obtain in the experiment, the more accurate the description of the spray in the simulation is. However, as presented in the experiment of the NIST flame [4], the scattering of the droplets often leads to a very low measured spray flux close to the atomizer, i.e. about one tenth of the total spray flux in the experiment of the NIST flame. Therefore with the measured data of droplets, which 
is just a small part of the total injection, the accuracy of the boundary conditions is arguable and they still require further adjustments as done in the simulations of Crocker et al. It is possible to measure a larger fraction of the number of droplets at further downstream positions, but there it is more likely that the droplets have already interacted with the surroundings and they can hardly be used as boundary conditions. In some situations, i.e. with strong air flow, hot co-flow or intense flame radiation, droplets may have been affected before they can be measured in the experiment. Besides, in order to guarantee an accurate description of the spray, a new set of measured data is required for the simulation when any change of the spray occurs, such as change of mass flow or pressure of the liquid fuel, effect of air flow or radiation, etc., even when the same atomizer is used.

By contrast, in the present study the mass flow and pressure of the liquid fuel, spray angle and dispersion angle are used to determine the droplet size distribution and velocity components, and this approach can be easily transferred to other conditions of research, especially for comparative study. One of the key points in this method is the analysis of the initial spray trajectory, which may differ with a different atomizer or liquid fuel. Unlike the other data, i.e. SMD or droplet velocity components, the spray trajectory can be analysed in the experiment relatively easily, and can be analysed even at closer positions to the atomizer in order to eliminate the influences of the surroundings. The obtained initial spray trajectory is usually accurate enough for simulations even if just a small proportion of droplets can be measured in the experiment. As shown above, in regions of high importance (regions with high droplet number density), the droplet number density, SMD, and the mean axial and radial velocities of the droplets predicted in current research have shown improved agreement with the experimental data in comparison to other studies. The disadvantage of the method used in the present study is that the models for droplet coalescence, collision and secondary break-up require further improvements so that the droplets in regions with low number density can also be predicted correctly. Therefore, we suggest improving the collision and coalescence model by generating more widely distributed small droplets. The trajectory of the spray will not change by this modification and the predicted droplet velocity and SMD in regions with low droplet number density will match the experiment better. 
Furthermore, temperature measurements in the flame are not present in the experimental study due to the large uncertainties associated with such measurements in spray flames. Only a temperature of about $550 \mathrm{~K}$ at the exit of the exhaust channel was indicated. However in both simulations of Crocker et al. [8] and the current study the exhaust channel is omitted. Therefore the direct comparison is not possible. A peak temperature of about $1800 \mathrm{~K}$ is reported by Crocker et al., while in the present study the magnitude is approximately $50 \mathrm{~K}$ higher. Fig. 11 shows the contours of the predicted mean temperature profile in the current research with the average temperature at the outlet location equal to around $700 \mathrm{~K}$. Since in the experiment the temperature was measured further downstream than in the numerical study, it is expected that a temperature of $700 \mathrm{~K}$ is a good approximation of the experimental conditions at the outlet.

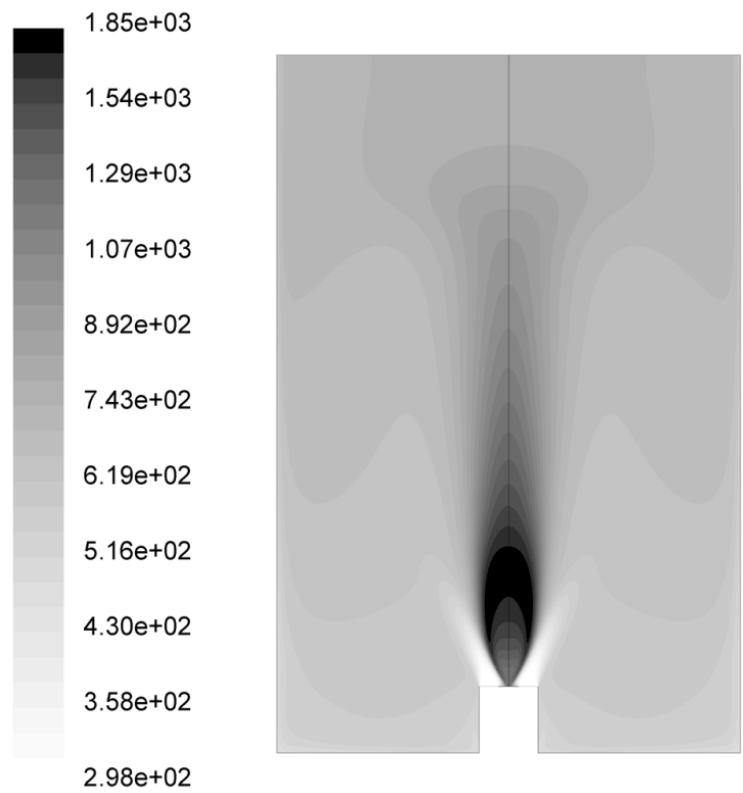

Fig.11. Contours of mean temperature $[\mathrm{K}]$

In order to further validate the spray flame behaviour, the definition of oxidation mixture ratio [31] is introduced:

$$
R_{O}=\frac{m_{O}}{m_{O}+\sum_{c} S_{c} m_{F, c}}
$$


where $S=n_{O} M_{O} / n_{F} M_{F}$ with $m$ the mass fraction, $\mathrm{n}$ the stoichiometric ratio, $\mathrm{M}$ is the molar mass, and index $\mathrm{O}, \mathrm{F}, \mathrm{C}$ representing oxygen, fuel and flue gas respectively. The lean flammability limit can be used to define the external boundary of the flame and the rich flammability limit can be used to define the inner boundary of the flame. Following [31] we assumed that $R_{O}=0.99$ is representative for the external boundary. From Fig. 12 it can be noticed that contours of mean oxidation mixture ratio resemble the flame profile in the experiment [4] well and it confirms that the predicted mean concentration of $\mathrm{OH}$ is capable of representing the flame.

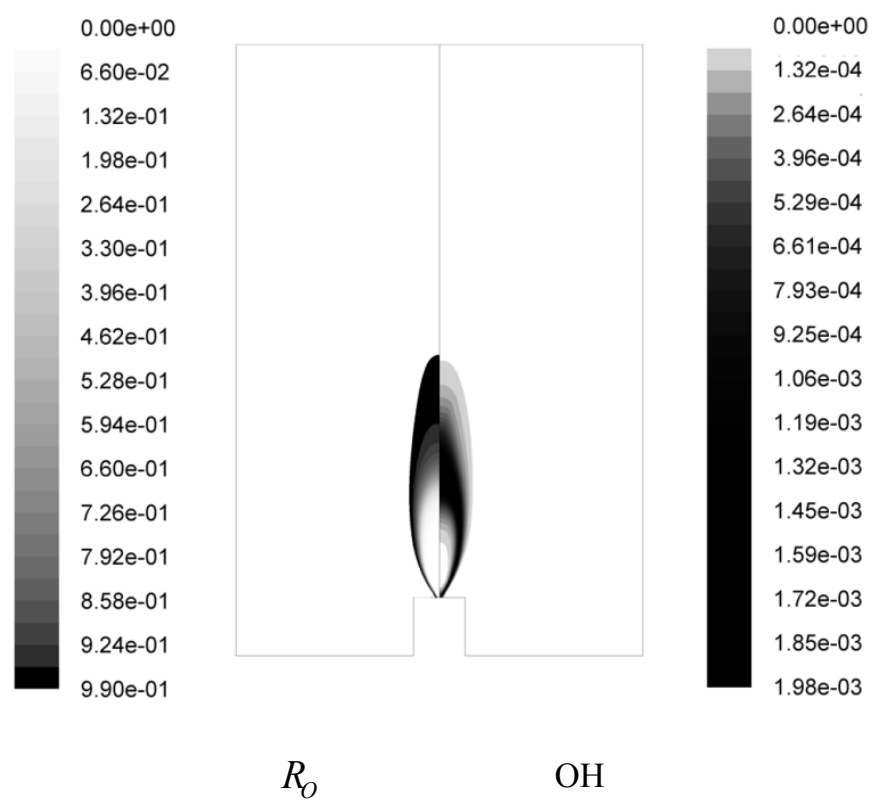

Fig.12. Contours of mean oxidation mixture ratio, $R_{O}$ and mean mole fraction of $\mathrm{OH}$

The influence of the source term of the mixture fraction variance because of evaporation on the NIST flame was investigated as well and presented in [32]. Due to the evaporation of the droplets, the peak value of mean mixture fraction variance rises from 0.013 to 0.016 . The main difference occurs at the root of the flame, where most of the evaporation takes place. This is also the same region where the scalar dissipation changes with the peak value of scalar dissipation increasing from $13 \mathrm{~s}^{-1}$ to $17 \mathrm{~s}^{-1}$. Since in the NIST flame the influence of the source term on the mixture fraction variance only occurs 
in this lower region while the combustion mainly occurs in the flame area, the combustion characteristics are not strongly influenced by the modelling of the variance equation.

\subsection{Conclusions}

We have presented results of a numerical investigation of a methanol spray flame studied experimentally at the NIST $[4,6]$. We also have analysed previous simulations of this flame $[8,9,10]$.

In spite of the asymmetric position of the exhaust channel, the flame can be considered to be statistically symmetric. Therefore in the employed RANS approach the computational domain can be taken two-dimensional, allowing for a sufficiently fine grid, especially in the near nozzle region where large velocity and temperature gradients are present.

Based on the analysis of $y+$ value in the near-wall region [30], we used the enhanced wall treatment, instead of the wall function used in previous simulations e.g. by De Jager [9] in the frame of the standard k- $\varepsilon$ model. The choice of model for the near wall region provided better predictions of the velocity components of the gaseous phase at various downstream positions. The observed deviations between model predictions and experimental results at small radial distance may be attributed to both numerical and experimental causes, and have been observed also in previous simulations by others $[8$, 9].

In order to take into account droplet collision, coalescence, and secondary breakup, the Eulerian-Lagrangian method was used with LISA model for the atomization process. The measured data were analysed in order to obtain relative accurate boundary conditions of the spray, which is especially of high importance to the inner diameter (see Equation (1)) for the analysis of the initial spray trajectory. This method was compared and discussed with the approach used in [8], in which the measured data of droplets were used as the boundary conditions of the spray. Since often a very low spray flux can be measured close to the atomizer in the experiment and the droplets may have interacted with the surroundings if they are measured further downstream, the measured data of droplets, i.e. droplet size distribution and velocity components, still require adjustments before they 
can be used. Also, when we use the measured data as boundary conditions of the spray, it is necessary to measure a new set of data if any change of the atomizer or process conditions is made. This limits the transferability of the models. In the method used in the present study, the required analysis of the initial spray trajectory needed to define the boundary conditions of the spray can be made relatively easy and the spray model can be easily transferred to other conditions, especially for comparative investigations. In regions of major importance with high droplet number density, the predictions of droplet number density, SMD, and the mean axial and radial velocities of the droplets showed improved match with the experimental data with regard to results of previous investigations. Nevertheless, it is found that models for droplet coalescence, collision and secondary break-up processes require further improvements so that the droplets in regions with low number density can also be predicted with higher precision, and we suggest to improve the collision and coalescence model by generating more widely distributed small droplets.

The introduction of the steady laminar flamelet model with a detailed reaction mechanism for gaseous combustion, and the Discrete Ordinates model for radiation also contributes to the good agreement between the predictions and the experimental data. Unfortunately temperature and species measurements in the flame zone are not available in the experiment for validation. It is found that contours of mean $\mathrm{OH}$ concentration and mean oxidation mixture ratio both resemble well the flame profile in the experiment [4], and a predicted temperature of $700 \mathrm{~K}$ at the outlet in the simulation is a good approximation of the experimental conditions at the exit. The investigation of the influence of the source term of evaporation on the mean mixture fraction variance has shown that due to the evaporation process, the peak value of mean mixture fraction variance increased from 0.013 to 0.016 . However, the change only occurred in the root part of the flame and not in the main flame area, so the combustion characteristics do not change much. 


\section{References}

[1] Jenny, P., Roekaerts, D. and Beishuizen, N. (2012) Modeling of turbulent dilute spray combustion, Progress in Energy and Combustion Science, 38, 846-887.

[2] McDonell, V.G. and Samuelsen, G.S. (1995) An experimental database for the computational fluid dynamics of reacting and nonreacting methanol sprays, Journal of Fluids Engineering, 117, 145-53.

[3] Karpetis, A. and Gomez, A. (2000) An experimental study of well-defined turbulent nonpremixed spray flames, Combustion and Flame, 121, 1-23.

[4] Widmann, J.F. and Presser, C. (2002) A benchmark experimental database for multiphase combustion model input and validation, Combust and Flame, 129, 47-86.

[5] Düwel, I., Ge, H.-W., Kronemayer, H., Dibble, R., Gutheil, E., Schulz, C. and Wolfrum, J. (2007) Experimental and numerical characterization of a turbulent spray flame, in Proceedings of the Combustion Institute, 31, 2247-2255.

[6] NIST. Materials measurement laboratory, Gaithersburg, Maryland. U. Benchmark spray combustion database. http://webbook.nist.gov/chemistry/spray-combust.

[7] Presser, C. (2006) Application of a benchmark experimental database for multiphase combustion modeling, Journal of Propulsion and Power, Technical Note, 22, 1145-1148.

[8] Crocker, D.S., Widmann, J.F. and Presser, C. (2001) CFD modeling and comparison with data from the NIST reference spray combustor, ASME International Mechanical Engineering Congress and Exposition.

[9] Jager, B. (2008) Combustion and noise phenomena in turbulent alkane flames, $\mathrm{PhD}$ thesis, Twente University.

[10] Collazo J., Porteiro, J., Patiño, D., Miguez, J.L., Granada, E. and Moran, J. (2009) Simulation and experimental validation of a methanol burner, Fuel, 88, 326-334.

[11] Schmidt, D. P., Nouar, I., Senecal, P. K. et al. (1999) Pressure-swirl atomization in the near field, SAE Technical Paper 01-0496, SAE. 
[12] Magnussen, B.F. (1981) On the structure of turbulence and a generalized eddy dissipation concept for chemical reaction in turbulent flow, in Proceedings of the 19th AIAA Meeting, St. Louis.

[13] Reitz, R.D. (1987) Modeling atomization processes in high-pressure vaporizing sprays, Atomization and Sprays Technology, 3, 309-337.

[14] Patterson, M.A. and Reitz, R.D. (1998) Modeling the effects of fuel spray characteristics on diesel engine combustion and emission, SAE 980131.

[15] O'Rourke, P.J. and Amsden, A.A. (1987) The TAB method for numerical calculation of spray droplet breakup, SAE 872089.

[16] Han, Z., Perrish, S., Farrell, P. V. and Reitz, R. D. (1997) Modeling atomization processes of pressure-swirl hollow-cone fuel sprays, Atomization and Sprays, 7, 663-684.

[17] Lefebvre, A. H. (1989) Atomization and sprays, Hemisphere Publishing Corporation.

[18] Weber, C. (1931) Zum Zerfall eines Flüssigkeitsstrahles, ZAMM, 11, 136-154.

[19] Dombrowski, N. and Hooper, P. C. (1962) The effect of ambient density or drop formation in sprays, Chemical Engineering Science, 17, 291-305.

[20] Schmidt, D. P., Corradini, M. L. and Rutland, C. J. (1999) A two-dimensional, nonequilibrium model of flashing nozzle flow, in Proceedings of the 3rd ASME/JSME Joint Fluids Engineering Conference, American Society of Mechanical Engineers.

[21] Taylor, G. I. (1963) The shape and acceleration of a drop in a high speed air stream, Technical Report, in the Scientific Papers of G. I. Taylor, ed., G. K. Batchelor.

[22] O'Rourke, P. J. (1981) Collective drop effects on vaporizing liquid sprays, $\mathrm{PhD}$ thesis, Princeton University, Princeton, New Jersey.

[23] Ranz, W. E. and Marshall, W. R. (1952) Jr. Evaporation from Drops, Part I. Chem. Eng. Prog., 48, 141-146.

[24] Ranz, W. E. and Marshall, W. R. (1952) Jr. Evaporation from Drops, Part II. Chem. Eng. Prog., 48, 173-180.

[25] Lindstedt, R.P. and Meyer, M.P. (2002) A dimensionally reduced reaction mechanism for methanol oxidation, in Proceedings of the Combustion Institute, 29, 1395-1402. 
[26] International workshop on measurement and computation of turbulent nonpremixed flames. http://www.sandia.gov/TNF/chemistry.html

[27] Muller, C. M., Breitbach, H. and Peters, N. (1994) Partially premixed turbulent flame propagation in jet flames, Technical Report, in Proceedings of the 25th Symposium (Int) on Combustion, The Combustion Institute.

[28] Binniger, B., Chan, M., Paczkko, G. and Herrmann, M. (1998) Numerical simulation of turbulent partially premixed hydrogen flames with the flamelet model, Technical Report, Advanced Combustion Gmbh, Internal Report.

[29] Hollmann, C. and Gutheil, E. (1996) Modeling of turbulent spray diffusion flames including detailed chemistry, in Proceedings of the 26th symposium (international) on combustion, The Combustion Institute, 1731-1738.

[30] Kader, B. (1981) Temperature and concentration profiles in fully turbulent boundary layers, International Journal of Heat and Mass Transfer, 24, 1541-1544.

[31] Yang, W. and Blasiak, W. (2005) Numerical study of fuel temperature influence on single gas jet combustion in highly preheated and oxygen deficient air, Energy, 30: 385-398.

[32] Zhu, S, Roekaerts, D. and van der Meer, T. (2011) Numerical simulation of a turbulent methanol spray flame using the Eulerian-Lagrangian method and the steady laminar flamelet model, in Proceedings of the 7th Mediterranean Combustion Symposium, Sardinia, Italy. 


\section{CHAPTER 3.}

\section{NUMERICAL INVESTIGATION OF ETHANOL SPRAY FLAMES TOWARDS HITAC CONDITIONS*}

This Chapter presents numerical study on the Delft Spray-in-Hot-Coflow ethanol spray combustion under various co-flow conditions. The pressure-swirl atomizer model with an Eulerian-Lagrangian approach is implemented in the modeling of ethanol spray flames. Collision, coalescence, secondary breakup and evaporation of the drops are taken into account as well. The steady laminar flamelet model for the combustion of ethanol, the Discrete Ordinate model for radiation and the k- $\varepsilon$ model for the turbulence with enhanced wall treatment, which have been validated in the previous chapter for the methanol spray flame under the conventional condition, are used in this chapter for comparative study on the ethanol spray flames towards HiTAC conditions.

\footnotetext{
${ }^{*}$ Content in this chapter has been partially included in a paper submitted to journal Fuel.
} 


\subsection{Introduction}

As discussed in the previous chapters, modeling of a turbulent spray flame poses a tremendous difficulty due to the complexities and interactions among the simultaneously occurred dispersion, modification of continuous phase turbulence, dispersed phase, interparticle collisions, evaporation, mixing and combustion [1]. To address all those phenomenon, hybrid models, such as models for turbulence, atomization, secondary break-up, collision and coalescence, evaporation, radiative heat transfer, combustion, etc. have been employed. These models have been validated already by the simulation of the NIST flame using methanol under conventional condition [2] and then were applied for comparison with preliminary results from the ethanol spray-in-hot-co-flow [3]. The predicted mean velocity components of the gaseous flow and the droplets, the droplet number density, and the Sauter Mean Diameter (SMD) of the droplets at various heights showed good agreement with the experimental data. The method to set inlet boundary conditions for the spray has been discussed and compared with direct application of data regarding measured droplet size and velocity distribution. In the application for modeling the ethanol spray-in-hot-co-flow case, relatively good agreement with experimental data of mean droplet velocity components and size distribution at various elevations has been observed, as well. It was recommended that under hot co-flow conditions, the evaporation model and the auto-ignition and local extinction processes requires more efforts in order to obtain more accurate prediction in the high strain region, which is in the vicinity of the injector exit. Ma et al. [4,5] further exploited more directly all available measured data and used a "conditional droplet injection model", in which large droplets are injected within a small range of angle around the main spray trajectory while small droplets are injected in a much wider range. In this way the prediction of SMD in low droplet number density region also showed good agreement with the experimental data, as well as in the vicinity of the injector exit. In the present study, we focus on the comparison of simulation results under different co-flow temperatures and $\mathrm{O}_{2}$ concentrations using the validated models. The local high strain region is not dominant in the flame towards HiTAC conditions, especially for the comparative study.

In the research, we used different co-flow temperatures $(300 \mathrm{~K}, 600 \mathrm{~K}, 900 \mathrm{~K}, 1200 \mathrm{~K}$ and $1500 \mathrm{~K})$ and oxygen concentrations $(21 \%, 18 \%, 15 \%, 12 \%, 9 \%$ and $6 \%)$ of the co- 
flow. The mass flow rate and pressure of the fuel-oil are kept constant. The simulation results from different cases, such as temperatures, flame profiles, droplet size distributions, etc., are studied with respect to HiTAC conditions. Two cases are compared to preliminary measurement data, respectively: one with $300 \mathrm{~K}$ and $21 \% \mathrm{O}_{2}$ concentration, and the other one with $1500 \mathrm{~K}$ and $6 \% \mathrm{O}_{2}$ concentration. These two cases are achievable in experiment, and they represent the typical conventional spray flame and spray flame in hot co-flow condition. The influences of temperature, $\mathrm{O}_{2}$ concentration, velocity and triatomic molecules in the co-flow are numerically investigated in order to get a better understanding of the achievement of HiTAC conditions for spray combustion.

\subsection{Numerical cases}

The numerical cases are based on the experimental set up available at Delft University of Technology using the DSHC burner. Fig.1 presents a schematic of the Delft spray burner [6,7]. An ethanol spray is produced by a pressure swirl atomizer, whereas the hot co-flow is assured by secondary burner whereby air and Dutch natural gas (DNG) mix and generate a matrix of 236 lean flames. The air/DNG ratios in combination with the effects of two perforated plates located along the pipe length dictate the temperature, oxygen and turbulence levels. Co-flow composition and temperature are selected to emulate the conditions of flue gas in large scale furnaces. This design enables a wide range of co-flow characteristics with good axisymmetric properties without the need for elaborate safety systems and allows easy optical access to laser diagnostics. 


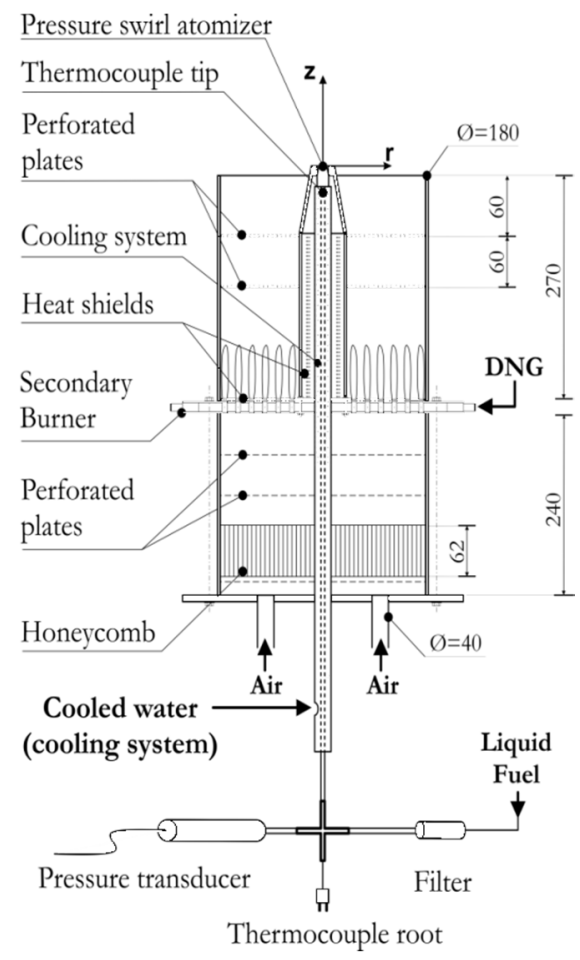

Fig.1 Schematic of the Delft spray flame set-up (mm)

\subsection{Mathematical models}

The mathematical formulation for turbulent spray combustion simulation consists of the consideration of the fining of computational grid, turbulence model, spray model, radiation and combustion model, and $\mathrm{NO}_{\mathrm{x}}$ model etc. Since these models and methods are expected to be validated and developed to generate the knowledge needed for the extension of the application of HiTAC technology to other fuel oils in various applications, for which detailed reaction mechanisms may still need to be investigated and various geometries of chambers/furnaces may be involved, the Reynolds averaged equations are employed, using ANSYS Fluent software. As a result, the models used in the study remain as general as possible in order to be implemented for various applications. 


\subsubsection{Computational grid, near-wall treatment and turbulence model}

For the simulation of the Delft spray flame, a 2D axisymmetric simulation is employed. The grid independence was tested by introducing a series of different cell sizes. The same axial/radial aspect ratio of 3 was kept in order to avoid the interference of potential errors caused by the aspect ratio. A considerable larger aspect ratio however leads to large cells close to the outlet which reduces the accuracy of results, while a considerable lower aspect ratio enhances the amount of cells requiring unnecessary computational cost. The role of the near-wall treatment was analyzed, and a 2D mesh with about 0.6 million quadrilateral cells in combination with the second order upwind scheme was found suitable for this study. A standard k- $\varepsilon$ turbulence model with the enhanced wall treatment is applied based on the comparative analysis. The use of the enhanced wall treatment can possess the accuracy of the standard two-layer (a viscosity affected region and a fully-turbulent region) approach for the fine near-wall mesh and at the same time, not to reduce accuracy for the wall-function mesh.

\subsubsection{Spray model}

In spray combustion studies, often the focus is on the modelling of dilute spray combustion due to the complexity of the processes of injection and atomization $[1,8]$. The experimental data of droplets, i.e. velocity components and size distribution, are frequently used as boundary conditions. Those data are supposed to be measured at a certain axial location, where the atomization has already finished while the injected droplets have not been influenced by the airflow and only a minor part of the evaporation has occurred. However, on one hand, the scattering of the droplets in the experiment may lead to a very low measured spray flux close to the atomizer; on the other hand, at further downstream positions, it is more likely that the droplets have already interacted with the surroundings and they can hardly be used as boundary conditions, especially in hot coflow as in the present study [2]. As a result, we keep using the Linearized Instability Sheet Atomization (LISA) model to simulate the transition of ethanol from the internal injector flow to fully developed spray by a pressure-swirl atomizer [9] as described in chapter 2. 
In many real applications, there may need a few trajectories to be superimposed together in order to resemble better the real droplet diameter distribution and droplet velocity. Moreover, even with the same injector, the droplet diameter distribution and droplet velocity vary due to thermal expansion of the injector under various operating conditions. This makes the validation of simulation challenging. On one hand, even if there are experimentally measured data of droplets, in the vicinity of the injector they are often inadequate for a complete set of droplet diameter distribution and droplet velocity, which means they have to be tuned and verified by data at downstream elevations. On the other hand, even if well-tuned droplet diameter distribution and droplet velocity for one case are obtained and have been verified by data at downstream elevations, they have to be tuned and verified again if the operating condition varies, especially when the measured data are directly used [2].

In the present study, however, we assume that the droplet size distribution and droplet velocity from the injector keep the same in various cases. This allows us for the comparative investigation of the influence of only the co-flow conditions.

Besides, as introduced in chapter 2, the Taylor Analogy Breakup (TAB) model is used for secondary breakup; the algorithm of O'Rourke is employed for droplet collision and coalescence; the same evaporation model is employed, as well.

\subsubsection{Radiation and combustion model}

In this study, the Discrete Ordinates (DO) radiation model with a variable absorption coefficient, weighted-sum-of-gray-gases model (WSGGM) is employed, which has been discussed in [10] and validated in our previous investigation [2].

According to the relative fast chemistry of ethanol, the laminar flamelet method provides a feasible way to include detailed chemical reactions in turbulent combustion simulations without a considerable increase in computational time. It assumes that in the gaseous phase combustion, the diffusion coefficients for all species are equal, and then the species mass fraction and temperature are mapped from physical space to mixture fraction space and can be uniquely described by two parameters: the mixture fraction $\xi$ 
and the scalar dissipation $\chi$. The Favre-averaged values of quantities in the turbulent flame are then obtained through the use of Favre-averaged probability density function, $\widetilde{f}(\xi, \chi)$ :

$$
\tilde{\Phi}=\int_{0}^{\infty} \int_{0}^{1} \Phi(\xi, \chi) \tilde{f}(\xi, \chi) d \xi d \chi
$$

The detailed reaction mechanism for ethanol employed in the present study was developed by Marinov [11] consisting of 57 species and 383 reactions.

In the model, the heat gain/loss to the system is assumed to have a negligible effect on the species mass fractions, and adiabatic mass fractions are used [12,13]. The flamelet profiles are then convoluted with the assumed $\beta$-function-shape PDFs as in Equation (1), and then tabulated for look-up. The equations for the mean mixture fraction, mixture fraction variance, and mean enthalpy are solved. The scalar dissipation field is calculated from the turbulence fields $\tilde{k}, \tilde{\varepsilon}$ and the mixture fraction variance $\tilde{\xi}^{\prime \prime 2}$ as follows:

$$
\tilde{\chi}=\frac{2 \tilde{\varepsilon} \tilde{\xi}^{\prime \prime 2}}{\tilde{k}}
$$

The mean values of temperature, density, and species mass fraction are obtained from the PDF look-up table.

\subsubsection{NOx model}

Since the fuel, i.e. ethanol, used in the present study contains no nitrogen, $\mathrm{NO}_{\mathrm{x}}$ formation mainly consists of thermal $\mathrm{NO}_{x}$ and $\mathrm{N}_{2} \mathrm{O}$ intermediate mechanism $[14,15,16]$. Although prompt $\mathrm{NOx}$ is also taken into account in the simulation, our numerical results have shown that it has little contribution to the total $\mathrm{NO}_{\mathrm{x}}$ formation. This was also observed by other researchers [17].

Thermal $\mathrm{NO}_{\mathrm{x}}$ is calculated by the extended Zeldovich mechanism [18,19], and it consists of oxidation of atmospheric nitrogen at high temperature conditions. The 
principal reactions governing the formation of thermal $\mathrm{NO}_{\mathrm{x}}$ from molecular nitrogen are as follows:

$$
\begin{array}{r}
\mathrm{O}+\mathrm{N}_{2} \stackrel{k_{1}}{\leftrightarrow} \mathrm{N}+\mathrm{NO} \\
\mathrm{N}+\mathrm{O}_{2} \stackrel{k_{2}}{\leftrightarrow} \mathrm{O}+\mathrm{NO} \\
\mathrm{N}+\mathrm{OH} \stackrel{\mathrm{k}_{3}}{\leftrightarrow} \mathrm{H}+\mathrm{NO}
\end{array}
$$

These reactions are considered to be reversible and the rate constants with units of $\mathrm{m}^{3} / \mathrm{mol} \cdot \mathrm{s}$ are as follows:

$$
\begin{gathered}
k_{f, 1}=1.8 \times 10^{8} e^{-38370 / T}, \quad k_{r, 1}=3.8 \times 10^{7} e^{-425 / T} \\
k_{f, 2}=1.8 \times 10^{4} T e^{-4680 / T}, k_{r, 2}=3.81 \times 10^{3} T e^{-20820 / T} \\
k_{f, 3}=7.1 \times 10^{7} e^{-450 / T} \quad k_{r, 3}=1.7 \times 10^{8} e^{-24560 / T}
\end{gathered}
$$

where "f" and " $r$ " in superscript denotes forward and reverse rates, respectively. T means temperature in Kelvin.

In order to compute the $\mathrm{NO}$ concentration, concentrations of nitrogen radical $[\mathrm{N}]$, oxygen radical $[\mathrm{O}]$ and hydroxyl radical $[\mathrm{OH}]$ must be known.

Concentrations of $[\mathrm{N}]$ can be assumed in a quasi-steady state according to its nearly immediate consumption after creation. This N-radical formation is the rate limiting factor for thermal NO production, due to the extremely high activation energy of nitrogen molecule dissociation, which is caused by a triple bond between two nitrogen atoms as shown in equation (3). Hence the NO formation rate $\left(\mathrm{mol} / \mathrm{m}^{3} \cdot \mathrm{s}\right)$ becomes:

$$
\frac{d[N O]}{d t}=2 k_{f, 1}[O]\left[N_{2}\right] \frac{\left(1-\frac{k_{r, 1} k_{r 2}[N O]^{2}}{k_{f, 1}\left[N_{2}\right] k_{f, 2}\left[O_{2}\right]}\right)}{\left(1+\frac{k_{r, 1}[N O]}{k_{f, 2}\left[O_{2}\right]+k_{f, 3}[O H]}\right)}
$$

Concentration of $[\mathrm{O}]$ and $[\mathrm{OH}]\left(\mathrm{mol} / \mathrm{m}^{3}\right)$ can be described by following partial equilibrium approaches $[20,21,22]$ : 


$$
\begin{gathered}
{[O]=36.64 T^{1 / 2}\left[O_{2}\right]^{1 / 2} e^{-27123 / T}} \\
{[O H]=2.129 \times 10^{2} T^{-0.57} e^{-4595 / T}[O]^{1 / 2}\left[H_{2} O\right]^{1 / 2}}
\end{gathered}
$$

The form of $\mathrm{N}_{2} \mathrm{O}$ intermediate mechanism takes into account two reversible elementary reactions:

$$
\begin{gathered}
N_{2}+\mathrm{O}+\mathrm{M} \leftrightarrow \mathrm{N}_{2} \mathrm{O}+\mathrm{M} \\
\mathrm{N}_{2} \mathrm{O}+\mathrm{O} \leftrightarrow 2 \mathrm{NO}
\end{gathered}
$$

where $\mathrm{M}$ is a general third body.

$\mathrm{N}_{2} \mathrm{O}$ can be assumed to be at quasi-steady-state, and the rate of $\left[\mathrm{N}_{2} \mathrm{O}\right]$ and the rate of $\mathrm{NOx}$ formation via the $\mathrm{N}_{2} \mathrm{O}$-intermediate mechanism are:

$$
\begin{aligned}
& {\left[N_{2} O\right]=\frac{k_{f, 1}\left[N_{2}\right][O][M]+k_{r, 2}[N O]^{2}}{k_{r, 1}[M]+k_{f, 2}[O]}} \\
& \frac{d[N O]}{d t}=2\left(k_{f, 2}\left[N_{2} O\right][O]-k_{r, 2}[N O]\right.
\end{aligned}
$$

where

$$
\begin{gathered}
k_{f, 1}=4.44 \times 10^{32} T^{-8.358} e^{-28234 / T}, k_{r, 1}=4.00 \times 10^{8} e^{-28234 / T} \\
k_{f, 2}=2.90 \times 10^{7} e^{-11651 / T}, k_{r, 2}=1.45 \times 10^{-29} T^{9.259} e^{-11651 / T}
\end{gathered}
$$

in which the units of $k_{f, 1}$ is $\mathrm{m}^{6} / \mathrm{mol} \cdot \mathrm{s}$, while the other constants have the units of $m^{3} / \mathrm{mol} \cdot s$ 


\subsection{Boundary conditions for modelling}

The computational domain is illustrated in Fig.2, which gives an image of a typical experimental flame. Further illustration of the computational domain, including spray angle (SA) and dispersion angle (DA) of the fuel spray are given in Fig. 3.

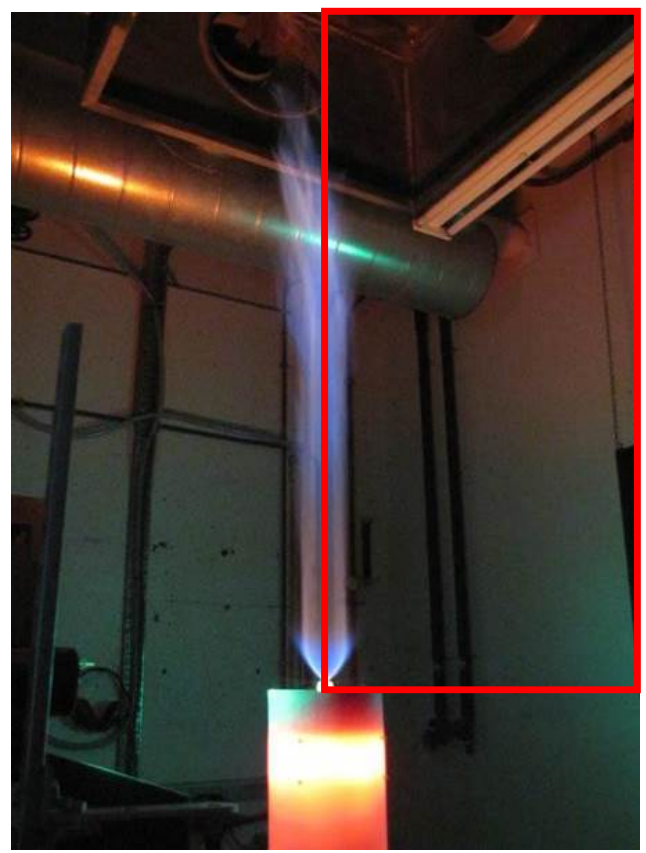

Fig.2 The Delft spray flame (1500K, $9 \% \mathrm{O}_{2}$; frame: computational domain)

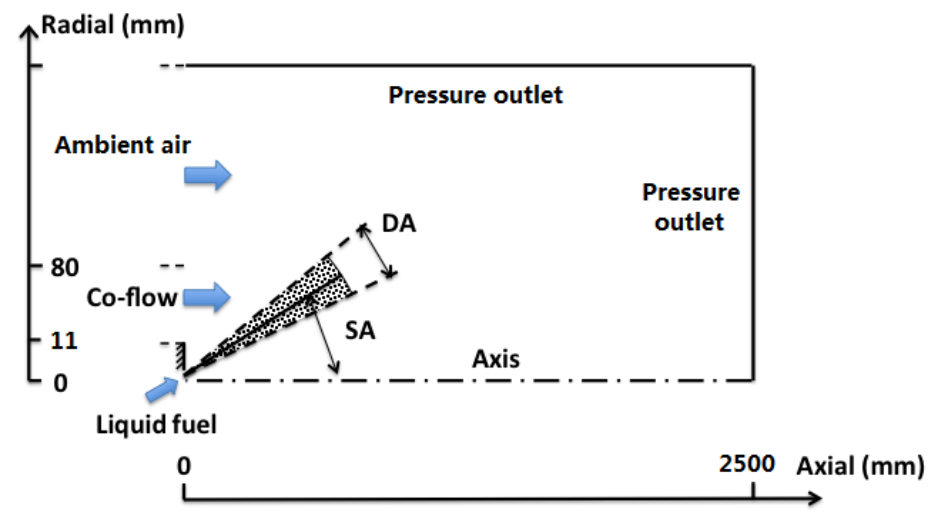

Fig.3 Schematic of computational domain (SA: Spray Angle, DA: Dispersion Angle) 
As shown in Fig.3, ambient air is taken into account in order to investigate its influence on the spray combustion. The ambient air is entrained by the co-flow coming out from the pre-combustor, and may penetrate the co-flow and take part in the combustion process. The condition in which the spray combustion is most likely influenced by the ambient air is the one whose co-flow characteristics have the largest gradients with the ambient air $\left(300 \mathrm{~K}\right.$ and with $21 \%$ vol of $\left.\mathrm{O}_{2}\right)$, i.e. the largest differences of $\mathrm{O}_{2}$ concentration, temperature and velocity.

In the present study, we keep the velocity of the co-flow at $3.5 \mathrm{~m} / \mathrm{s}$ and vary the $\mathrm{O}_{2}$ concentration $(6 \%, 9 \%, 12 \%, 15 \%, 18 \%$ and $21 \%$ vol $)$ and temperature $(300 \mathrm{~K}, 600 \mathrm{~K}$, $900 \mathrm{~K}, 1200 \mathrm{~K}$ and $1500 \mathrm{~K}$ ) of the co-flow. As a result, the spray flame, which has $6 \% \mathrm{O}_{2}$ in the co-flow with a temperature of $1500 \mathrm{~K}$, is most likely to be influenced by the ambient air.

The ethanol spray characteristics are kept the same in various cases, as shown in Tab.1. There is always sufficient oxygen amount for complete combustion.

Table 1. Boundary conditions of the ethanol spray

\begin{tabular}{|c|c|}
\hline Fuel type & Ethanol \\
\hline Fuel flow rate & $0.383 \mathrm{~g} / \mathrm{s}$ \\
\hline Fuel temperature & $303 \mathrm{~K}$ \\
\hline Injection pressure & $700 \mathrm{kPa}$ \\
\hline Spray angle & $30^{\circ}$ \\
\hline Dispersion angle & $10^{\circ}$ \\
\hline Sheet constant & 12 \\
\hline Inner diameter & $0.21 \mathrm{~mm}$ \\
\hline
\end{tabular}


In order to investigate the influence of the ambient air on the spray combustion, we applied different hydraulic diameters for the ambient air inlet, ranging from 6 to 14 times diameter of the co-flow inlet. This was done for the simulation of the case with $1500 \mathrm{~K}$ and $6 \% \mathrm{O}_{2}$ in the co-flow. With the employed vertical height of $2.5 \mathrm{~m}$ for the computational domain, we found that when the diameter of ambient air inlet is smaller than 8 times the diameter of the co-flow inlet, the back flow through the defined lateral outlet cannot be avoided and the computational stability is reduced. When diameter is larger than 12 times the diameter of the co-flow inlet, the recirculation zone caused by the co-flow and the back flow through the defined top outlet also increase the instability of the calculation. Therefore, a hydraulic diameter of $1600 \mathrm{~mm}$ (10 times the diameter of the co-flow inlet) is used in the present study and it results in relatively smooth streamlines of airflow. It must be noted that in the simulation there is a part of the ambient air, which does not turn into turbulent flow with the co-flow, but still keeps laminar. This aspect should be taken into account as boundary conditions of the ambient air in the simulation. Four different flow speeds (i.e. $0.1 \mathrm{~m} / \mathrm{s}, 0.05 \mathrm{~m} / \mathrm{s}, 0.025 \mathrm{~m} / \mathrm{s}, 0.01 \mathrm{~m} / \mathrm{s}$ ) of the ambient air are simulated and compared to each other. The predicted velocity components and temperature show minor difference at various elevations. As a result, the ambient air shows minor influence on the spray combustion characteristics and the steady laminar flamelet combustion model can be applied.

\subsection{Results and discussion}

Due to the limitation of the experiment, it is not feasible to tune to the exact co-flow and spray conditions for the comparative study. As a result, in this study a typical spray trajectory with the design inner diameter shown in tab.1 is used for all cases. In order to investigate the influence of the co-flow temperature and the $\mathrm{O}_{2}$ concentration on the combustion characteristics separately, all other parameters are kept the same except the parameter being studied. 


\subsubsection{Influence of co-flow temperature}

In this section, the volume fraction of oxygen in the co-flow is kept constant at $21 \%$ and the velocity of the co-flow is kept at $3.5 \mathrm{~m} / \mathrm{s}$. The predicted temperature contours of the ethanol spray flames under $300 \mathrm{~K}, 900 \mathrm{~K}$ and $1500 \mathrm{~K}$ co-flow conditions are presented in Fig.9.

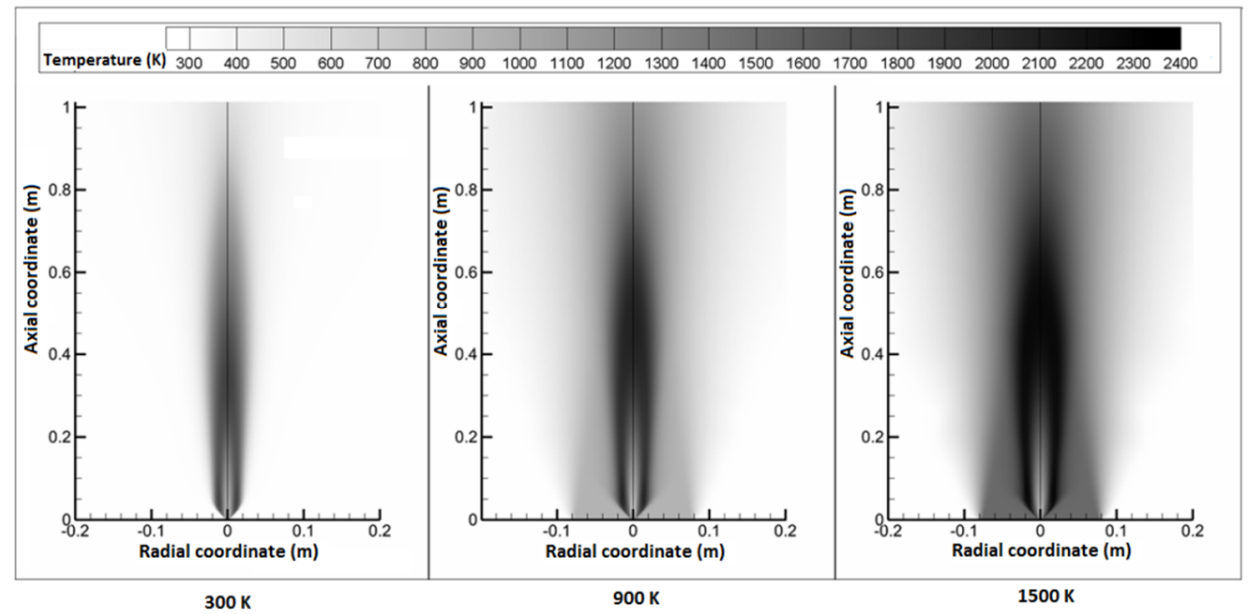

Fig.9 Temperature contours of ethanol spray flames with different co-flow temperatures at constant velocity $3.5 \mathrm{~m} / \mathrm{s}$ and at constant $\mathrm{O}_{2} \% \mathrm{vol} 21 \%$ )

In all these conditions, an inner low temperature zone in the flame is observed. With the increase of co-flow temperature from $300 \mathrm{~K}$ to $1500 \mathrm{~K}$, the peak temperature rises from $1809 \mathrm{~K}$ to $2267 \mathrm{~K}$. The volume of peak temperature zone increases and it extends downstream. In consequence, the high temperature of co-flow does not lead to a HiTAC condition, but increases the peak temperature and thus the thermal $\mathrm{NO}_{\mathrm{x}}$ formation. In many other HiTAC applications, a high temperature of combustion air can result in a more uniform temperature distribution and a lower peak temperature. That is due to the increased velocity of combustion air under high temperature conditions. The high velocity leads to a larger amount of entrainment of flue gas, and thus created a low $\mathrm{O}_{2}$ concentration "co-flow", leading to a HiTAC-like condition. By increasing the velocity of the fuel, which can enhance the entrainment of flue gas as well, the HiTAC condition is also achievable for gaseous fuel [23]. 


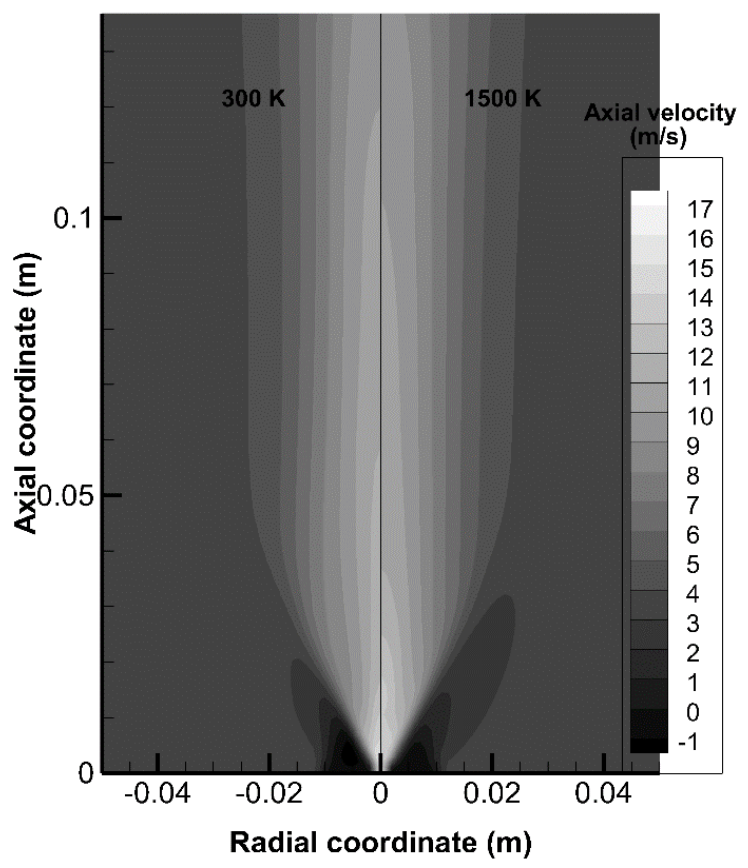

Fig. 10 Axial velocity contours under $300 \mathrm{~K}$ and $1500 \mathrm{~K}$ co-flow conditions $(\mathrm{m} / \mathrm{s})$

Fig. 10 shows the axial velocity contours under $300 \mathrm{~K}$ and $1500 \mathrm{~K}$ co-flow conditions. A higher local velocity of co-flow near the fuel injection is found under $1500 \mathrm{~K}$ co-flow condition. This is attributed to increased fuel evaporation rate of the droplets under high co-flow temperatures. The fuel evaporation rate changes can be validated by the droplet number density and SMD distribution below.

Fig. 11 shows the droplet distribution at various elevations under $300 \mathrm{~K}, 900 \mathrm{~K}$ and $1500 \mathrm{~K}$ co-flow conditions. Below the height of $\mathrm{z}=20 \mathrm{~mm}$, the droplet concentration is alike for all investigated conditions. Further downstream, it can be noticed that the droplets evaporate faster under high temperature co-flow conditions. In $300 \mathrm{~K}$ co-flow case some droplets still exist at the height of $z=400 \mathrm{~mm}$ and at large radii, while very few droplets can be found already at $\mathrm{z}=100 \mathrm{~mm}$ under $900 \mathrm{~K}$ and $1500 \mathrm{~K}$ cases, and no droplet found at radial locations larger than $0.06 \mathrm{~m}$. This is confirmed by the experiment, where it has been observed that some droplets escape from the flame under cold co-flow conditions, while this is not seen under hot co-flow conditions. 


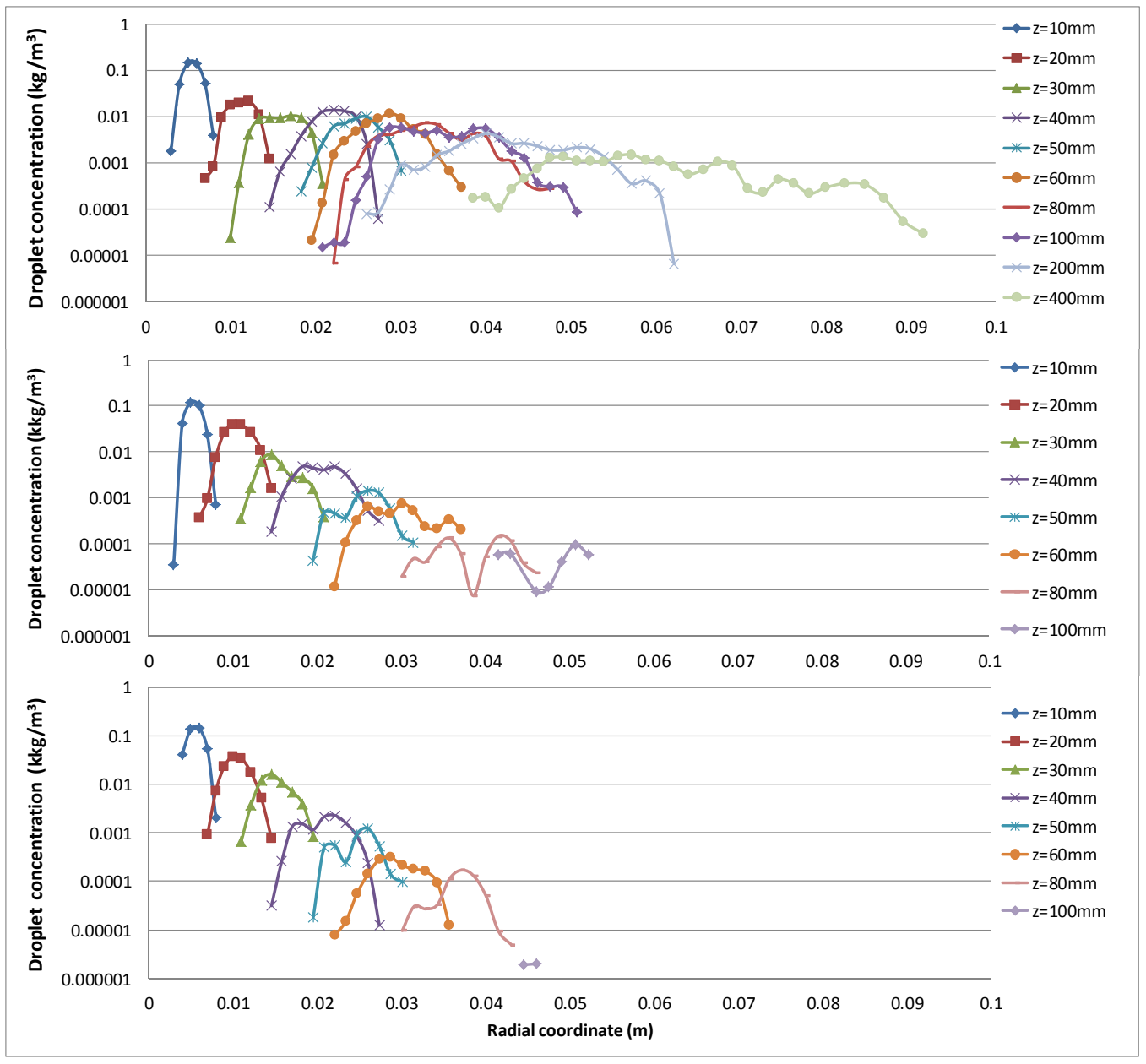

Fig.11 Droplet concentration at various elevations under different co-flow temperatures (from top: co-flow temperature: $300 \mathrm{~K}, 900 \mathrm{~K}, 1500 \mathrm{~K}$; velocity: $3.5 \mathrm{~m} / \mathrm{s} ; \mathrm{O}_{2} \% \mathrm{vol}: 21 \%$ ) 


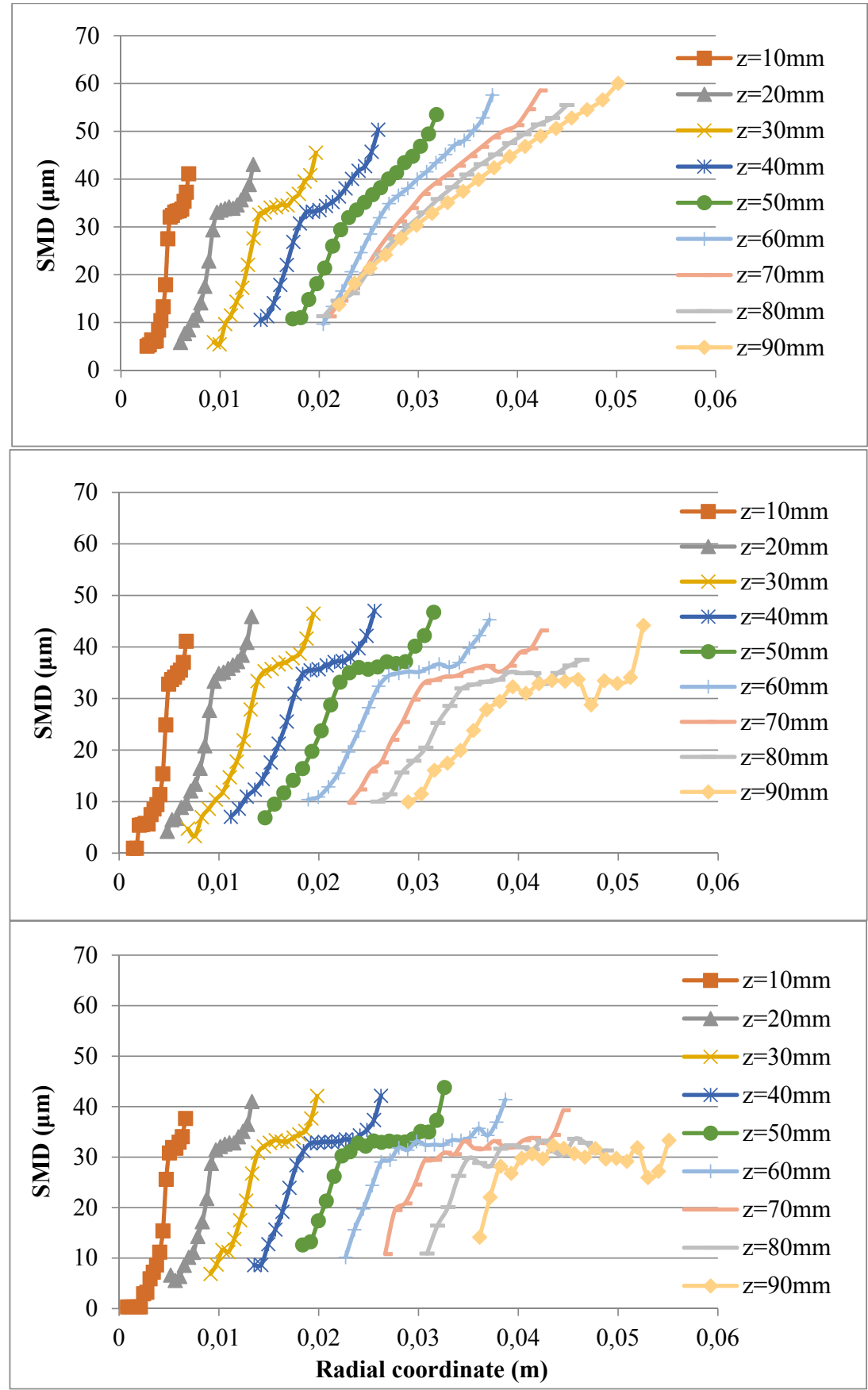

Fig.12 SMD at various elevations under different co-flow temperatures

(from top: co-flow temperature: $300 \mathrm{~K}, 900 \mathrm{~K}, 1500 \mathrm{~K}$; co-flow velocity: $3.5 \mathrm{~m} / \mathrm{s}$; $\mathrm{O}_{2} \% \mathrm{vol}: 21 \%$ ) 
The simulation results show that the droplets present at large radii have the possibility to escape under low temperature co-flow conditions. Under $900 \mathrm{~K}$ and $1500 \mathrm{~K}$ co-flow conditions, the droplets reach the boiling temperature very fast due to the presence of hot co-flow at radii larger than $0.02 \mathrm{~m}$. The evaporation rate is then mainly dependent on the liquid-vapor equilibrium around the droplets. As a result, at radii smaller than $0.03 \mathrm{~m}$, the droplet concentration under $900 \mathrm{~K}$ and $1500 \mathrm{~K}$ is similar, whereas at larger radii, the droplets evaporate and disappear faster with the presence of $1500 \mathrm{~K}$ co-flow.

The SMD trend at downstream elevations is shown in Fig.12. The peak in SMD values increases at higher downstream elevations for the $300 \mathrm{~K}$ co-flow conditions. This effect is caused by rapid evaporation of small droplets. However, for the high temperature co-flow, at each high elevation (radii above $0.02 \mathrm{~m}$ from where co-flow affects effectively) both large and small droplets decrease their size quickly and simultaneously, especially at locations of low droplet number density. This results with the vanishing of small droplets inside the spray cone and large droplets outside of the cone at each high elevations. Compared to the $900 \mathrm{~K}$ case, the droplets at high elevations (e.g. $z=90 \mathrm{~mm}$ ) evaporate faster in $1500 \mathrm{~K}$ co-flow, and the SMD values in the middle of the profile, where a relatively large droplet number density exists, decrease from about $34 \mu \mathrm{m}$ to about 30 $\mu \mathrm{m}$. The profiles for both 900 and $1500 \mathrm{~K}$ are a bit wrinkled since a much lower amount of droplets exist at high elevations (see Fig.11) and thus the captured samples can cause noticeable fluctuations.

Once the evaporated fuel meets the co-flow, a combustion process occurs. The $\mathrm{O}_{2}$ concentration contours under $300 \mathrm{~K}$ and $1500 \mathrm{~K}$ co-flow conditions are presented in Fig. 13 . A high temperature of co-flow accelerates the combustion process, whereas the low density of co-flow has a positive effect on enlarging the combustion zone. As a result, although the peak temperature increases adequately to the co-flow temperature, the temperature difference between the peak temperature and the co-flow temperature decreases. The increment of peak temperature from the case with $300 \mathrm{~K}$ co-flow to $1500 \mathrm{~K}$, is only $458 \mathrm{~K}$ (from $1809 \mathrm{~K}$ to $2267 \mathrm{~K}$ ), much less than the increase of absolute co-flow temperature, i.e. $1200 \mathrm{~K}$ (from $300 \mathrm{~K}$ to $1500 \mathrm{~K}$ ). 


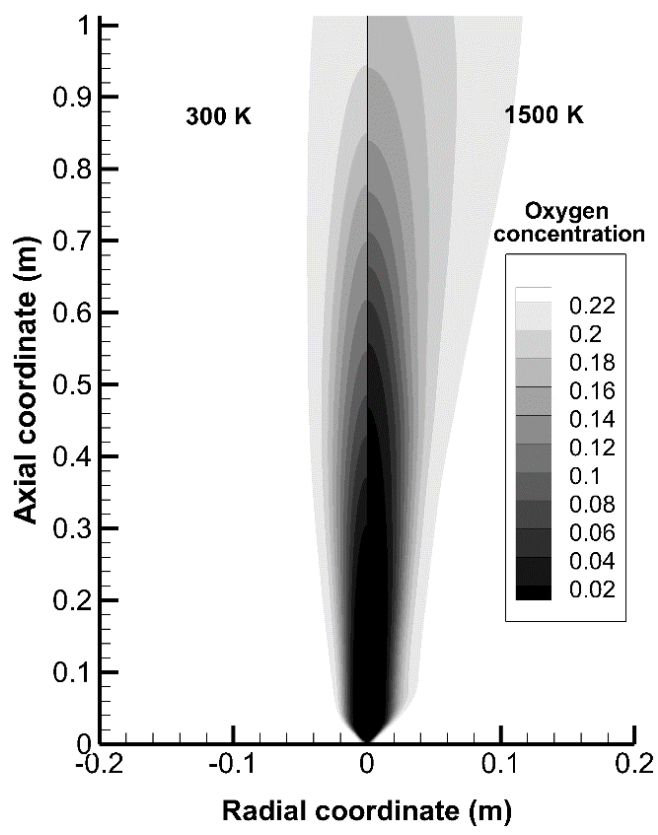

Fig. $13 \mathrm{O}_{2}$ concentration contours under $300 \mathrm{~K}$ and $1500 \mathrm{~K}$ co-flow conditions (mass fraction) (co-flow velocity: $3.5 \mathrm{~m} / \mathrm{s} ; \mathrm{O}_{2} \%$ vol: $21 \%$ )

\subsubsection{Influence of $\mathrm{O}_{2}$ concentration in the co-flow}

In the present study, the applied co-flow conditions resemble properties of combustion air mixed with flue gas, i.e. high temperature and low oxygen concentration. The simulation results discussed in the previous section, indicate that although the decreased density of co-flow (due to a higher temperature) enlarges the flame zone, the increased enthalpy input still results in a higher peak temperature in the flame and thus leads to more thermal $\mathrm{NO}_{\mathrm{x}}$ formation. Additionally, a higher co-flow temperature also accelerates the evaporation of droplets along the spray trajectories, which has negative effect on the "delay" of combustion process and creating HiTAC-like conditions. Since various studies of HiTAC on gaseous fuel show that the combination of an increased temperature and a lowered $\mathrm{O}_{2}$ concentration, which is created by entraining flue gas with combustion air/fuel, leads to HiTAC condition, we further investigate the effect of $\mathrm{O}_{2}$ concentration in the co-flow on spray combustion in this section. 


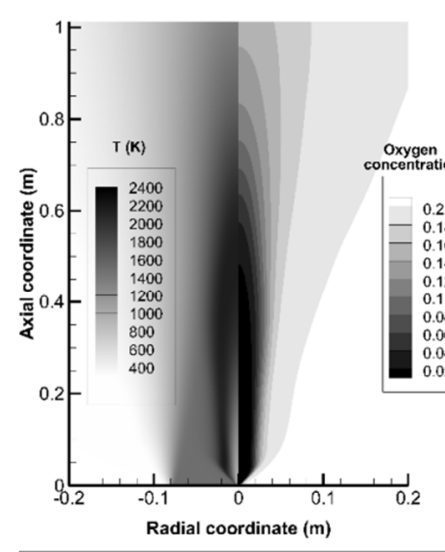

$18 \%$ vol O2

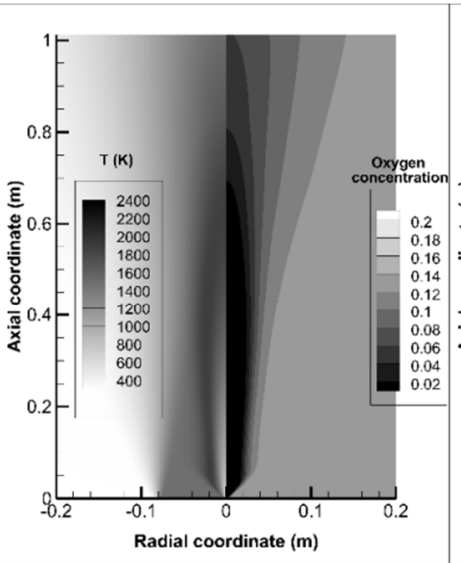

$12 \% \mathrm{vol} \mathrm{O}_{2}$

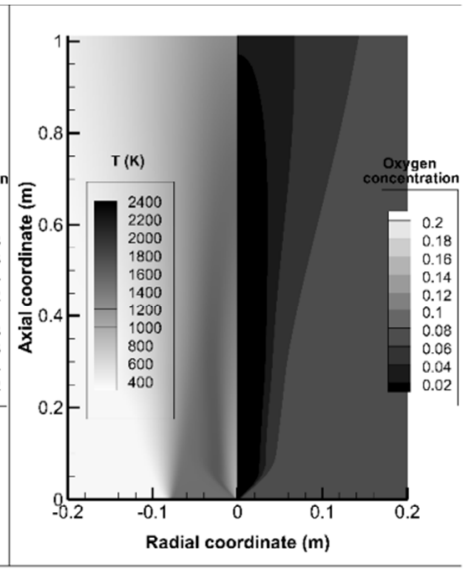

$6 \% \mathrm{vol} \mathrm{O}_{2}$

Fig. 14 Temperature $(\mathrm{K})$ and $\mathrm{O}_{2}$ concentration (mass fraction) contours with different co-flow $\mathrm{O}_{2}$ concentration (left to right: co-flow $\mathrm{O}_{2} \%$ vol: $18 \% ; 12 \% ; 6 \%$; velocity: $3.5 \mathrm{~m} / \mathrm{s}$; T: $1500 \mathrm{~K}$ )

Fig. 14 shows the predicted average temperature and $\mathrm{O}_{2}$ concentration contours of the ethanol spray flames under $18 \%, 12 \%$ and $6 \%$ volume fraction of $\mathrm{O}_{2}$ co-flow conditions. The co-flow temperature is kept at $1500 \mathrm{~K}$ and the co-flow velocity remains $3.5 \mathrm{~m} / \mathrm{s}$. The peak temperature decreases from $2175 \mathrm{~K}$ to $1705 \mathrm{~K}$ and $1689 \mathrm{~K}$ with reduction of $\mathrm{O}_{2}$ concentration from $18 \%$ to $12 \%$, and to $6 \%$ in the co-flow, respectively. An enlargement of combustion zone is also found. Compared to the co-flow temperature, $1500 \mathrm{~K}$, the temperature difference in the flame has been reduced from $675 \mathrm{~K}$ to $205 \mathrm{~K}$, and to $189 \mathrm{~K}$. 

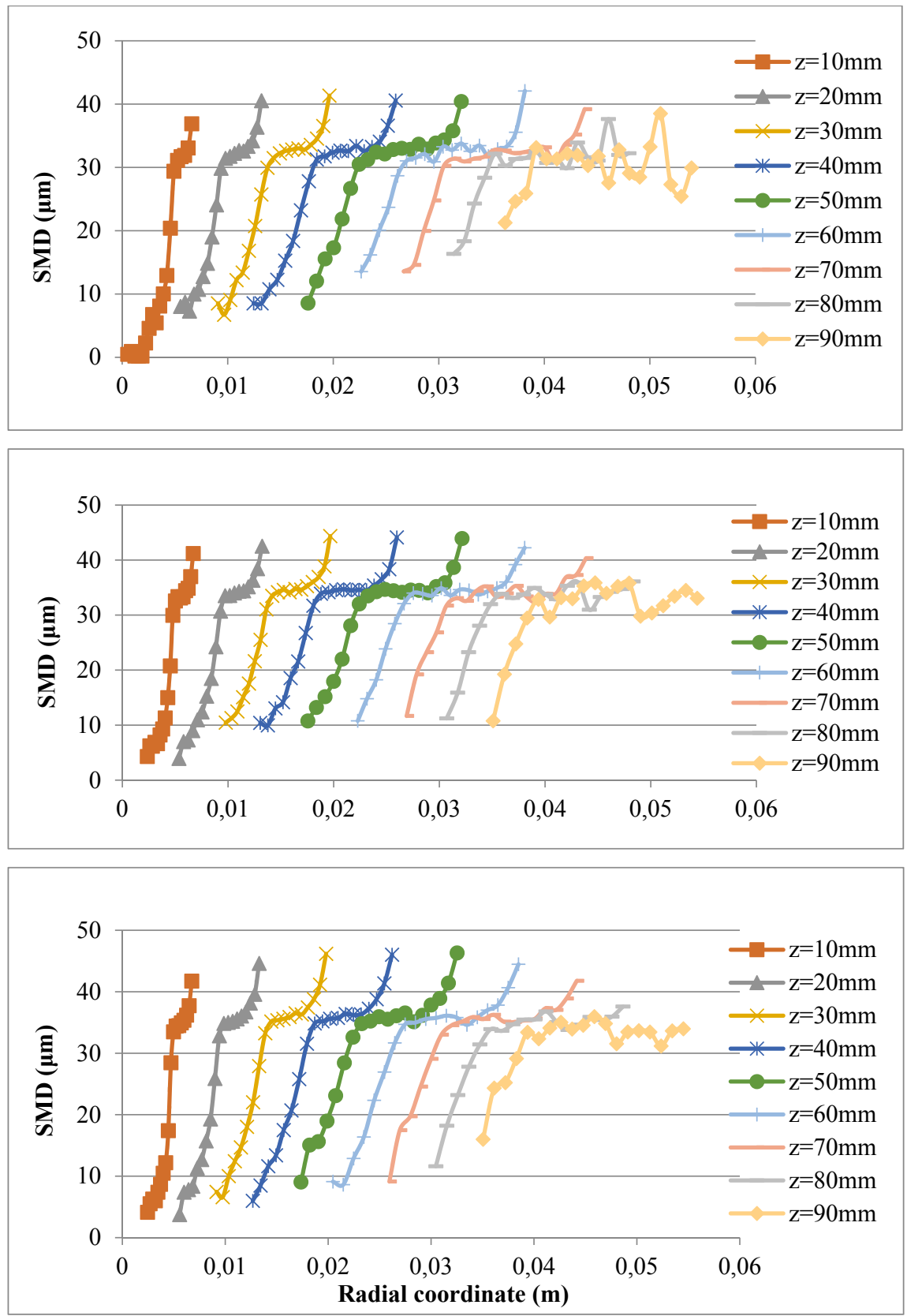

Fig.15 SMD of droplets at various elevations under different co-flow $\mathrm{O}_{2}$ concentration (from top: co-flow $\mathrm{O}_{2} \%$ vol: $18 \% ; 12 \% ; 6 \%$; velocity: $3.5 \mathrm{~m} / \mathrm{s} ; \mathrm{T}$ : $1500 \mathrm{~K}$ ) 


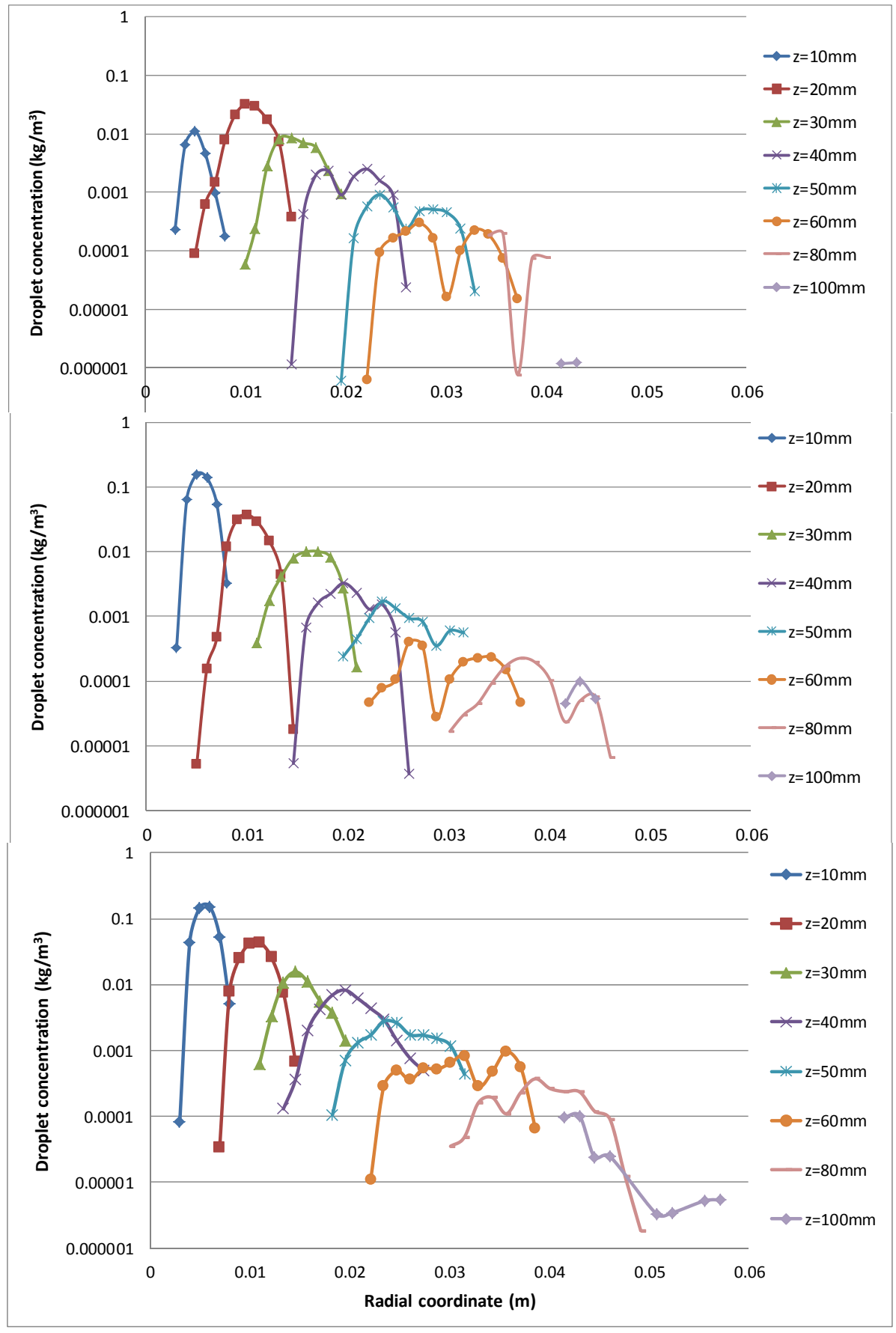

Fig.16 Droplet concentration at various elevations under different co-flow $\mathrm{O}_{2}$ concentration (from top: co-flow $\mathrm{O}_{2} \%$ vol: $18 \% ; 12 \% ; 6 \%$; velocity: $3.5 \mathrm{~m} / \mathrm{s} ; \mathrm{T}$ : $1500 \mathrm{~K}$ ) 
SMD of the drops and their concentration profiles at different elevations under various co-flow $\mathrm{O}_{2}$ concentrations $(18 \%, 12 \%$ and 6\%) are presented in Fig. 15 and Fig. 16, respectively. According to Fig.15, with the decreasing of $\mathrm{O}_{2}$ concentration in the co-flow, the SMD profile at $\mathrm{z}=90 \mathrm{~mm}$ is less wrinkled. As we discussed before, the wrinkled profile is mainly due to the low droplet concentration. Thus more droplets still exist at that elevation with a lower $\mathrm{O}_{2}$ concentration co-flow. This is also visible from Fig.16. Besides, SMD values at location of high droplet concentration for cases with $1500 \mathrm{~K}$ and $21 \%$ vol $\mathrm{O}_{2}$ concentration are generally lower than those comparable data for cases of $1500 \mathrm{~K}$ and low $\mathrm{O}_{2}$ content. This indicates that the evaporation process has been reduced for the low $\mathrm{O}_{2}$ concentration co-flow. This is confirmed further by the droplet concentration distribution shown in Fig.16. At elevations $\mathrm{z}=10 \mathrm{~mm}$ and $20 \mathrm{~mm}$ in Fig.16, the droplet concentration is similar for various $\mathrm{O}_{2}$ co-flow conditions. From $\mathrm{z}=30 \mathrm{~mm}$, it is clear that more droplets survives in a lower $\mathrm{O}_{2}$ concentration co-flow. As a result, when the evaporated fuel mixes with the co-flow containing a lower $\mathrm{O}_{2}$ concentration $(18 \%$, $12 \%$ and $6 \%$ co-flow $\mathrm{O}_{2} \% \mathrm{vol}$ ), it leads to a lower peak temperature in the flame and a reduced consumption of fuel. This combined with a lowered temperature in return slows down the evaporation process of droplets. Thus the volume of combustion zone increases creating a HiTAC-like condition. Based on previous observation, i.e. that a high temperature co-flow leads to a high peak temperature in the flame, we concluded that in the combination of a high temperature and a low $\mathrm{O}_{2}$ concentration in the co-flow, which can lead to HiTAC- like conditions, reducing the $\mathrm{O}_{2}$ concentration is the dominant factor for decreasing the peak temperature in the flame. However, the combustion process is continuously consuming $\mathrm{O}_{2}$. If no sufficient $\mathrm{O}_{2}$ in the low $\mathrm{O}_{2}$ co-flow can be provided for the combustion process, some other process like secondary cracking can occur and soot formation can be increased as well. For gaseous fuels, velocity components or locations of fuel injection can be tuned in a relatively simple way to mix fuel with low $\mathrm{O}_{2}$ concentration co-flow (mixture of combustion air and flue gas). Spray flames have a fuelrich zone along or confined by the spray, which makes the mixing more difficult to be optimized towards HiTAC conditions. The optimization needs to be carried out based on the analysis of a specific fuel in order to create a HiTAC-like condition.

Fig. 17 shows the peak temperatures in the cases with different $\mathrm{O}_{2}$ concentration at various co-flow temperature conditions. Each point represents one test case. The 64 
condition with a temperature of $300 \mathrm{~K}$ and $6 \% \mathrm{vol} \mathrm{O}_{2}$ in the co-flow is beyond the lean flammability limit. Under constant co-flow temperature regime, the peak temperature is reduced when the $\mathrm{O}_{2}$ concentration in the co-flow decreases. Besides, the temperature difference between the peak and co-flow temperature drops with the reduced $\mathrm{O}_{2}$ concentration in the co-flow.

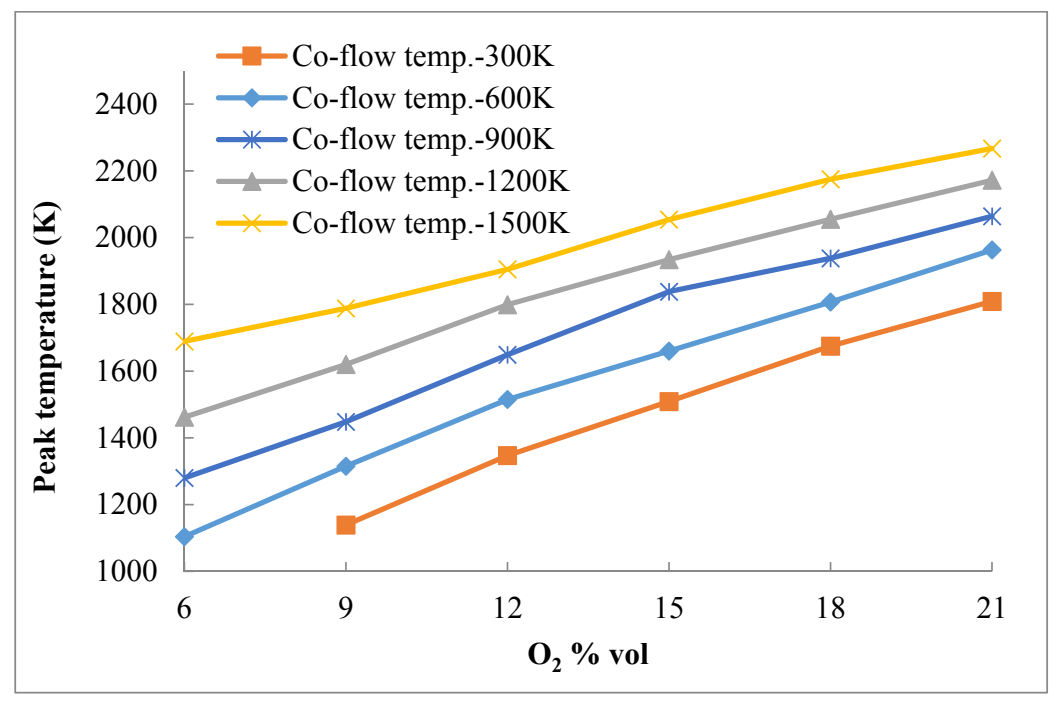

Fig.17 Peak temperatures in various co-flow conditions

For the same co-flow $\mathrm{O}_{2}$ concentration, the peak temperature increases with an increase of co-flow temperature, however, the temperature difference between the peak and co-flow temperatures decreases. As a result, among the investigated cases, the one with $6 \%$ vol $\mathrm{O}_{2}$ concentration and $1500 \mathrm{~K}$ co-flow condition has the most uniform temperature distribution. 


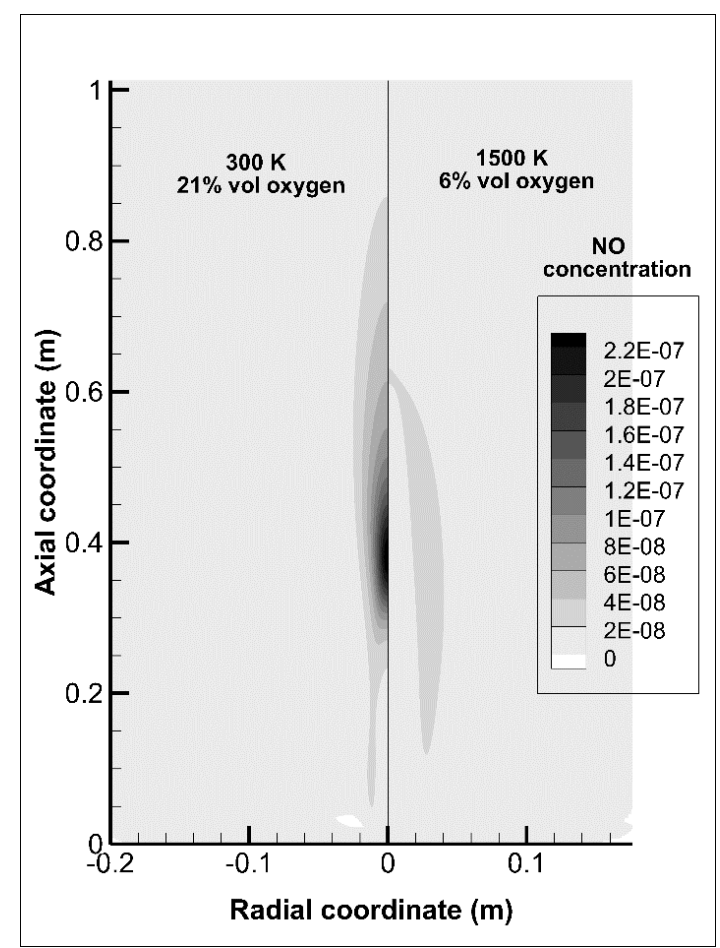

Fig.18 NO mass fraction contours under conventional and HiTAC conditions

NO average mass fraction contours for conventional $\left(300 \mathrm{~K}, 21 \%\right.$ vol $\mathrm{O}_{2}$ concentration) and $\mathrm{HiTAC}\left(1500 \mathrm{~K}, 6 \% \mathrm{vol} \mathrm{O}_{2}\right.$ concentration) flames are shown in Fig. 18. The former has a peak temperature of $1809 \mathrm{~K}$ and the latter of $1689 \mathrm{~K}$ according to the simulation results. The NO formation occurs mainly in the region with peak temperature, therefore it is suppressed under HiTAC regime. Considering the extra enthalpy input from the $1500 \mathrm{~K}$ co-flow, the NO formation is reduced considerably, since the peak temperature in the regular spray flame under co-flow temperature equal to that of the HiTAC, i.e. $1500 \mathrm{~K}$ and $21 \% \mathrm{vol} \mathrm{O}_{2}$ concentration is $2267 \mathrm{~K}$.

The peak temperature under various co-flow conditions is related to the flame volume. The flame volume can be explained with support of oxidation mixture ratio [24] in form of Equation (18):

$$
R_{O}=\frac{m_{O}}{m_{O}+\sum_{c} S_{c} m_{F, c}}
$$


where $S=n_{O} M_{O} / n_{F} M_{F}$ with $m$ the mass fraction, $\mathrm{n}$ the stoichiometric ratio, $\mathrm{M}$ the molar mass, and index $\mathrm{O}, \mathrm{F}, \mathrm{C}$ representing oxygen, fuel and flue gas respectively. Following [24] we assume that $R_{O}=0.99$ is representative for the external boundary of the flame and $R_{O}=0.01$ is representative for the internal boundary.

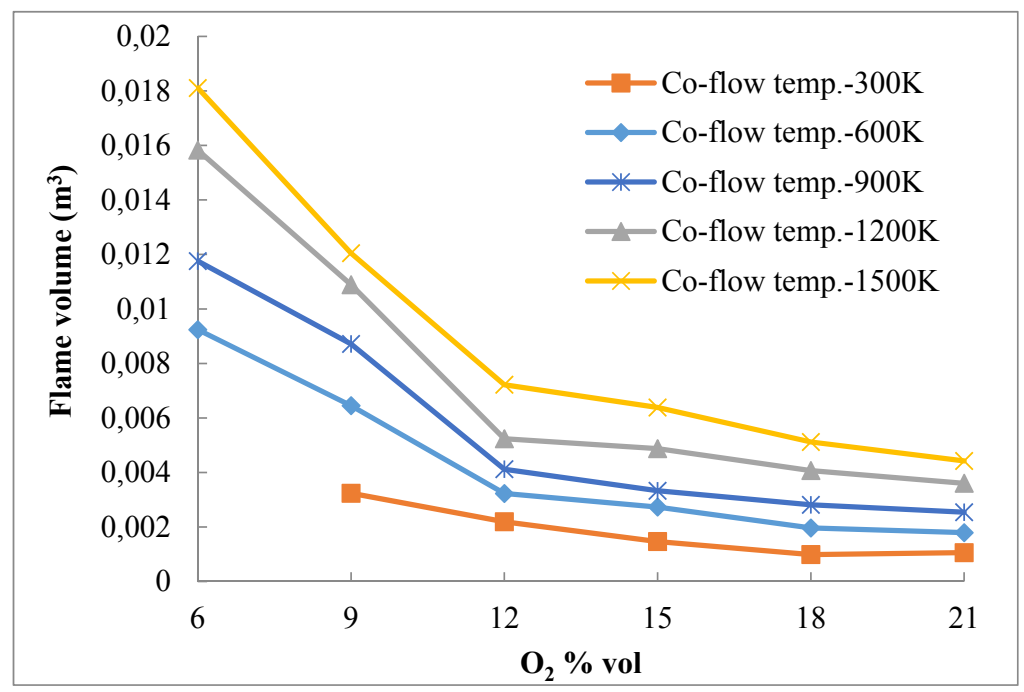

Fig.19 Calculated flame volumes under various co-flow conditions

Fig.19 shows the calculated flame volumes under various co-flow conditions. It is noted that the flame extinguishes under $300 \mathrm{~K}, 6 \% \mathrm{vol} \mathrm{O}_{2}$ condition in the simulation and thus no result is available. With the same co-flow temperature, when the $\mathrm{O}_{2}$ concentration decreases in the co-flow, the ethanol spray flame volume is enlarged (see Fig.20), especially in case when the $\mathrm{O}_{2}$ concentration is lower than $12 \%$ vol. Since for the same co-flow temperature, the heat dissipated by the flame with a bigger volume (co-flow with reduced $\mathrm{O}_{2}$ concentration) is absorbed via a larger combustion zone, the peak temperature in the flame decreases. 


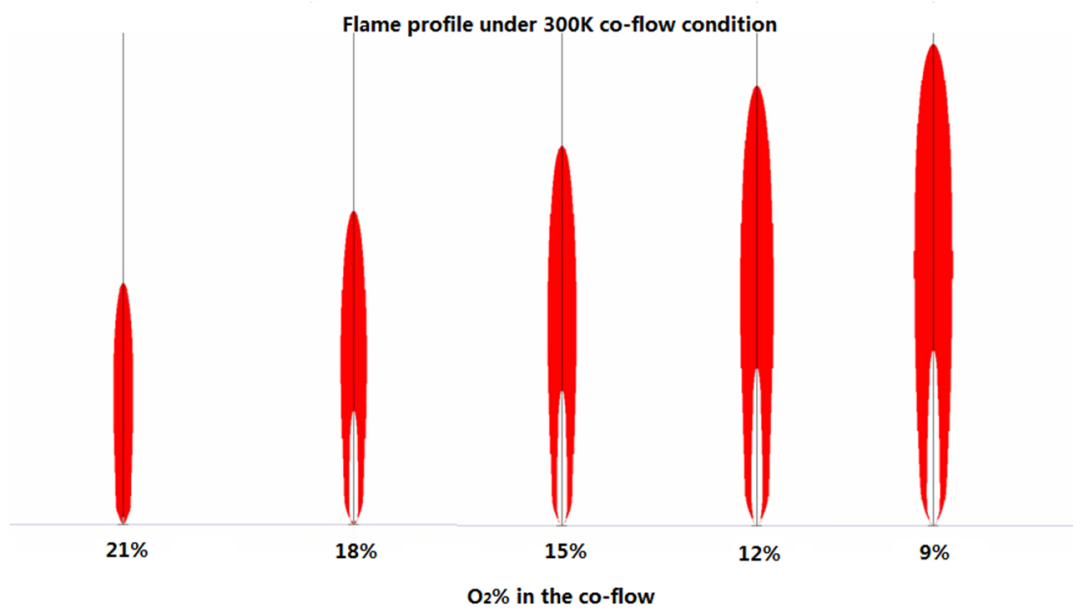

Fig.20 Flame profile under 300K co-flow condition

With respect to constant $\mathrm{O}_{2}$ concentration in the co-flow, the change in the flame volume caused by a high temperature co-flow is not sufficient to cover the local enthalpy increase in the system and thus the peak temperature is enhanced. For the co-flow with $6 \% \mathrm{vol}$ and $9 \% \mathrm{vol} \mathrm{O}_{2}$ concentrations, when the co-flow temperature increases, the flame volume is enlarged much more than in other $\mathrm{O}_{2}$ concentration conditions. Since the coflow velocity is the same for all investigated cases, the increment of enthalpy input due to co-flow with a higher temperature in all $\mathrm{O}_{2}$ concentration conditions is almost the same. As a result, the ethanol spray flames in the co-flow with $6 \%$ vol and $9 \%$ vol $\mathrm{O}_{2}$ concentrations have greater potentials than other cases to reach HiTAC conditions. The HiTAC is related to the uniformity of the temperature distribution mainly, and also to the ignition temperature and adiabatic temperature for a specific fuel. Since the $1500 \mathrm{~K}$ and $6 \% \mathrm{vol} \mathrm{O}_{2}$ concentration case has a peak temperature of $1689 \mathrm{~K}$, with only a difference of $189 \mathrm{~K}$ from the co-flow temperature, and shows a "flameless" feature in the experiment, it is then considered to be the HiTAC condition.

\subsection{Conclusions}

We presented results of the numerical investigation of ethanol spray combustion under various co-flow conditions. The different temperature and $\mathrm{O}_{2}$ concentration content 
in the co-flow were applied to mimic the mixing conditions of combustion air and flue gas. Their influence on the spray combustion was numerically studied in order to achieve HiTAC-like conditions with uniform temperature distributions and correspondingly low NOx emissions. Up to now only little was known about flameless spray combustion due to the complexity of all involved processes and the limitations of experiments.

The present study was based on the analysis of the Delft Spray-in-Hot-Coflow (DSHC) experimental set-up and the operating conditions. The experiment was carried out in open space due to the optical measurement. Thus our defined computational domain contains the air flow of ambient air. However, the ambient air showed minor influence on the flame zone, which indicates the combustion characteristics is dependent mainly on the co-flow properties.

In the study we employed the standard k- $\varepsilon$ turbulence model with the enhanced wall treatment, the Linearized Instability Sheet Atomization (LISA) model for spray, weighted-sum-of-gray-gases model (WSGGM) for radiation, and the steady laminar flamelet model for combustion. These models have been validated by our previous investigation on the NIST flame using methanol under conventional conditions and a preliminary study of ethanol spray flames in hot co-flow $[2,3]$. In the simulation, we extended the limited co-flow conditions of experiment to a series of combinations of temperatures $(300 \mathrm{~K}, 600 \mathrm{~K}, 900 \mathrm{~K}, 1200 \mathrm{~K}$ and $1500 \mathrm{~K})$ and $\mathrm{O}_{2}$ concentrations $(21 \%, 18 \%$, $15 \%, 12 \%, 9 \%$ and $6 \% \mathrm{vol})$.

The simulation results showed that although the increased temperature leads to a lowered density of co-flow which then enlarges the flame zone, the increased enthalpy input still results in a high peak temperature in the flame and thus leads to more thermal $\mathrm{NO}_{\mathrm{x}}$ formation. Moreover, a high co-flow temperature also accelerates the evaporation of droplets along the spray trajectories, which has negative effect on the "delay" of combustion process and creation of HiTAC-like conditions. However, due to the enlarged flame zone, the temperature difference between the peak temperature and the co-flow temperature decreases with the increased co-flow temperature.

In some HiTAC applications with gaseous fuels, a high temperature of combustion air can result in a more uniform temperature distribution and a lower peak temperature. 
This is due to the increased velocity of combustion air under high temperature conditions, with which more flue gas is entrained and it creates a lower $\mathrm{O}_{2}$ concentration "co-flow", leading to a HiTAC-like condition. According to previous research [23], increasing the velocity of the gas fuel can create the same situations and thus supports achieving the HiTAC conditions. However, if a larger amount of entrainment does not contain a relatively low $\mathrm{O}_{2}$ concentration, it may strengthen the combustion process rather than reducing the peak temperature and thermal $\mathrm{NO}_{\mathrm{X}}$ formation.

For ethanol spray flames, a lower $\mathrm{O}_{2}$ concentration leads to a lower peak temperature in the flame and reduced consumption rate of fuel. Both in return slow down the evaporation process of droplets. Thus the combustion zone volume increases creating a HiTAC-like condition.

The calculated flame volumes in various co-flow conditions were compared and discussed. The ethanol spray flames in the co-flow with $6 \%$ vol and $9 \%$ vol $\mathrm{O}_{2}$ concentrations resembles the HiTAC flames mainly due to the considerable enlargement of combustion zone (the enthalpy input from high temperature co-flow remains similarly). Since the $1500 \mathrm{~K}$ and $6 \% \mathrm{vol} \mathrm{O}_{2}$ concentration case has a peak temperature of $1689 \mathrm{~K}$, with only a difference of $189 \mathrm{~K}$ from the co-flow temperature, and shows a "flameless" feature in the experiment, it is then considered as a HiTAC condition.

For heavy fuel oils, the mixing process is more difficult to be optimized towards HiTAC conditions than light fuel oils. On one hand, the peak temperature can be reduced in a low $\mathrm{O}_{2}$ concentration co-flow condition in spray flames; on the other hand, the even lower $\mathrm{O}_{2}$ concentration condition created after combustion may lead to problems of secondary cracking, soot formation and flame extinction. The optimization needs to be carried out based on the analysis of a specific fuel in order to create a HiTAC-like condition. 


\section{References}

[1] P. Jenny, D. Roekaerts, and N. Beishuizen, Modeling of turbulent dilute spray combustion, Prog. Energy Comb. Sci. 38 (2012): 846-887.

[2] S.Zhu, D.J.E.M.Roekaerts, A.Pozarlik, T.H.van der Meer, Eulerian-Lagrangian RANS model simulations of the NIST turbulent methanol spray flame, Combustion Science and Technology 187(7):1110-1138.

[3] L. Ma, S. Zhu, H. Rodrigues, M. Tummers, T. van der Meer, D. Roekaerts, Numerical investigation of ethanol spray-in hot-coflow flame using steady flamelet model, In: Proceedings of the 8th Mediterranean Combustion Symposium, Turkey (2013).

[4] L.Ma , B. Naud, D. Roekaerts, Transported PDF modeling of ethanol spray in hot-diluted coflow flame. Flow, Turbulence and Combustion, 96(2) (2016): 469-502.

[5] L. Ma, D. Roekaerts, Modeling of spray jet flame under MILD condition with non-adiabatic FGM and a new conditional droplet injection model, Combustion and Flame, 165 (2016): 402-423.

[6] H. Correia Rodrigues, M.J. Tummers, E.H. van Veen, D.J.E.M. Roekaerts, Effects of coflow temperature and composition on ethanol spray flames in hot-diluted coflow, Int. J. Heat Fluid Flow, 51 (2015): 309-323.

[7] H. Correia Rodrigues, M. J. Tummers, E. H. van Veen, D. J.E.M. Roekaerts, Spray flame structure in conventional and hot-diluted combustion regime, Combustion and Flame, 162 (2015): 759-773.

[8] E.Gutheil, Issues in computational studies of turbulent spray combustion, experiments and numerical simulations of diluted spray turbulent combustion, Merci, B., Roekaerts, D. and Sadiki, A. (Eds.), Springer, 2011, 1-39.

[9] D. P. Schmidt, I. Nouar, P. K. Senecal, et al, Pressure-swirl atomization in the near field. SAE Paper 01-0496, SAE, 1999.

[10] H. Tsuji, A. Gupta , T. Hasegawa, et al., High temperature air combustion: from energy conservation to pollution reduction, CRC Press, Boca Raton, 2002.

[11] Marinov, N. M., Kinetic model for high temperature ethanol oxidation, Int. J. Chem. Kinet. 32 (1998): 183-220.

[12] C. M. Muller, H. Breitbach, and N. Peters, Partially premixed turbulent flame propagation in jet flames, Technical report, 25th Symposium (Int) on Combustion, The Combustion Institute, 1994. 
[13] B. Binniger, M. Chan, G. Paczkko, and M. Herrmann, Numerical simulation of turbulent partially premixed hydrogen flames with the flamelet model, Technical report, Advanced Combustion Gmbh, Internal Report, 1998.

[14] P. Glarborg, J. E.Johnsson, and K. Dam-Johansen, Kinetics of homogeneous nitrous oxide decomposition. Combustion and Flame. 99 (1994): 523-532.

[15] R.S.Barlow, G.J.Fiechtner, C.D.carter, and J.Y.Chen, Experiments on the scalar structure of turbulent $\mathrm{CO} / \mathrm{H}_{2} / \mathrm{N}_{2}$ jet flames. Combustion and Flame. 120 (2000): 549-569.

[16] D.Tabacco, C.Innarella, and C.Bruno, Theoretical and numerical investigation on flameless combustion. Combustion Science and Technology. 2002.

[17] Barrie Jenkins, Peter Mullinger, Industrial and process furnaces: principles, design and operation. 2014.

[18] J. B. Zeldovich, The oxidation of nitrogen in combustion and explosion, Acta Physicochimica, vol. 21 (1946): 577-628.

[19] C. T. Bowman, D. J. Seery, Emissions from continuous combustion systems, Plenum Press: New York, 1972.

[20] J. Warnatz, NOx Formation in high temperature processes, University of Stuttgart: Germany, 2001.

[21] D. L. Baulch, C. J. Cobos, R. A. Cox, et al., Evaluated kinetic data for combustion modelling, Journal of Physical and Chemical Reference Data, Vol. 21 (1992): 411-734.

[22] C. K. Westbrook and F. L. Dryer, Chemical kinetic modelling of hydrocarbon combustion, Progress in Energy and Combustion Science, Vol. 10 (1) (1984): 1-57.

[23] S. Zhu, L. Chen, T. Zhu, J. Wu, Effect of length-width ratio of the rectangular air-jet on NOx emission in HiTAC, Industrial Furnace, Vol.27(6) (2005): 4-8.

[24] W. Yang, W. Blasiak, Numerical study of fuel temperature influence on single gas jet combustion in highly preheated and oxygen deficient air, Energy, Vol.30 (2005): 385-398. 


\section{CHAPTER 4.}

\section{VALIDATION AND DISCUSSION OF SPRAY COMBUSTION UNDER VARIOUS CO-FLOW CONDITIONS*}

In this chapter the results of selected numerical simulations are discussed and compared with experimental data for similar flow conditions. The effect of boundary conditions and spray parameters is discussed with relation to other literature findings. It has been shown that the presented numerical model performs well and it is an effective and reliable tool for parameters research towards HiTAC conditions.

\footnotetext{
${ }^{*}$ Content in this chapter has been partially included in a paper submitted to journal Fuel.
} 


\subsection{Introduction}

With the DSHC setup, the co-flow temperature and oxygen dilution cannot be varied independently [1]. As a result, the temperature, velocity of gas and liquid, gas components in the co-flow and their distribution vary depending on the investigated test case. Furthermore, due to the performance of atomizer under different co-flow temperature conditions, the mass flow of ethanol can be different from the designed one. This can be verified by the increased/ decreased pressure of ethanol leading to a lower/ higher mass flow rate of ethanol in [2].

In chapter 2 it has been discussed that both the boundary condition and spray trajectory analysis are essential for validation of spray flames. Thus the validation of the DSHC ethanol spray flame requires both a well-defined boundary condition of co-flow and a detailed analysis of spray trajectory.

Since the focus of the current study is on spray combustion towards HiTAC conditions, we compare here two typical operation conditions of DSHC test rig, i.e. cold co-flow condition $\left(300 \mathrm{~K}, 21 \% \mathrm{vol} \mathrm{O}_{2}\right)$ and hot co-flow condition $\left(1500 \mathrm{~K}, 6 \% \mathrm{vol} \mathrm{O}_{2}\right)$, to the experimental data with the similar co-flow. They represent spray flames under conventional condition and towards-HiTAC condition, respectively.

Furthermore, validation with models and methods described by L. Ma, et.al $[3,4,5]$ is introduced and discussed, in order to understanding the spray flames.

\subsection{Validation with models in the previous chapter}

Among the cases with various co-flow conditions presented in the previous chapter, only several are feasible to be carried out in the experiment. The co-flow in the experiment is generated by the secondary burner located in the middle of the setup. The $\mathrm{O}_{2}$ concentration and the temperature of the co-flow are dependent on the inlet conditions of this burner. As a result, two typical spray flames (hot co-flow and cold co-flow) shown in the previous chapter are compared to experimental results. The former represents a HiTAC-like combustion regime whereas the latter is a conventional spray flame. 
The $300 \mathrm{~K}$ and $21 \%$ vol $\mathrm{O}_{2}$ case is used for the cold co-flow condition, whereas the $1500 \mathrm{~K}, 6 \%$ vol $\mathrm{O}_{2}$ is applied as the hot co-flow condition. In both, the co-flow velocity and the mass flow rate of ethanol are kept the same. In the experiment however, it is not possible to maintain the co-flow velocity the same as in simulations and neither match exactly the mass flow of ethanol due to the limitation of the mass flow control and influence of high temperature on the atomizer. Besides, as discussed in our previous study [6], the trajectories of the spray need to be analyzed from the experiment in order to obtain agreement of SMD distribution between the experiment and simulation. As a result, the validation in the present study focuses mainly on the flame profile, and the range and trend of SMD at various elevations as discussed below.

Fig.1 shows the experimental flames (LHS) and temperature contours of corresponding numerical solutions (RHS). The conventional flame is luminous and shows a low frequent turbulence, while the flame in hot co-flow turns into bluish and is very stable. Except for the low frequent turbulence feature of the case with cold co-flow, which cannot be shown by the average temperature field in the present study, both of the two cases present high similarities between the simulation and the experiment. In hot co-flow, the flame becomes "flameless" and shows the features of the HiTAC condition. Even though the input enthalpy of the hot co-flow is much higher than that of the cold co-flow, the predicted peak temperature is about $100 \mathrm{~K}$ lower than in the cold co-flow $(1790 \mathrm{~K})$. This can be attributed to the enlarged flame zone produced by the flame with low $\mathrm{O}_{2}$ concentration co-flow, which results in a more uniform temperature distribution. Since the $\mathrm{NO}_{\mathrm{x}}$ formation is mainly dependent on the peak temperature zone, the lower peak temperature in hot co-flow leads to a remarkably reduced $\mathrm{NO}_{\mathrm{x}}$ emission as shown in the previous chapter. 


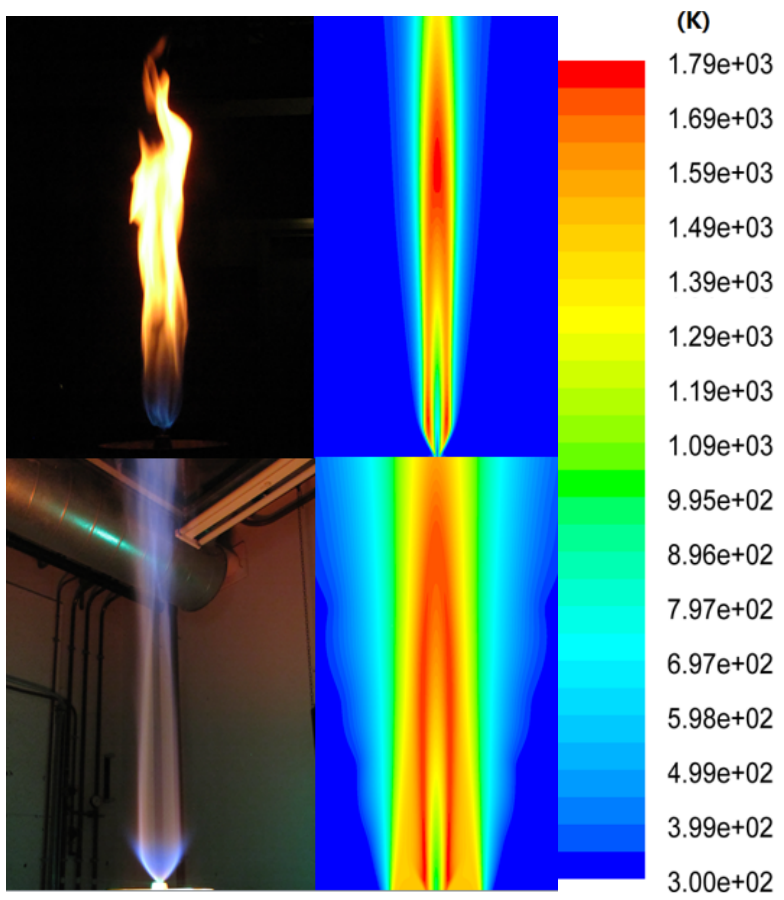

Fig.1 Experimental (left) and numerical (right) results from ethanol combustion in cold co-flow (top) and hot co-flow (bottom)

Besides, it is observed that the conventional ethanol spray flame is a diffusion flame, and its main body is attached to the spray by a triple flame composed of a rich premixed flame where the droplets are vaporizing and two lean premixed flames on both sides of the jet, as reported by Ruetsch et al. in [7].

The ethanol spray flame in hot co-flow exhibits strong conical shape. The relatively large cone observed in the experiment, compared to the conventional flame, is shown also in the simulation.

Fig. 2 shows the predicted SMD of the drops at different elevations for the conventional flame, together with the experimentally measured SMD under similar conditions. In the numerical simulation, the SMD ranges from $5 \mu \mathrm{m}$ to $40 \mu \mathrm{m}$ at height $\mathrm{z}=10 \mathrm{~mm}$, and gradually changes to the range from $10 \mu \mathrm{m}$ to $50 \mu \mathrm{m}$ at height $\mathrm{z}=40 \mathrm{~mm}$. The measured data show a range from $12 \mu \mathrm{m}$ to $38 \mu \mathrm{m}$ at height $\mathrm{z}=10 \mathrm{~mm}$, and it changes to a range from $18 \mu \mathrm{m}$ to $52 \mu \mathrm{m}$ at height $\mathrm{z}=40 \mathrm{~mm}$. The predicted SMD matches the experimental data in the region of high droplet density, which is approximately in the 
middle of the range at each elevation. The trend of the SMD at each elevation also shows similarity between the simulation and the experiment. However, the range of radial locations of the SMD in the simulation is narrower than those in the experiment. This is attributed to two reasons. Firstly, as what we observed in the experiment, even at higher elevations, some small droplets still exist in the near center area, while few droplets are found in this region in the simulation. Both the low co-flow velocity of $0.29 \mathrm{~m} / \mathrm{s}$ in the experiment, and the spray model in the simulation can be the causes of the difference. Secondly, we used an injector exit diameter of $0.21 \mathrm{~mm}$ (see Table 1 in the previous chapter) in the simulation according to the nozzle design. As we discussed in chapter 2, this parameter is often larger than the design value and it requires further analysis in a specific case. With an adjusted injector exit diameter, the predicted SMD is supposed to spread in a wider range of radial position and match better with the measured data.

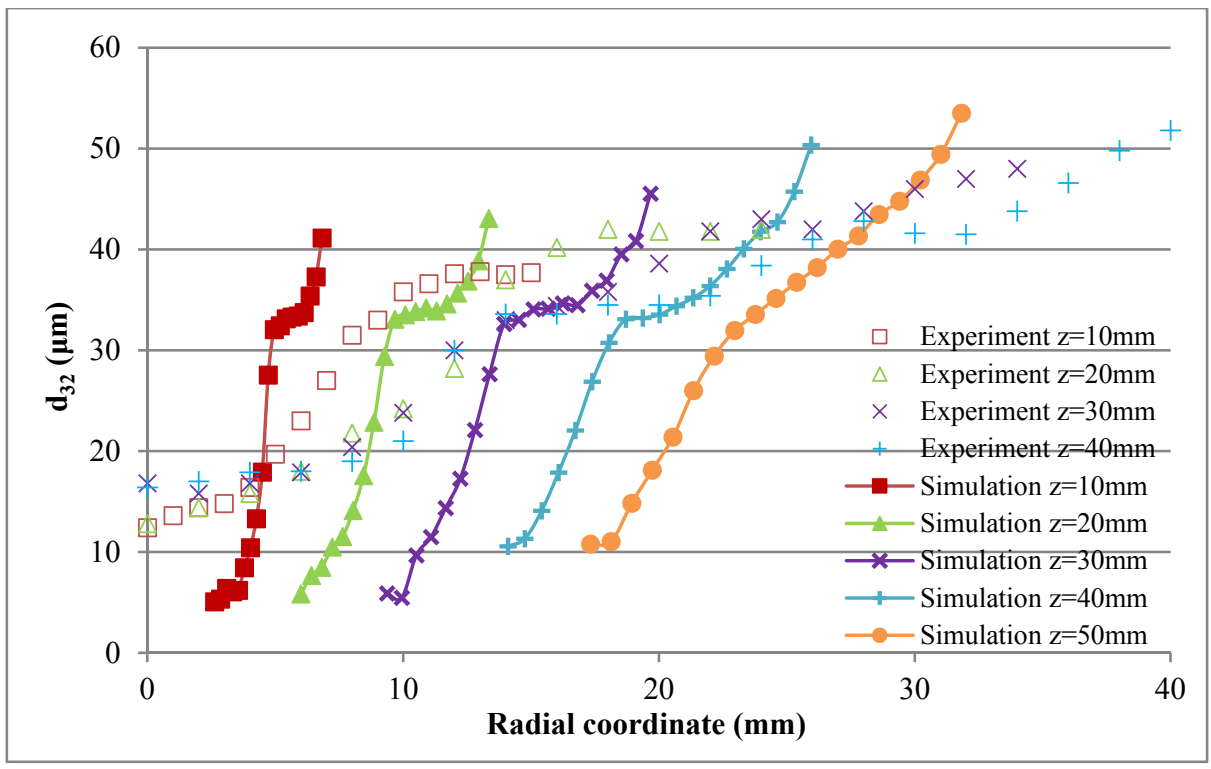

Fig.2 Predicted SMD at various elevations in the case with $21 \% \mathrm{O}_{2}$ and $300 \mathrm{~K}$ co-flow condition (ethanol mass flow rate: $0.47 \mathrm{~g} / \mathrm{s}$ (experiment); $0.383 \mathrm{~g} / \mathrm{s}$ (simulation), inlet co-flow velocity: $0.29 \mathrm{~m} / \mathrm{s}$ (experiment); $3.5 \mathrm{~m} / \mathrm{s}$ (simulation), injector exit diameter of $0.21 \mathrm{~mm}$ and a full spray angle of $60^{\circ}$ ) 
The predicted and measured SMD of the droplets in hot co-flow conditions at various elevations are shown in Fig.3. At height $\mathrm{z}=10 \mathrm{~mm}$, the SMD range and distribution is almost the same as for the conventional flame (i.e. with $21 \% \mathrm{O}_{2}$ and $300 \mathrm{~K}$ co-flow conditions). However, in the experiment the small droplets we observed in the conventional flame at higher elevations do not exist in the near-center-line area, but at larger radial locations. This makes the match of simulation results and experimental data of SMD distribution better than the conventional flame. Differently from the conventional conditions, the peak values of SMD at high elevations in hot co-flow do not increase gradually, but they are keeping the same value of approx. $40 \mu \mathrm{m}$. Both simulation and experiment show the same phenomena.

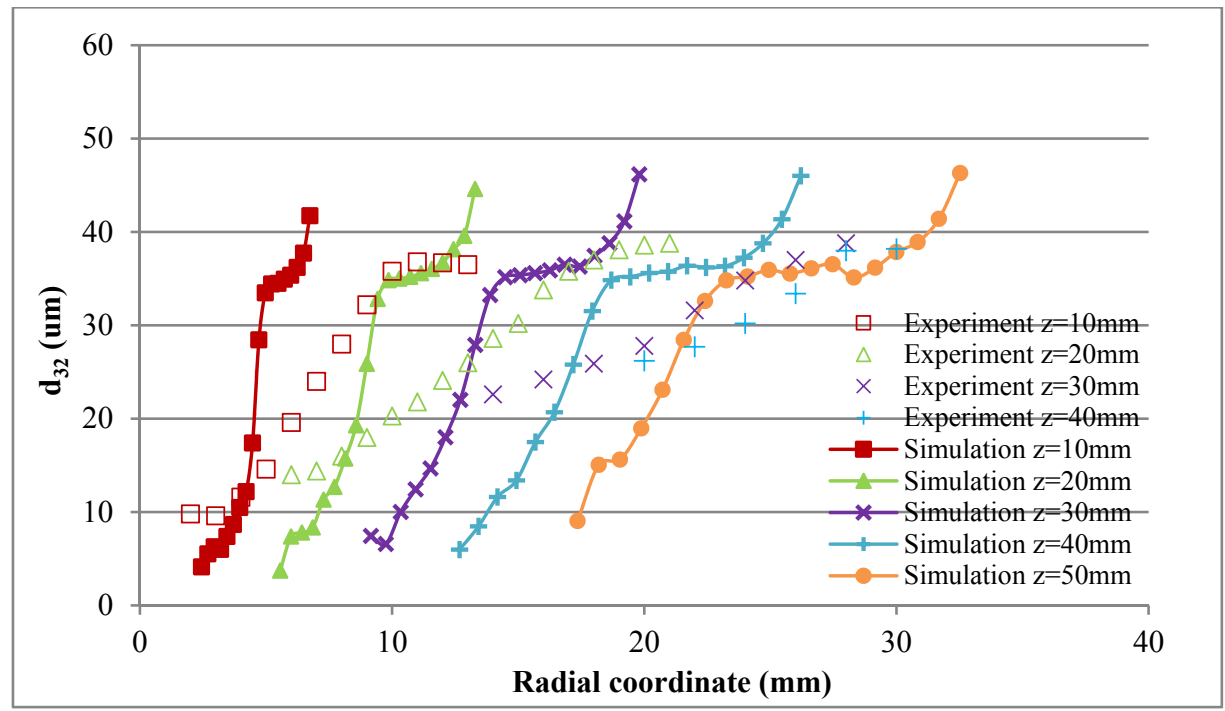

Fig.3 Predicted SMD at various elevations in the case of hot co-flow condition (ethanol mass flow rate: $0.38 \mathrm{~g} / \mathrm{s}$ (experiment); $0.383 \mathrm{~g} / \mathrm{s}$ (simulation), co-flow temperature: $1480 \mathrm{~K}$ (experiment); 1500K (simulation), co-flow velocity: $3.25 \mathrm{~m} / \mathrm{s}$ (experiment); $3.5 \mathrm{~m} / \mathrm{s}$ (simulation), $\mathrm{O}_{2}$ vol\% in co-flow: $6.5 \%$ (experiment); $6 \%$ (simulation), injector exit diameter of $0.21 \mathrm{~mm}$ and a full spray angle of $60^{\circ}$ )

In the experiment, the data were measured at elevation $\mathrm{z}=10 \mathrm{~mm}, 20 \mathrm{~mm}, 30 \mathrm{~mm}$ and $35 \mathrm{~mm}$. At higher elevations the droplet number density drops and thus it is more 
difficult to measure accurately the SMD distribution. However, the less "steep" trend at a higher elevation in hot co-flow conditions shown in the experiment is predicted by the simulation with results at further elevations $\mathrm{z}=40 \mathrm{~mm}$ and $50 \mathrm{~mm}$.

It is also shown that in the simulation some droplets located at the outskirts of the spray, which represent small droplets and large droplets, can be predicted as well. In the experiment these droplets are almost invisible. This behavior can be explained due to the Phase Doppler Anemometry (PDA) measurement, as discussed in chapter 1.

Based on the obtained results it can be concluded that there is a good match between experimental data and numerical simulation using the methods and models introduced in previous chapters.

\subsection{Validation from other researchers and discussion}

The LISA model and steady laminar flamelet model were also used and discussed for the validation of the case shown in Tab.1 and 2 by Ma et al. [3].

The spray trajectory was analyzed as shown in Fig.4 with an injector exit diameter of $0.9 \mathrm{~mm}$.

Table 1. Coflow temperature and composition (mole fraction) in [3]

\begin{tabular}{|c|c|}
\hline Temperature (K) & 1316.5 \\
\hline $\mathrm{O}_{2}$ & $8.70 \%$ \\
\hline $\mathrm{CO}_{2}$ & $5.55 \%$ \\
\hline $\mathrm{H}_{2} \mathrm{O}$ & $10.95 \%$ \\
\hline $\mathrm{N}_{2}$ & $74.8 \%$ \\
\hline
\end{tabular}

Table 2. Spray inlet conditions in [3]

\begin{tabular}{|c|c|}
\hline Fuel temperature (K) & 301.15 \\
\hline Fuel flow rate $(\mathrm{kg} / \mathrm{h})$ & 1.46 \\
\hline Injection pressure (bar) & 7 \\
\hline Spray angle & $70^{\circ}$ \\
\hline
\end{tabular}




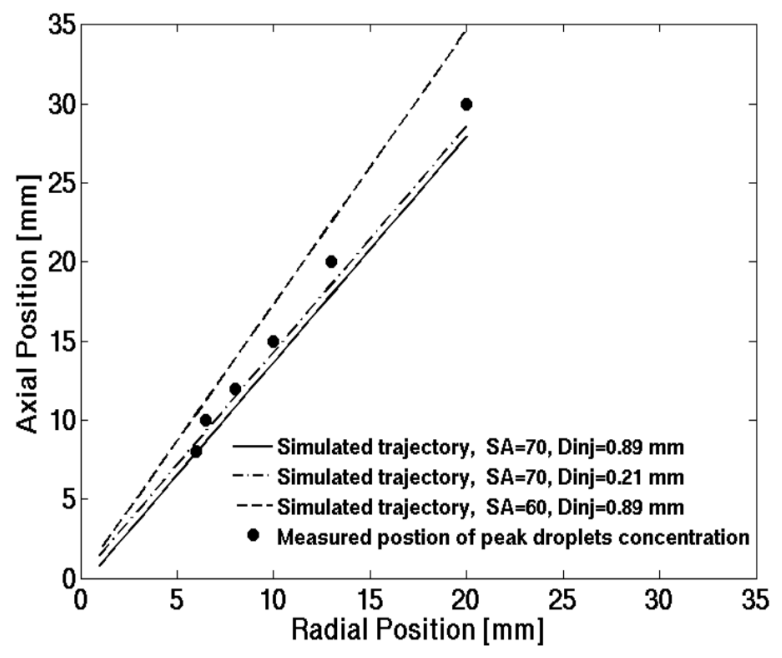

Fig.4 Estimation of the spray trajectory in [3]

The range of droplet size and the trend of SMD distribution show good agreement with the experimental data at various axial positions, as shown in Fig.6. However, the radial distribution of droplets was considered not well predicted. It was also found that $\mathrm{OH}$ concentration near the injector was high which led to an early ignition in the simulation [3].

To the understanding of the author of the present study, the discrepancies can be attributed to several reasons. Firstly, as discussed in chapter 2, the estimation of spray trajectory is based on the assumption that the peak droplet concentration occurs along the main spray trajectory. As a result, the more accurate the radial position of the peak droplet number density is, the more precise the estimation of main spray trajectory can be performed. Especially for the elevations at which gaseous flow has little effect on droplets. However, in the DSHC flames, the measurement starts from elevation $\mathrm{z}=8 \mathrm{~mm}$, and then are continued at elevations $\mathrm{z}=10 \mathrm{~mm}$ and $12 \mathrm{~mm}$, where the droplets have already interactions with the co-flow, especially under hot co-flow conditions much earlier. This leads to the difficulty of an accurate estimation of spray trajectory.

Secondly, although the commercial atomizers as used in the experiment are quite robust, the guaranteed atomization is in general based on a suggested range of pressure and temperature. Besides, the injector exit diameter per manufacturing data is quite small 
$(0.21 \mathrm{~mm})$. With a temperature difference of more than $1000 \mathrm{~K}$ in the co-flow, the thermal expansion of the atomizer tip may have a non-negligible effect on atomization. Moreover, for the often used metals of atomizers, brass and stainless steel, their melting temperatures are around $1300 \mathrm{~K}$ and around $1700 \mathrm{~K}$, respectively [8]. The long term operation under high temperature co-flow conditions can damage the atomizer tip easily, i.e. during a short period of no atomized ethanol to cool it down.

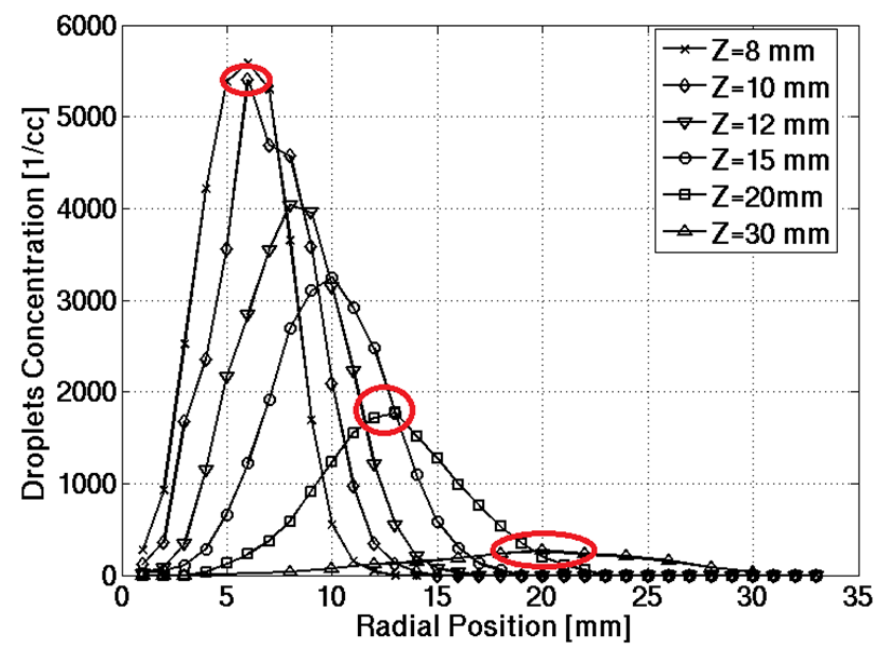

Fig.5 Droplet concentration in [3] (circles in color marked by the author of the present study)

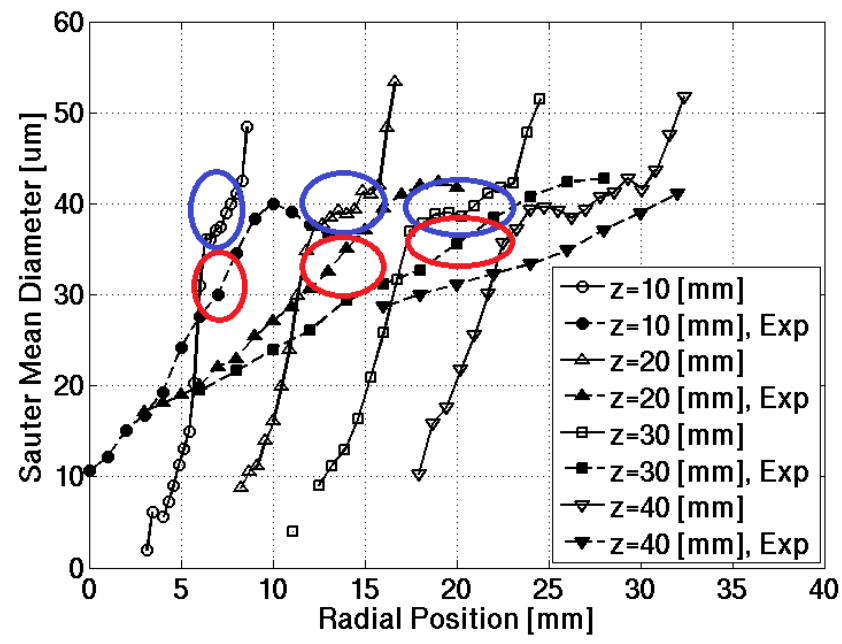

Fig.6 Droplet SMD in [3] (circles in color marked by the author of the present study) 
For the test case presented by Ma et al. [3], the droplet concentration is given in Fig.8. The estimation of spray trajectory shown in Fig.4 was carried out based on Fig.5. Fig.6 shows the comparison of droplet SMD between experimental data and simulation results. The regions with measured peak droplet concentration marked in red circles in Fig.5 are also marked in Fig.6, and in blue circles are the corresponding predicted peak droplet concentrations.

If the estimation in Fig. 4 is correct (this will be discussed later), then the red circles in Fig.6 means either the droplet distribution at height $\mathrm{z}=10 \mathrm{~mm}$ has already been influenced by hot co-flow, or the droplet distribution coming from the used atomizer is different from a presented Rosin-Rammler distribution. If the former is the case, lower elevations of measurement are required for a better estimation of the spray trajectory. If the latter is the case, more analysis of droplet distribution is required in order to take into account the considerable amount of big droplets outside the main spray trajectory. This analysis for the latter condition has been carried out by Ma et.al [5], with a "conditional droplet injection model". With this model, large droplets were injected within a small range of angle around the main spray trajectory while small droplets were injected in a much wider range. However, as discussed in chapter 2, this not only requires the availability of a large amount of measured data, but also analysis by trial and error since the measurement could only capture a portion of droplets in the experiment. As an alternative solution can be a combination of multiple spray trajectories still using the LISA model. As discussed in chapter 2, the key point of the modeling spray is to resemble the injected droplets' conditions before they start interacting with gaseous flow. Any model that can achieve this goal is then a good model in simulation, no matter whether the boundary condition of the spray starts from elevation $z=0 \mathrm{~mm}$ or $\mathrm{z}=8 \mathrm{~mm}$ from the atomizer tip as shown in $[3,4,5]$. 


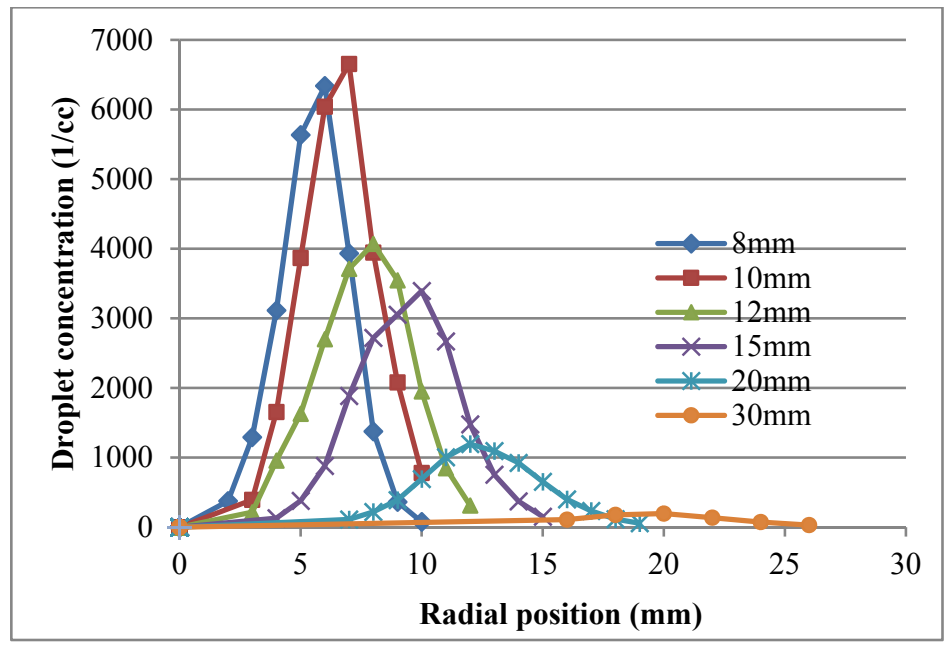

Fig.7 Droplet concentration in DSHC case SHCii [9]

(co-flow velocity: $3.25 \mathrm{~m} / \mathrm{s} ; \mathrm{O}_{2} \% \mathrm{vol}: 6.5 \%$ )

(Ethanol mass flow rate under upstream pressure of $15.2 \mathrm{bar}: 1.51 \mathrm{~kg} / \mathrm{hr}$ )

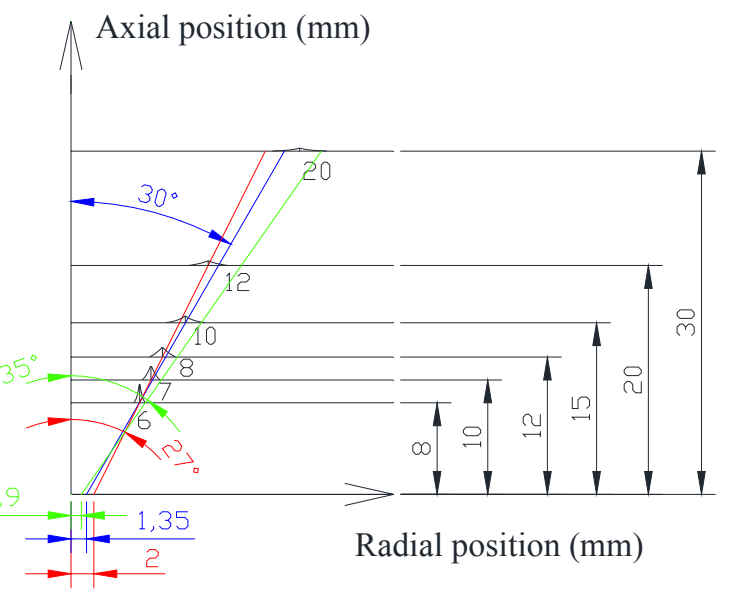

In black: radial positions with peak number density of droplets;

In blue: estimated spray trajectory with a half spray angle of 30 degrees; In red: estimated spray trajectory with a half spray angle of 27 degrees; In green: spray trajectory with a half spray angle of 35 degrees.

Fig.8 Estimation of the spray trajectory of DSHC case SHCii 


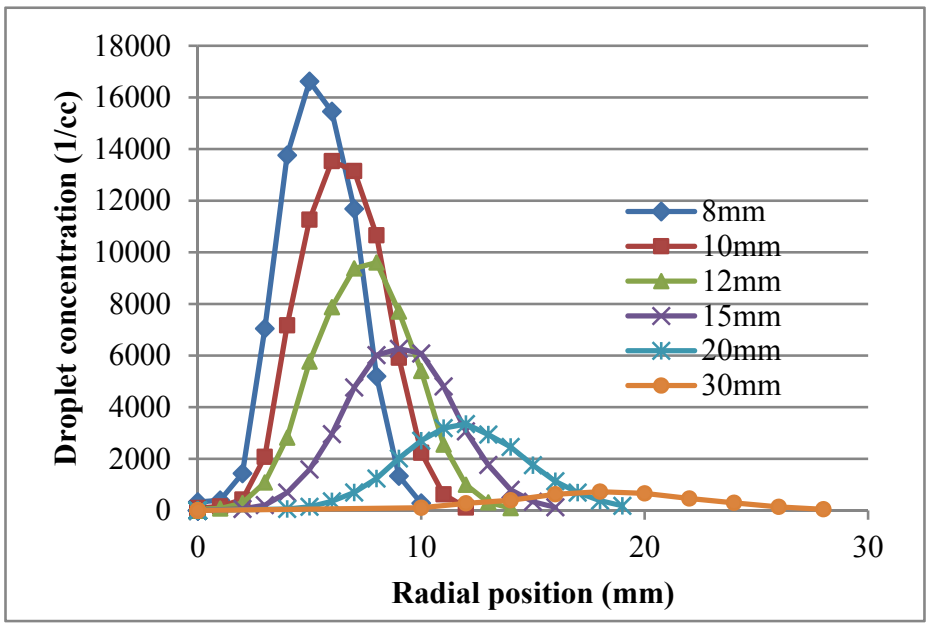

Fig.9 Droplet concentration in DSHC case SHCiv [9]

(co-flow velocity: $2.25 \mathrm{~m} / \mathrm{s} ; \mathrm{O}_{2} \% \mathrm{vol}: 8.7 \%$ )

(Ethanol mass flow rate under upstream pressure of 14.7 bar: $1.62 \mathrm{~kg} / \mathrm{hr}$ )

Axial position (mm)

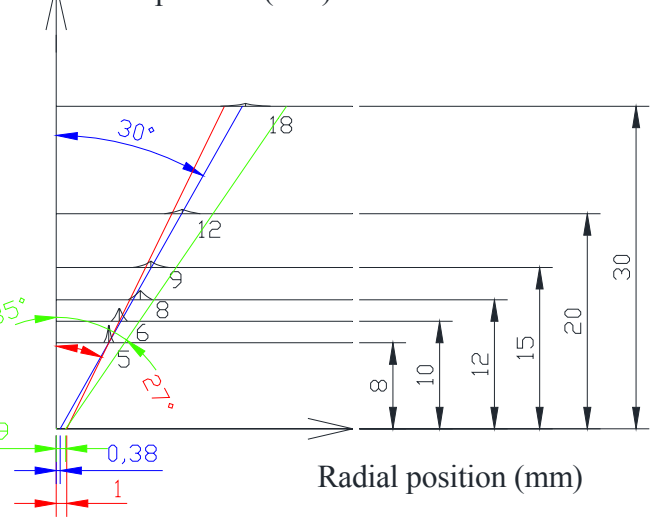

In black: radial positions with peak number density of droplets;

In blue: estimated spray trajectory with a half spray angle of 30 degrees;

In red: estimated spray trajectory with a half spray angle of 27 degree;

In green: spray trajectory with a half spray angle of 35 degrees.

Fig.10 Estimation of the spray trajectory of DSHC case SHCiv

With regard to the accuracy of the estimation of spray trajectory in [3], Fig.7 and Fig.9 show two other droplet concentration measurements from DSHC flames with the 
same pressure-swirl atomizer. In Fig.8 and Fig.10 the spray trajectories are analyzed, respectively.

In the above two cases, the $\mathrm{O}_{2}$ concentration in the co-flow has been changed from $6.5 \%$ to $8.7 \%$, while the upstream pressures for atomization vary slightly from 15.2 bar to 14.7 bar. Since in the experiment co-flow temperature changes with $\mathrm{O}_{2}$ concentration, in case SHCii and SHCiv they are above $1480 \mathrm{~K}$ and $1300 \mathrm{~K}$, respectively [2].

As discussed in chapter 2, for the estimation of spray trajectories the measured data at low elevations should be used since droplets at those elevations have been interacted less with surrounding co-flow than at high elevations, especially under high temperature co-flow conditions. In Fig. 8 and Fig. 10 the estimated spray trajectories in red matches the first two elevations of measured data better than the blue lines with a design spray angle of $60^{\circ}$. However, the injector exit diameter differs from $2 \mathrm{~mm}$ to $4 \mathrm{~mm}$ in these two cases. This will affect the calculation of droplet velocity and film thickness according to the equation introduced in chapter 2. Moreover, none of the spray trajectories is close to the one obtained in study of Ma et al. [3] with a spray angle of $70^{\circ}$, as marked in green. Thus even if the spray distribution is a Rosin-Rammler distribution, more analysis is required for a more accurate estimation of spray trajectory.

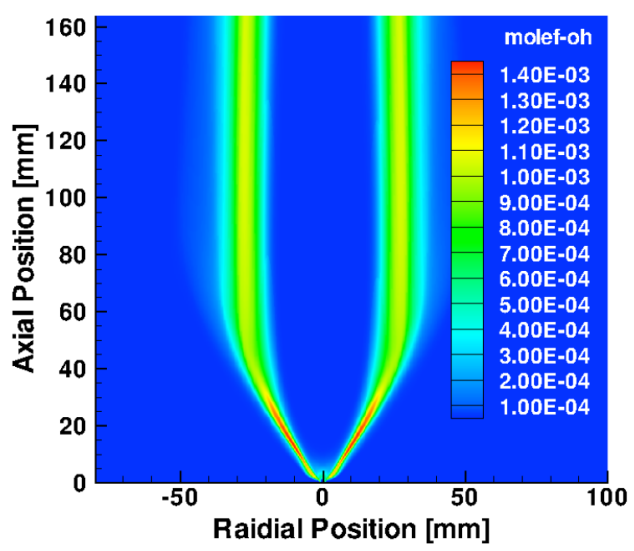

Fig.11 Predicted $\mathrm{OH}$ distribution in [3] 


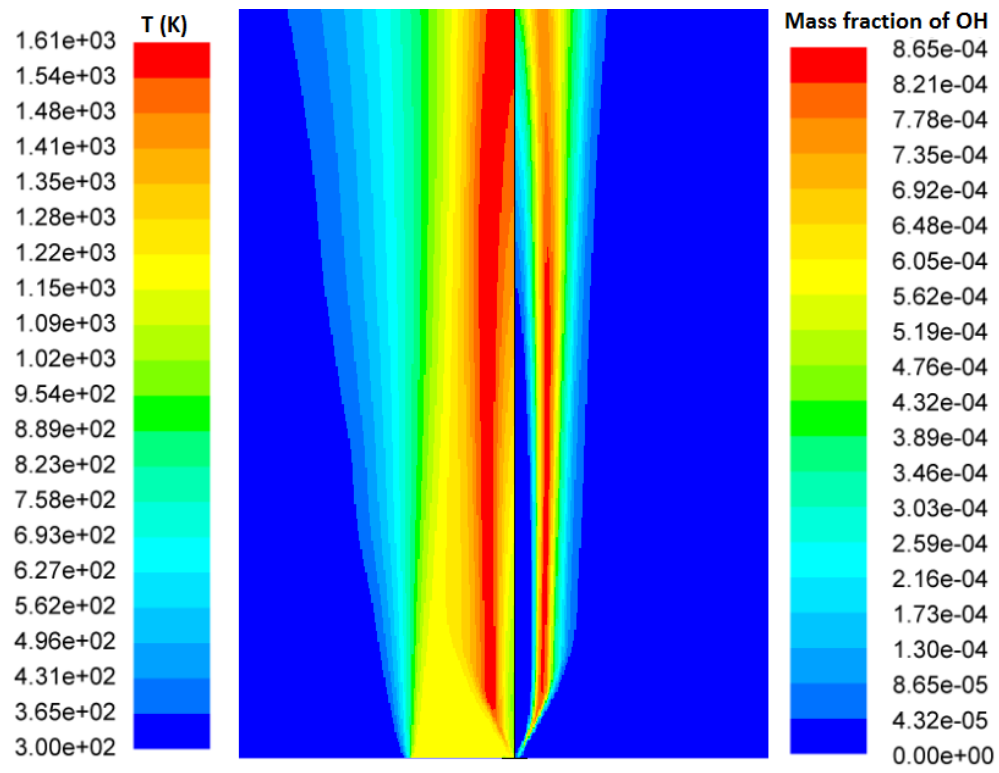

Fig.12 Averaged temperature and mass fraction of $\mathrm{OH}$ contours under $1200 \mathrm{~K}$ co-flow conditions (co-flow velocity: $3.5 \mathrm{~m} / \mathrm{s} ; \mathrm{O}_{2} \% \mathrm{vol}: 9 \%$ )

It is also observed that the predicted SMD in Fig. 6 are in general larger than the SMD we obtained as shown in Fig.2 and Fig.3. This may be attributed to some differences of models or droplet property used in discussed works. The consequence is that in study of Ma et al. [3] high concentration of $\mathrm{OH}$ is found near the injector as shown in Fig.11, while in the present study, for similar co-flow condition $\left(1200 \mathrm{~K}\right.$ and $\left.9 \% \mathrm{vol} \mathrm{O}_{2}\right)$, the high $\mathrm{OH}$ concentration and high temperature is located elsewhere, see Fig.12.

In the current study our main focus is on the comparative study of the influences of co-flow conditions on spray combustion. The methods of data analysis (including boundary conditions, measured data and fuel property data, etc.) and the models for all processes (including turbulence, spray, evaporation, and combustion, etc.) are the same as employed in chapter 2 for simulation of conventional spray combustion. Without any tuning of models or parameters' adjustment as one can see from many validation study, they are able to capture major features observed in the experiment, for both methanol and ethanol spray combustion, and for both conventional and HiTAC conditions.

As a result, using the presented models and methods is a very effective and efficient way to investigate the influences of co-flow conditions on spray flames, when focus is 
placed mainly on the reaction zone above the cone-shape region. Of course, for a detailed prediction of ignition and lift-off height in the near nozzle region, using a non-adiabatic FGM lookup table and LES allows the simulation to capture more features of spray flames $[4,5]$. In that case, the analysis of spray and boundary conditions, and the validation of the implemented models and methods in multiple cases are still essential to obtain a convincing and transferable modeling approach. As presented by Ma et al. [4] and [5] with detailed analysis of droplet size and velocity distribution, improved agreements were observed for gaseous and droplet velocity components, droplet size distribution, and temperature profiles at various elevations.

\subsection{Conclusions}

The numerical results of the cold co-flow case ( $300 \mathrm{~K}$ and $21 \% \mathrm{vol} \mathrm{O}_{2}$ concentration) and the hot co-flow case $\left(1500 \mathrm{~K}\right.$ and $6 \%$ vol $\mathrm{O}_{2}$ concentration) were compared with the experimental data under the similar co-flow conditions. Good match was shown for the flame profiles and SMD at various elevations. Some deviations between numerical solutions and experimental data were discussed and attributed to limitations of either the experiment or models used in simulation.

The simulation results of the DSHC flames from other researchers were compared to the results from the present study and discussed in order to obtain a better understanding of spray modeling and required experimental data. The models and methods used in the present study are effective and efficient for a comparative study, to investigate the influences of co-flow conditions on spray flames in the reaction zone. However, for proper model validation multiple cases are required to obtain a convincing and transferable modeling approach. 


\section{References}

[1] H.C. Rodrigues, Spray combustion in moderate and intense low-oxygen conditions -An experimental study, PhD thesis, Delft University of Technology, 2015.

[2] H.C. Rodrigues, M.J. Tummers, E.H. van Veen, D.J.E.M. Roekaerts, Effects of coflow temperature and composition on ethanol spray flames in hot-diluted coflow, Int. J. Heat Fluid Flow, 51 (2015) pp. 309-323.

[3] L. Ma, S. Zhu, H. Rodrigues, M. Tummers, T. van der Meer, D. Roekaerts, Numerical investigation of ethanol spray-in hot-coflow flame using steady flamelet model, In: Proceedings of the 8th Mediterranean Combustion Symposium, Turkey (2013).

[4] L.Ma, B. Naud, D. Roekaerts, Transported pdf modeling of ethanol spray in hot-diluted coflow flame. Flow, Turbulence and Combustion, 96(2): 469-502, 2016.

[5] L. Ma, D. Roekaerts, Modeling of spray jet flame under MILD condition with non-adiabatic FGM and a new conditional droplet injection model, Combustion and Flame, 165: 402-423, 2016.

[6] S.Zhu, D.J.E.M.Roekaerts, A.Pozarlik, T.H.van der Meer, Eulerian-Lagrangian RANS model simulations of the NIST turbulent methanol spray flame, Combustion Science and Technology 187(7):1110-1138.

[7] G. R. Ruetsch, L. Vervisch and A. Linan, Effects of heat release on triple flame. Phys. Fluids. 7, (6) 1447-1454, 1995.

[8] The engineering toolbox, http://www.engineeringtoolbox.com/melting-temperature-metalsd_860.html.

[9] H.C.Rodrigues, M.J. Tummers, D.J.E.M. Roekaerts, Turbulent spray combustion in hotdiluted co-flow, 9th Asia-Pacific Conference on Combustion, Gyeongju Hilton, Gyeongju, Korea, 19-22 May 2013. 


\section{CHAPTER 5.}

\section{NUMERICAL INVESTIGATION TOWARDS A HITAC CONDITION IN A 9MW HEAVY FUEL OIL BOILER*}

In this study, a $9 \mathrm{MW}$ heavy fuel-oil boiler was numerically investigated in order to get an understanding of the application of HiTAC in such system. Simulations were performed with an Euler- Lagrange approach. The Eddy Dissipation model with twostep reaction mechanism was used for combustion modeling. The results showed that by recycling various ratios of flue gas into the primary and secondary air, a relatively uniform temperature distribution inside the boiler can be achieved. Besides, soot formation and fuel $\mathrm{NO}_{\mathrm{x}}$ are both investigated in this chapter.

\footnotetext{
* Content in this chapter has been partially published in the following paper:

S.Zhu, B. Venneker, D.J.E.M.Roekaerts, A.Pozarlik, T.H.van der Meer, Numerical investigation towards a HiTAC condition in a 9MW heavy fuel-oil boiler. In: 6th European Combustion Meeting, Lund, June 25-28, 2013.
} 


\subsection{Introduction}

The key features of HiTAC combustion process can be potentially utilized to lead to simple, cheap and very reliable designs of boilers, with very low emissions of harmful species. It lends itself ideally for the combustion of all sorts of "difficult" fuels, ranging from low-calorific gases such as waste-gases, to heavy fuel-oils.

However, to date little is known about spray combustion in boiler under HiTAC condition [1], especially about heavy fuel-oil. The IFRF carried out semi-industrial scale tests using both a light and a heavy fuel oil $[2,3]$. Realization of flameless combustion for the light oil was straightforward. The whole furnace glowed without any visible presence of flame. In contrast, the heavy fuel oil flames were luminous and particulate emissions reached level of around $400 \mathrm{mg} / \mathrm{Nm}^{3}$. However, in Seng-Rung Wu's study [4], reduction of $\mathrm{NO}_{\mathrm{x}}$ was observed in heavy fuel oil combustion. The penetration depths of the jets, the role of buoyancy, and locations of fuel oil atomizer in the burner, were found important parameters for the mixing of fuel oil with high temperature air and for the final $\mathrm{NO}_{\mathrm{x}}$ emission. Several configurations of atomizers were studied. Two specific air-assisted oil atomizers, the effervescent atomizer and the double mixed-vortex atomizer (DMV) were developed to overcome coking of the heavy fuel oil in the oil atomizer during the regenerator mode. These indicate that the implementation of HiTAC for heavy fuel oil requires detailed research on mixing of reactants and the corresponding chemical mechanisms.

In order to investigate the feasibility of the application of heavy fuel-oil combustion with HiTAC, an industrial $9 \mathrm{MW}$ boiler at Stork Thermeq B.V. is considered. In the present study, several realizable conditions were numerically studied in order to get knowledge regarding the influence of primary and secondary air flow on combustion characteristics and $\mathrm{NO}_{\mathrm{x}}$ emissions in such boiler.

\subsection{Experimental setup}

The industrial boiler investigated here works as a test-bed for various burner designs at Stork Thermeq B.V. It has air preheating facility and multiple independent combustion air supplies. The furnace room is around $3 \mathrm{~m}$ high and around $4.4 \mathrm{~m}$ deep. 
The back of the furnace is partly water-cooled and some evaporator tubes are present at the side walls. The boiler produces up to $12 \mathrm{ton} / \mathrm{h}$ of steam at a pressure of $20 \mathrm{bar}$. A sketch of the boiler is shown in Fig.1.

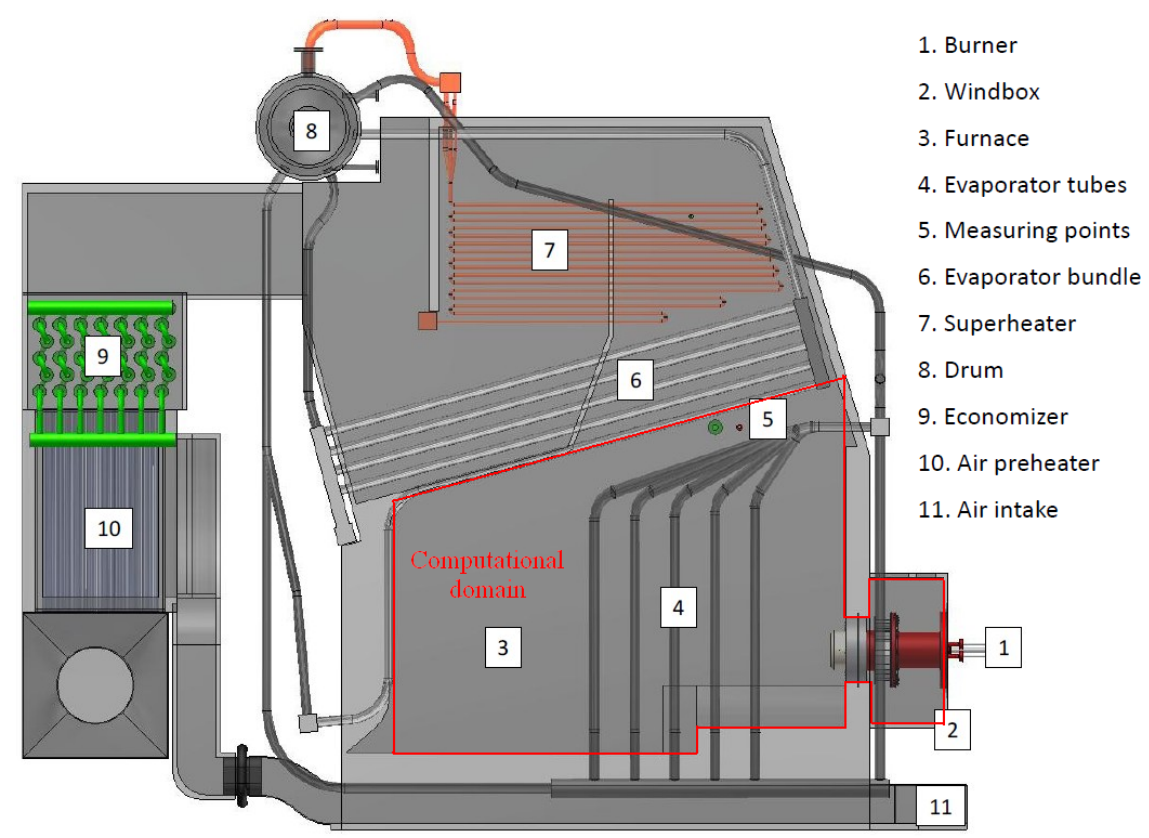

Fig.1. Schematic sketch of the boiler (side view)

The burner used in this boiler is a Stork Double Register Burner (DRB) as shown in Fig.2. This burner has a proven track record for stable and low-NOx combustion for a large envelope of liquid as well as gaseous fuels. A typical feature of this burner type is the staged supply of highly swirled combustion air. In the sub-stoichiometric primary flame zone, fuel-bound nitrogen is converted to $\mathrm{N}_{2}$, whereas in the secondary or burnout zone the remainder of the fuel is combusted at a low flame temperature in flow. Through an enhanced Y-jet steam assisted atomizer (see Fig.3), the steam is injected with the oil in a small channel and this mixture is atomized as it exits the channel. The atomizing steam pressure is 1.5 bar above the oil pressure. As also shown in Fig. 3 the stabilizer consists of 12 impeller blades surrounding two sets of oil outlets. The diameter of the inner outlets is $2.1 \mathrm{~mm}$ while the outer is $1.9 \mathrm{~mm}$. 

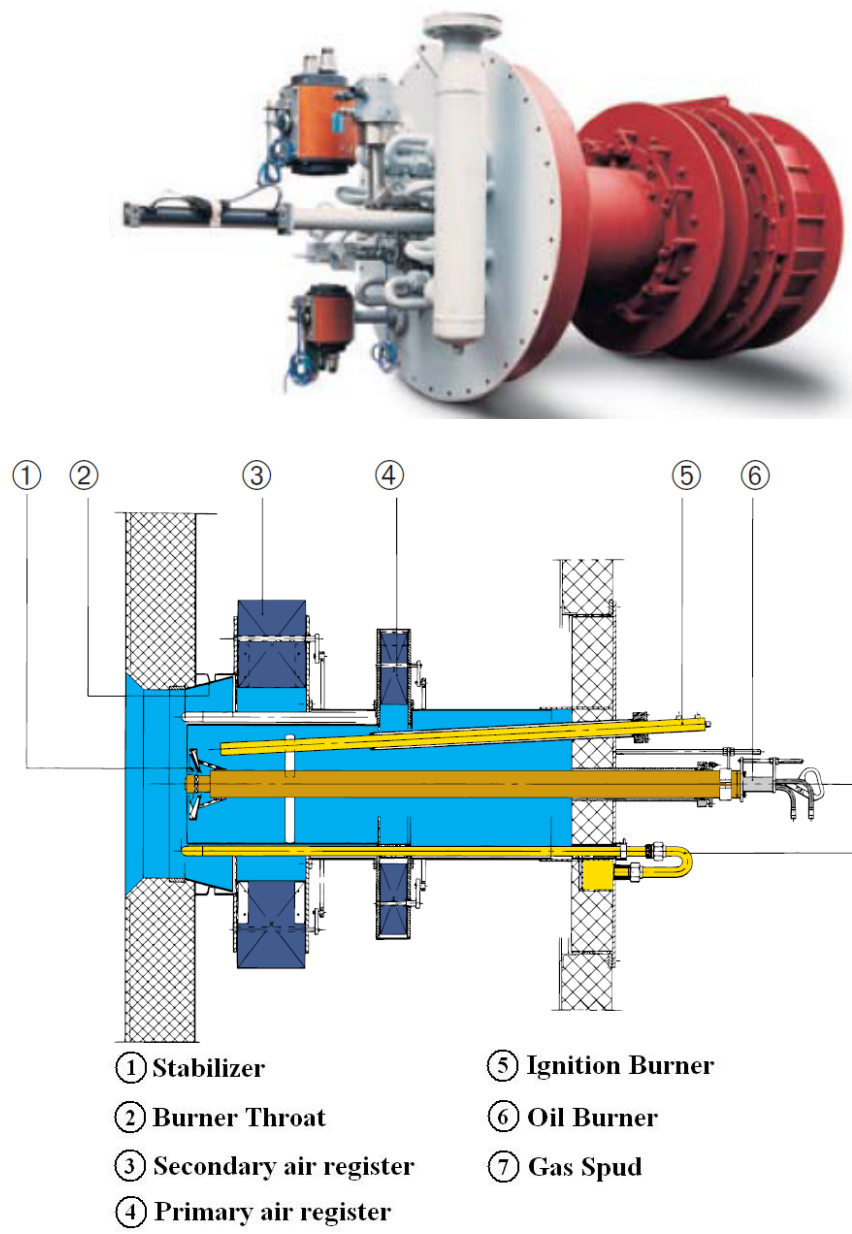

Fig.2. Picture of the DRB burner and a schematic view of the burner
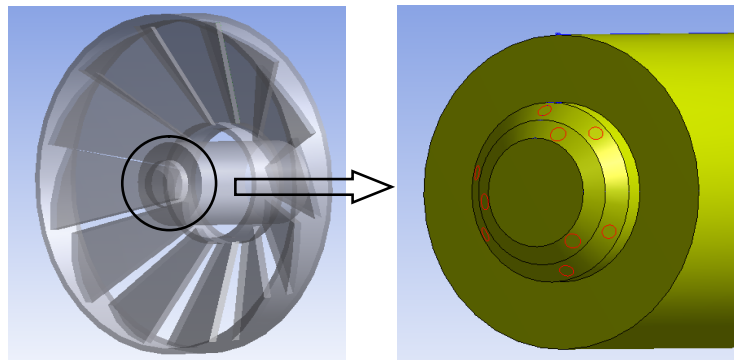

Fig.3. Geometry of the impeller (left) and atomizer (right) in the simulation 


\subsection{Mathematical models and boundary conditions}

\subsubsection{Computational domain, grid and turbulence model}

Due to the asymmetric geometry of the boiler and the burner, as well as the atomizer, full 3D simulations are carried out. The computational domain consists of the furnace room, the burner and the windbox as shown in Fig.1. Since there are no chemical reactions near the swirl vanes in the air registers or in the windbox, to reduce computational cost, the numerical simulation of heavy fuel-oil combustion in this boiler is divided into two steps.

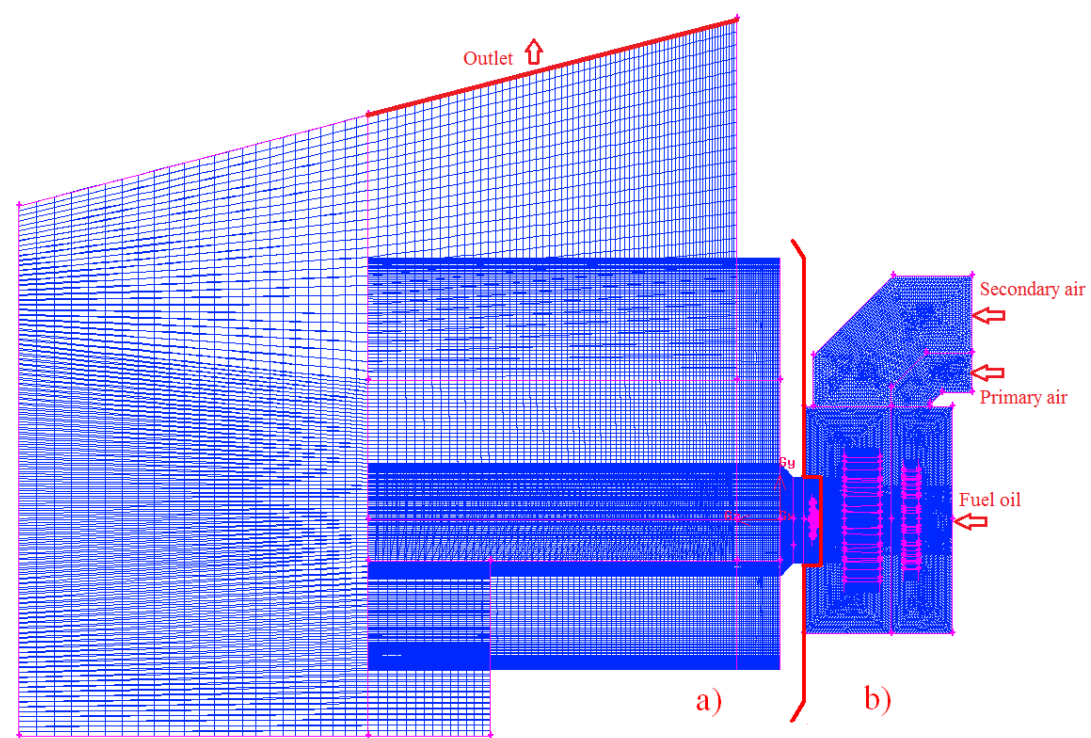

Fig.4. 3D mesh of the computational domain

a) + b): cold state cellulation; a): hot state cellulation

In the first step, the whole computational domain (see Fig.4) with the air registers and windbox is modelled without spray ignition (cold state). The calculated velocity components, the kinetic energy $\mathrm{k}$, and the turbulent dissipation $\varepsilon$, at a cross-section between the stabilizer and the air registers are obtained. The mesh independency was also studied. In the second step, these properties are applied as inlet boundary conditions for gas flow in reduced geometry, as prescribed in Fig.4. In this way the computational effort for heavy fuel oil combustion computation has been reduced significantly. Also, this arrangement allows finer grid in the flame zone, especially in 
the region close to the atomizer with high speed of steam, which has major importance for flame behavior prediction.

As a result, a 3D mesh with about 7.5 million cells for the cold state and one with about 5 million cells for the hot state are used in the present study (as shown in Fig.4). Based on the comparative analysis of the grid and flow characteristics, the standard k- $\varepsilon$ turbulence model with the standard wall function for the near-wall treatment is employed. Besides, the second order upwind scheme was used in order to obtain relatively accurate results.

\subsubsection{Spray model}

Since the properties of heavy fuel-oil, as well as the detailed reaction mechanism are not well known yet, the heavy fuel-oil in the simulation is treated as a single component fuel. Droplets of the fuel are assumed to have spherical shapes and be fully atomized. In the simulation a Rosin- Rammler distribution and a cone angle according to the empirical data of the atomizer is given in order to mimic the actual application. See for details in section 5.3 .5 boundary conditions.

The motions of the droplets in the turbulent combustion flow field are calculated using a stochastic tracking method. The momentum, mass, and energy exchange between the droplets and the gas phase is simulated by tracking a large number of numerical parcels.

Since the droplets are injected into the boiler by the steam-blast atomizer and a complete atomization is assumed, no secondary break-up or collision process (dispersed flow) is taken into account in the simulation.

The rate of fuel vaporization is governed by gradient diffusion, with the flux of droplet vapour into the gas phase related to the difference in vapour concentration at the droplet surface and the bulk gas. The concentration of vapour at the droplet surface is evaluated by assuming that the partial pressure of vapour at the interface is equal to the saturated vapour pressure at the droplet temperature. 


\subsubsection{Radiation and combustion model}

Radiative heat transfer cannot be neglected in the simulation of heavy fuel-oil combustion, since it contributes to reduction of the temperature gradient in the boiler through the presence of $\mathrm{CO}_{2}, \mathrm{H}_{2} \mathrm{O}$ and soot. The Discrete Ordinates (DO) radiation model with a variable absorption coefficient, weighted-sum-of-gray-gases model (WSGGM), is then employed in the simulation.

As combustion model, the Eddy Dissipation Model (ED) is used with a two-step global reaction mechanism including $\mathrm{CO}$.

\subsubsection{NOx and soot model}

For $\mathrm{NO}_{\mathrm{x}}$ formation, there are two major processes contributing to the total $\mathrm{NO}_{\mathrm{x}}$. The first one is known as Thermal NOx or extended Zeldovich mechanism [5,6], and simply consists of oxidation of atmospheric nitrogen at high temperature conditions. The principle reactions governing the formation of thermal $\mathrm{NO}_{\mathrm{x}}$ has been explained in chapter 3. The second one is called Fuel NOx and describes NOx formation from nitrogen, which is chemically bounded in liquid fuel. Although prompt $\mathrm{NOx}$ and $\mathrm{N}_{2} \mathrm{O}$ intermediate mechanism are also taken into account in the simulation, they showed to have little contribution to the total $\mathrm{NO}_{\mathrm{x}}$ formation by a comparative analysis.

Concentration of $[\mathrm{N}]$ is assumed in a quasi-steady state according to its nearly immediate conservation after formation. Concentrations of $[\mathrm{O}]$ and $[\mathrm{OH}]$ are calculated by partial equilibrium approach see also $[7,8,9]$.

Fuel $\mathrm{NO}_{\mathrm{x}}$ formation is dependent on the local combustion characteristics and the initial concentration of nitrogen-bound compounds. Fuel-bound compounds that contain nitrogen are released into the gas phase when the fuel droplets are heated during the devolatilization stage. Then nitrogen transforms to NO via intermediates, which usually are hydro-cyanide $\mathrm{HCN}$ and ammonia $\mathrm{NH}_{3}[10]$ as follows:

$$
\begin{gathered}
H C N \underset{\text { oxidation }}{\stackrel{1: O}{\longrightarrow}} N O \\
H C N \underset{\text { reduction }}{\stackrel{2: N O}{\longrightarrow}} N O
\end{gathered}
$$




$$
\begin{aligned}
& \mathrm{NH}_{3} \underset{\text { oxidation }}{\stackrel{3: \mathrm{O}}{\longrightarrow}} \mathrm{NO} \\
& \mathrm{NH}_{3} \underset{\text { reduction }}{\stackrel{4: \mathrm{NO}}{\longrightarrow}} \mathrm{N}_{2}
\end{aligned}
$$

The source terms in the transport equations can be written as follows:

$$
\begin{gathered}
S_{H C N}=\frac{S_{\text {fuel }} Y_{N, f u e l} M_{w, H C N}}{M_{w, N} V}-\Re_{1} \frac{M_{w, H C N} p}{R \bar{T}}-\mathfrak{R}_{2} \frac{M_{w, H C N} p}{R \bar{T}} S_{N O, H C N}=\mathfrak{R}_{1} \frac{M_{w, N O} p}{R \bar{T}}-\mathfrak{R}_{2} \frac{M_{w, N O} p}{R \bar{T}} \\
S_{N H_{3}}=\frac{S_{f u e l} Y_{N, f u e l} M_{w, N H_{3}}}{M_{w, N} V}-\mathfrak{R}_{3} \frac{M_{w, N H_{3}} p}{R \bar{T}}-\mathfrak{R}_{4} \frac{M_{w, N H_{3}} p}{R \bar{T}} \\
S_{N O, N H_{3}}=\mathfrak{R}_{3} \frac{M_{w, N O} p}{R \bar{T}}-\mathfrak{R}_{4} \frac{M_{w, N O} p}{R \bar{T}}
\end{gathered}
$$

where $S_{\text {fuel }}$ is the rate of fuel release from the liquid droplets to the gas, $Y_{N, f u e l}$ is the mass fraction of nitrogen in the fuel, $M_{w, i}$ is the molecular weight of species i. $V$ is the cell volume, $\mathrm{p}$ is the pressure, $\bar{T}$ is the mean temperature, and $\mathrm{R}$ is the universal gas constant. $\mathfrak{R}_{1}$ and $\mathfrak{R}_{2}$ are conversion rates of $\mathrm{HCN}$, and $\mathfrak{R}_{3}$ and $\mathfrak{R}_{4}$ are conversion rates of $\mathrm{NH}_{3}$ calculated as follows [11]:

$$
\begin{aligned}
& \mathfrak{R}_{1}=1.0 \times 10^{10} X_{\mathrm{HCN}} X_{\mathrm{O}_{2}}^{a} e^{-280451.95 / R T} \\
& \mathfrak{R}_{2}=3.0 \times 10^{12} X_{\mathrm{HCN}} X_{\mathrm{NO}} e^{-251151 / R T} \\
& \mathfrak{R}_{3}=4.0 \times 10^{6} X_{\mathrm{NH}_{3}} X_{\mathrm{O}_{2}}^{a} e^{-133947.2 / R T} \\
& \mathfrak{R}_{4}=1.8 \times 10^{8} X_{\mathrm{NO}} X_{\mathrm{O}_{2}} e^{-113017.95 / R T}
\end{aligned}
$$

where $\mathrm{T}$ is the instantaneous temperature, $X_{i}$ is the mole fraction of species $\mathrm{i}$, and $a$ is the oxygen reaction order. Oxygen reaction order depends on flame conditions. According to De Soete [11], it is uniquely related to oxygen mole fraction in the flame:

$$
a= \begin{cases}1.0, & X_{\mathrm{O}_{2}} \leq 4.1 \times 10^{-3} \\ -3.95-0.9 \ln X_{\mathrm{O}_{2}}, & 4.1 \times 10^{-3} \leq X_{\mathrm{O}_{2}} \leq 1.11 \times 10^{-2} \\ -0.35-0.1 \ln X_{\mathrm{O}_{2}}, & 1.11 \times 10^{-2}<X_{\mathrm{O}_{2}}<0.03 \\ 0, & X_{\mathrm{O}_{2}} \geq 0.03\end{cases}
$$


The investigations [12] have shown that HCN appears to be the principal product if fuel nitrogen is present in aromatic or cyclic form, while when fuel nitrogen is present in the form of aliphatic amines, $\mathrm{NH}_{3}$ becomes the main product of fuel nitrogen conversion. In the present study, the intermediate $\mathrm{HCN}$ is assumed to be the primary route for $\mathrm{NOx}$ production.

For soot formation, the two-step Tesner model $[13,14]$, which predicts the formation of nuclei particles, with soot formation on the nuclei, is employed. Transport equation for the soot mass fraction and the normalized radical nuclei concentration can be written as follows:

$$
\begin{gathered}
\left.\frac{\partial}{\partial t}\left(\rho Y_{\text {soot }}\right)+\nabla \cdot\left(\rho \vec{v} Y_{\text {soot }}\right)=\nabla \cdot\left(\frac{\mu_{t}}{\sigma_{\text {soot }}} \nabla Y_{\text {soot }}\right)+\mathfrak{R}_{\text {soot }}\right) \\
\left.\frac{\partial}{\partial t}\left(\rho b_{\text {nuc }}^{*}\right)+\nabla \cdot\left(\rho \vec{v} b_{\text {nuc }}^{*}\right)=\nabla \cdot\left(\frac{\mu_{t}}{\sigma_{\text {nuc }}} \nabla b_{\text {nuc }}^{*}\right)+\mathfrak{R}_{\text {nuc }}^{*}\right) \\
\mathfrak{R}_{\text {soot }}=m_{p}\left(\alpha-\beta N_{\text {soot }}\right) c_{\text {nuc }}- \\
\min \left[A p Y_{\text {soot }} \frac{\varepsilon}{k}, A p\left(\frac{Y_{\text {ox }}}{v_{\text {soot }}}\right)\left(\frac{Y_{\text {soot }} v_{\text {soot }}}{Y_{\text {soot }} v_{\text {soot }}+Y_{\text {fuel }} v_{\text {fuel }}}\right) \frac{\varepsilon}{k}\right] \\
\mathfrak{R}_{\text {nuc }}=\eta_{0}+(f-g) c_{\text {nuc }}^{*}-g_{0} c_{\text {nuc }}^{*} N_{\text {soot }}- \\
\frac{b_{\text {nuc }}^{*}}{Y_{\text {soot }}} \min \left[A p Y_{\text {soot }} \frac{\varepsilon}{k}, A p\left(\frac{Y_{\text {ox }}}{v_{\text {soot }}}\right)\left(\frac{Y_{\text {soot }} v_{\text {soot }}}{Y_{\text {soot }} v_{\text {soot }}+Y_{\text {fuel }} v_{\text {fuel }}}\right) \frac{\varepsilon}{k}\right]
\end{gathered}
$$

where A is a constant in the Magnussen model. $Y_{o x}, Y_{\text {fuel }}$ and $Y_{\text {soot }}$ are mass fraction of oxidizer, fuel and soot. $v_{\text {soot }}$ and $v_{\text {fuel }}$ are mass stoichiometries for soot and fuel combustion. $\sigma_{\text {soot }}$ and $b_{n u c}^{*}$ are turbulent Prandtl numbers for soot and nuclei transport. $\mathfrak{R}_{\text {soot }}$ and $\mathfrak{R}_{\text {nuс }}^{*}$ are net rates of soot generation and normalized radical nuclei concentration. $m_{p}$ is mean mass of soot particle, $N_{\text {soot }}$ is concentration of soot particles, $c_{n u c}$ is radical nuclei concentration equals to $\rho b_{n u c} \cdot c_{n u c}^{*}$ is normalized nuclei concentration. $c_{\text {fuel }}$ is fuel concentration. $\alpha$ and $\beta$ are empirical constants. $g_{0}$ is linear termination on soot particle, and $(f-g)$ is linear branching-termination coefficient. 
The term $(f-g) c_{n u c}^{*}$ is included only when the kinetic rate $\eta_{0}$, is greater than the limiting formation rate, $10^{5}$ particles $/ \mathrm{m}^{3}-\mathrm{s}$ :

$$
\eta_{0}=a_{0} c_{f u e l} e^{-E / R T}
$$

where $a_{0}$ is a pre-exponential rate constant.

\subsubsection{Boundary conditions}

According to the actual application of the DRB burner, in a typical case with a power of about $5 \mathrm{MW}$, a mass flow of $0.5927 \mathrm{~kg} / \mathrm{s}$ of primary air and a mass flow of $1.7781 \mathrm{~kg} / \mathrm{s}$ of secondary air are used at a temperature of $373 \mathrm{~K}$. The mass flow of the heavy fuel-oil is $0.1363 \mathrm{~kg} / \mathrm{s}$ and the steam/oil ratio is about 0.06 . The fuel-oil is heated up to $353 \mathrm{~K}$ to reach a proper viscosity for atomization and the steam is injected with a temperature of $493 \mathrm{~K}$. The same boundary conditions of staged air, fuel oil and steam are used in the simulation, as shown in Tab.1. The predicted velocity components at the defined cross-section from the first step of cold state lead to mass flow rates of primary and secondary air both within $1 \%$ error.

The lower heating value (LHV) of the used heavy fuel oil is $40.36 \mathrm{MJ} / \mathrm{kg}$ and the average molecular weight is about $268 \mathrm{~kg} / \mathrm{kmol}$, with $0.42 \mathrm{wt} \%$ nitrogen contained. Since its detailed properties, as well as the detailed reaction mechanism, are not well known yet, the heavy fuel-oil in the simulation is assumed to be a single component, $\mathrm{C}_{19} \mathrm{H}_{30}$, whose molecular weight is $258 \mathrm{~kg} / \mathrm{kmol}$ and lower heating value is $40.49 \mathrm{MJ} / \mathrm{kg}$. An empirical Rosin- Rammler distribution of droplets size with a cone angle of $6^{\circ}$ is used in the simulation. The mean diameter of the droplets is $75 \mu \mathrm{m}$ with a spread parameter of 3.5 (minimum diameter of $10 \mu \mathrm{m}$ and maximum diameter of $200 \mu \mathrm{m}$ ). The droplets are assumed to be injected into the boiler through each oil outlet with an initial velocity magnitude of $35 \mathrm{~m} / \mathrm{s}$.

In order to do investigations towards HiTAC conditons, two cases are simulated. In Case 1 the temperature of both primary and secondary air is increased to $746 \mathrm{~K}$, and in Case 2 the mass fraction of $\mathrm{O}_{2}$ is decreased to half of the original one, see Tab.1. 
Tab.1. Inlet conditions of air, fuel and steam

\begin{tabular}{|l|c|c|c|}
\hline \multicolumn{1}{|c|}{ Parameters } & Base Case & Case 1 & Case 2 \\
\hline Primary air mass flow rate (kg/s) & 0.5927 & 0.5927 & 0.5927 \\
\hline Secondary air mass flow rate (kg/s) & 1.7781 & 1.7781 & 1.7781 \\
\hline Air temperature (K) & 373 & $\mathbf{7 4 6}$ & 373 \\
\hline $\mathrm{O}_{2}$ in the combustion air (wt\%) & 23.0650 & 23.0650 & $\mathbf{1 1 . 5 3 2 5}$ \\
\hline $\mathrm{H}_{2} \mathrm{O}$ in the combustion air (wt\%) & 0.7407 & 0.7407 & 0.7407 \\
\hline Fuel mass flow rate (kg/s) & 0.1363 & 0.1363 & 0.1363 \\
\hline $\mathrm{N}_{2}$ in fuel (wt\%) & 0.42 & 0.42 & 0.42 \\
\hline Fuel temperature (K) & 353 & 353 & 353 \\
\hline Steam mass flow rate (kg/s) & 0.0082 & 0.0082 & 0.0082 \\
\hline Steam temperature (K) & 493 & 493 & 493 \\
\hline
\end{tabular}


Tab.2. Inlet conditions of combustion air in four cases

\begin{tabular}{|c|c|c|c|c|c|c|c|c|}
\hline Composition & \multicolumn{2}{|c|}{ Case 3} & \multicolumn{2}{|c|}{ Case 4} & \multicolumn{2}{|c|}{ Case 5} & \multicolumn{2}{|c|}{ Case 6} \\
\hline Primary air & $\mathrm{kg} / \mathrm{s}$ & wt $\%$ & $\mathbf{k g} / \mathbf{s}$ & wt $\%$ & $\mathrm{~kg} / \mathrm{s}$ & wt $\%$ & $\mathrm{~kg} / \mathrm{s}$ & wt $\%$ \\
\hline Percentage of FGR & - & 5 & - & 0 & - & 10 & - & 8 \\
\hline $\mathrm{O}_{2}$ & 0.14268 & 20.06 & 0.13671 & 23.065 & 0.14864 & 17.913 & 0.14625 & 18.694 \\
\hline $\mathrm{CO}_{2}$ & 0.02046 & 2.877 & 0 & 0 & 0.04093 & 4.932 & 0.03274 & 4.185 \\
\hline $\mathrm{H}_{2} \mathrm{O}$ & 0.01024 & 1.44 & 0.00443 & 0.747 & 0.01605 & 1.934 & 0.01373 & 1.755 \\
\hline $\mathrm{N}_{2}$ & 0.53776 & 75.607 & 0.45158 & 76.188 & 0.62394 & 75.192 & 0.58947 & 75.343 \\
\hline Total & 0.71125 & 100 & 0.59271 & 100 & 0.8298 & 100 & 0.78238 & 100 \\
\hline Secondary air & $\mathrm{kg} / \mathrm{s}$ & wt $\%$ & $\mathrm{~kg} / \mathrm{s}$ & wt $\%$ & $\mathrm{~kg} / \mathrm{s}$ & wt\% & $\mathrm{kg} / \mathrm{s}$ & $w t \%$ \\
\hline Percentage of FGR & - & 15 & - & 20 & - & 10 & - & 12 \\
\hline $\mathrm{O}_{2}$ & 0.42803 & 20.06 & 0.43399 & 19.269 & 0.42206 & 20.944 & 0.42445 & 20.578 \\
\hline $\mathrm{CO}_{2}$ & 0.06139 & 2.877 & 0.08185 & 3.634 & 0.04093 & 2.031 & 0.04911 & 2.381 \\
\hline $\mathrm{H}_{2} \mathrm{O}$ & 0.03072 & 1.44 & 0.03653 & 1.622 & 0.02491 & 1.236 & 0.02723 & 1.32 \\
\hline $\mathrm{N}_{2}$ & 1.61327 & 75.607 & 1.69945 & 75.454 & 1.52709 & 75.778 & 1.56156 & 75.707 \\
\hline Total & 2.13376 & 100 & 2.25231 & 100 & 2.01522 & 100 & 2.06264 & 100 \\
\hline Primary + secondary & 2.84502 & - & 2.84502 & - & 2.84502 & - & 2.84502 & - \\
\hline
\end{tabular}


Furthermore, since $\mathrm{O}_{2}$ concentration shows considerable contribution on the decrease of peak temperature in the boiler, further numerical investigation is performed with recycling various ratios of flue gas (FGR) into the primary and secondary air, respectively (Case 3 - Case 6). This is done to introduce various $\mathrm{O}_{2}$ concentration conditions for the primary and secondary air flow. Four cases which are possible for application in the field tests are simulated and compared with the Base Case results. Boundary conditions of the primary and secondary conditions are shown in table 2.

\subsection{Results and Discussion}

Table 3 shows the results of predicted peak temperature $\left(T_{P}\right)$, its difference from combustion air temperature $\left(T_{D}\right)$, average $\mathrm{NO}$ x emissions $\left(M_{N O_{X}}\right)$ and $\mathrm{O}_{2}$ mole fraction at the exit for Base Case, Case 1 and Case 2.

With a preheated combustion air up to $706 \mathrm{~K}, T_{P}$ in the boiler increases from 2240 $\mathrm{K}$ (the Base Case) to $2390 \mathrm{~K}$. Although $T_{D}$ is reduced from $1867 \mathrm{~K}$ to $1644 \mathrm{~K}$, the increased peak temperature zone leads to enhanced $\mathrm{NO}_{\mathrm{x}}$ formation in the boiler. Due to $T_{P}$ which is about $150 \mathrm{~K}$ higher in Case 1 in comparison to Base Case, the $\mathrm{NO}_{\mathrm{X}}$ emissions are over two times higher, i.e. increases from $987 \mathrm{mg} / \mathrm{m}_{0}^{3} @ 3 \% \mathrm{O}_{2}$ to 1992 $\mathrm{mg} / \mathrm{m}_{0}^{3} @ 3 \% \mathrm{O}_{2}$. According to previously obtained data from Stork Thermeq B.V., a typical NOx emission for heavy fuel-oil firing with the DRB burner is about 550 $\mathrm{mg} / \mathrm{mo}^{3} @ 3 \% \mathrm{O}_{2}$ at a firing condition of $4.7 \mathrm{MW}$ and $4 \mathrm{vol} \%$,dry $\mathrm{O}_{2}$ in the flue gases [15]. A further field test at a firing condition of $5.7 \mathrm{MW}$, which is very close to the Base Case of about 5.5 MW, showed that the $\mathrm{NO}_{\mathrm{x}}$ emissions were at level of $850 \mathrm{mg} / \mathrm{m}_{0}^{3} @ 3 \% \mathrm{O}_{2}$ [16]. The predicted $\mathrm{NO}_{\mathrm{x}}$ emissions seem to resemble the measured data very well. However, the predictions should only be used qualitatively since the combustion process of heavy fuel oil is modeled as a single component, $\mathrm{C}_{19} \mathrm{H}_{30}$, with a 2-step ED model, thus many other components and processes such as thermal cracking, coking, etc. are not included. The 2-step ED model may lead to an overestimated temperature profile, while the underestimated soot formation in contrary can play a compensation role on the temperature predictions. As shown in table 3, soot formation has 
considerable influence on the peak temperature and $\mathrm{NO}_{\mathrm{x}}$ emissions, especially for the case with hot combustion air flow (Case 1). For that case the peak temperature is $140 \mathrm{~K}$ higher and the NOx emission is almost three times higher without soot formation in the model in comparison to the model with soot formation.

Tab.3. Predicted $T_{P}, T_{D}, M_{N O_{X}}$ and $\mathrm{O}_{2}$ mole fraction at exit for Base Case, Case 1 and Case 2, with and without soot model

\begin{tabular}{|c|c|c|c|}
\hline Predictions & Base Case & Case 1 & Case 2 \\
\hline Peak temperature, $T_{P}(\mathrm{~K})$ & 2240 & 2390 & 1510 \\
\hline $\begin{array}{c}\text { Temperature difference between combustion } \\
\text { air and peak temperature, } T_{D}(\mathrm{~K})\end{array}$ & 1867 & 1644 & 1137 \\
\hline NOx emissions, $M_{N O_{X}}\left(\mathrm{mg} / \mathrm{m}_{0}^{3} @ 3 \% \mathrm{O}_{2}\right)$ & $9840-373)$ & $(2390-746)$ & $(1510-373)$ \\
\hline Vol\% $\mathrm{O}_{2}$,dry at exit & $7.6 \%$ & $7.8 \%$ & $3.8 \%$ \\
\hline Peak temperature without soot model, $T_{P}(\mathrm{~K})$ & 2280 & 2530 & 1510 \\
\hline $\mathrm{NO}_{\mathrm{N} \text { emissions without soot model, }}\left(\mathrm{mg} / \mathrm{m}_{0}{ }^{3} @ 3 \% \mathrm{O}_{2}\right)$ & 1470 & 5337 & 4 \\
\hline$M_{N O_{X}}$ & & & 3 \\
\hline
\end{tabular}

Case 2 with reduced $\mathrm{O}_{2}$ concentration in the combustion air shows a remarkable decrease of $T_{P}$, from $2240 \mathrm{~K}$ in the Base Case to $1510 \mathrm{~K}$, and $T_{D}$ is further reduced to $1137 \mathrm{~K}$. The $\mathrm{NO}_{\mathrm{x}}$ emissions are reduced to only $3 \mathrm{mg} / \mathrm{m}_{0}^{3} @ 3 \% \mathrm{O}_{2}$. This is due to the fact that thermal $N O_{X}$ are significantly formed above $1600 \mathrm{~K}-1800 \mathrm{~K}$ [17] and fuel NOX formation is dependent on $\mathrm{HCN}$ and $\mathrm{NH}_{3}$, which are generated as intermediates at high enough temperatures [18]. With ED model, whose principle is 'mixed is burnt', such a low temperature profile leads to extremely low $\mathrm{NO}_{\mathrm{x}}$ emissions and complete consumption of fuel. The trends have demonstrated the influence of $\mathrm{O}_{2}$ concentration of 
combustion air on the flame and $\mathrm{NO}_{\mathrm{x}}$ emissions, as well as the influence of temperature in Case 1.

$\begin{array}{lllllllllll}2390 & 2190 & 1990 & 1780 & 1580 & 1380 & 1180 & 978 & 776 & 575 & 373\end{array}$

Temperature

(K)
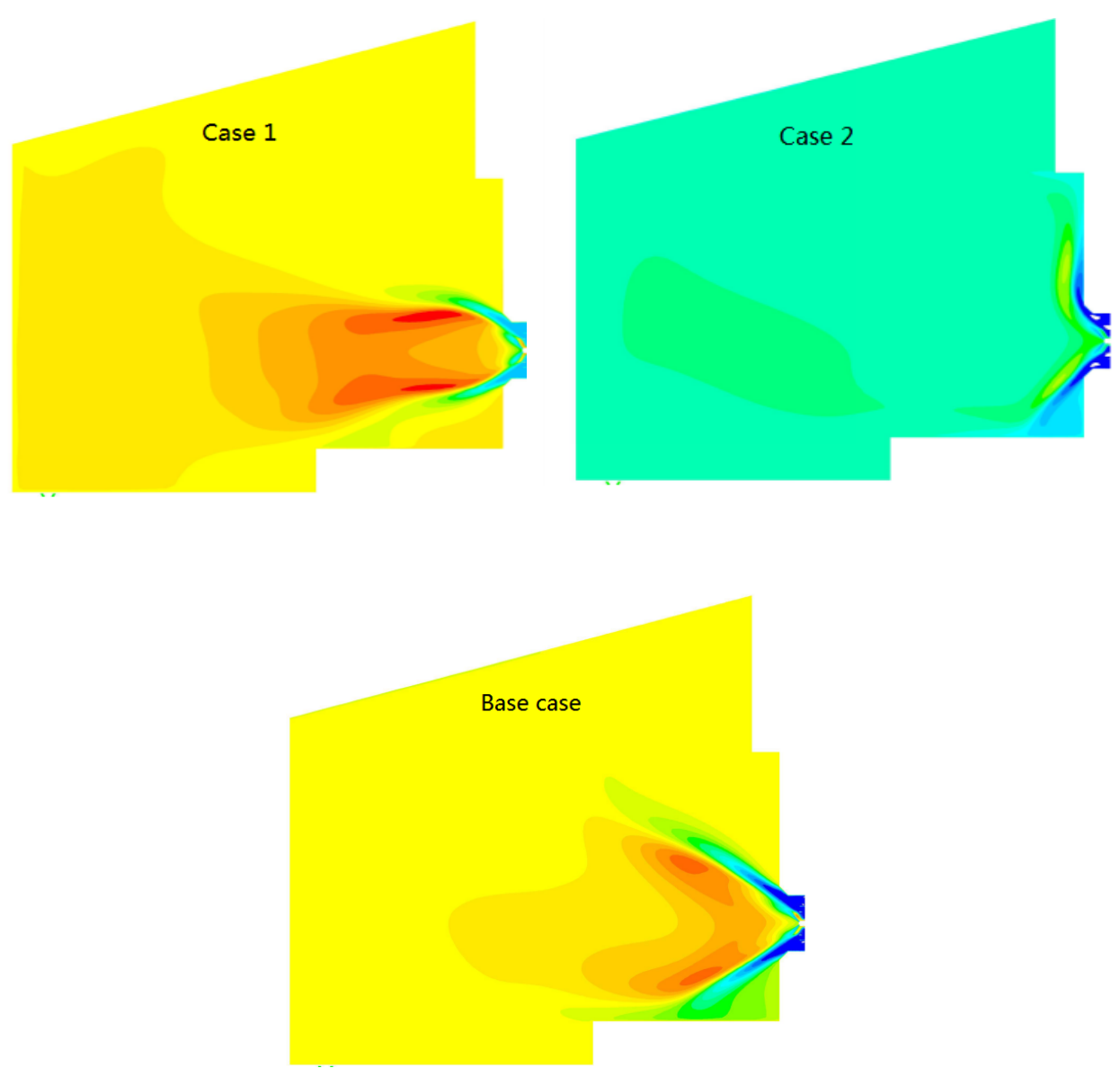

Fig.5 Temperature contours (K) at axial cross section in Case 1, Case 2 and Base Case

Fig.5 shows the temperature contours at axial cross section in Case 1, Case 2 and Base Case. With a high temperature of combustion air in Case 1, the peak temperature zone occurs in the region closer to the nozzle compared to Base Case, and the flame profile is more narrowed and prolonged. In Case 2 the peak temperature zone occurs 
even closer than in Base Case, but the peak temperature is much lower. This is attributed to the fact that less fuel is combusted in this region while some fuel is further consumed far from the nozzle creating a relatively high temperature zone.

Further investigation is focused on the influence of the $\mathrm{O}_{2}$ concentration in the primary and secondary air, taking into account the feasibility of operation in the field test (over-reduced $\mathrm{O}_{2}$ concentration in the combustion air may lead to operating and ignition problems). Various ratios of flue gas are designed for recycling and introduced into the primary and secondary air respectively. By doing this various $\mathrm{O}_{2}$ concentration conditions in combustion air flow are studied.

Fig. 6 shows the temperature contours at axial cross section of Case 3 to Case 6 . These are compared with the Base Case computation. The predicted peak temperature $T_{P}$, NOx emissions $M_{N O_{X}}$ and oxygen mole fraction at the exit of the boiler are shown in table 4.

Tab.4. Predicted $T_{P}, M_{N_{X}}$ and $\mathrm{O}_{2}$ mole fraction at exit in Case 3 to Case 6

\begin{tabular}{|c|c|c|c|c|c|}
\hline Predictions & Base Case & Case3 & Case4 & Case5 & Case6 \\
\hline Peak temperature, $T_{P}(\mathrm{~K})$ & 2240 & 1990 & 2010 & 1930 & 1960 \\
\hline NOx emissions, $M_{N O_{X}}\left(\mathrm{mg} / \mathrm{m}^{3} @ 3 \% \mathrm{O}_{2}\right)$ & 987 & 302 & 292 & 317 & 283 \\
\hline Vol $\% \mathrm{O}_{2}$,dry at exit & $7.6 \%$ & $7.0 \%$ & $7.0 \%$ & $7.3 \%$ & $7.2 \%$ \\
\hline
\end{tabular}




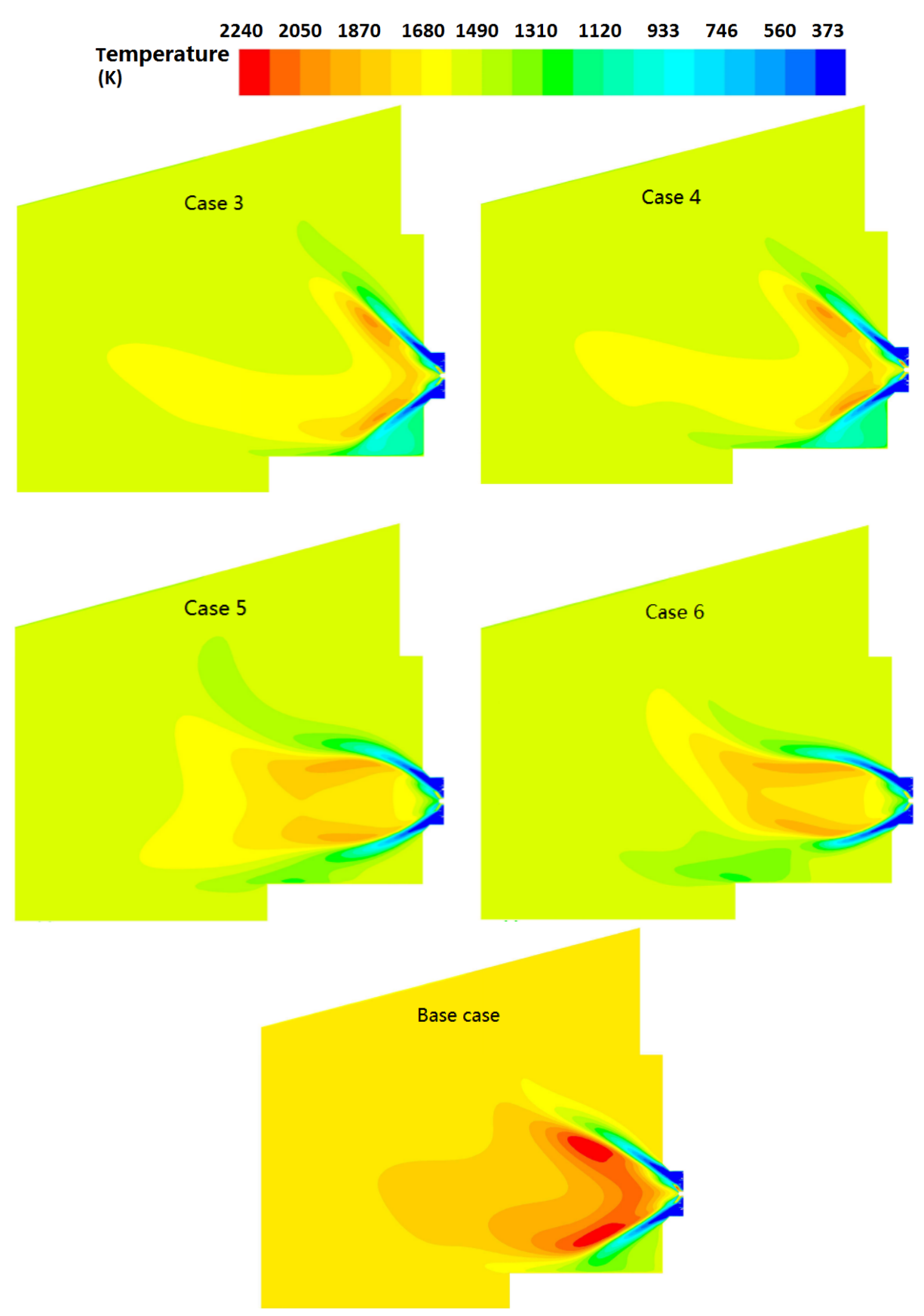

Fig.6 Temperature contours (K) at axial cross section

Case 3 to Case 6 compared with the Base Case 
The flame profiles in Case 3 and 4 are similar to Base Case, while the peak temperature has been reduced from $2240 \mathrm{~K}$ to $1990 \mathrm{~K}$ and $2010 \mathrm{~K}$ respectively due to flue gas recirculation. The 5\% flue gas mixing in primary air in Case 3 (see Tab.2) leads to peak temperature reduction by $20 \mathrm{~K}$. When more flue gas has been introduced in the primary air, the flame profiles changed as shown in Case 5 and Case 6 . For $10 \%$ flue gas in the primary air (Case 5), the peak temperature is decreased to $1930 \mathrm{~K}$ whereas for $8 \%$ flue gas in the primary air (Case 6) the peak temperature is equal to $1960 \mathrm{~K}$. The oxygen mole fraction at exit shows that more oxygen has been consumed for Case 3-6 compared to base load. This indicates that there is less remaining fuel.

Unlike the trends observed in previous chapters, the cases with low peak temperatures do not have the lowest $\mathrm{NO}_{\mathrm{x}}$ emissions. This is due to the contribution of fuel $\mathrm{NO}_{\mathrm{X}}$ to $\mathrm{NO}_{\mathrm{x}}$ formation. According to the investigation on the formation of the $\mathrm{NO}_{\mathrm{X}}$, for the Base Case, only about $40 \%$ of the $\mathrm{NO}_{\mathrm{x}}$ emissions come from thermal NOx. The peak temperatures in all four cases with flue gas recirculation are reduced, thus the thermal $\mathrm{NO}_{\mathrm{X}}$ is also reduced to a low level, making the fuel $\mathrm{NO}_{\mathrm{X}}$ a dominant $\mathrm{NO}_{\mathrm{X}}$ source. Furthermore, the fuel $\mathrm{NO}_{\mathrm{X}}$ formation is also decreased with flue gas recirculation in the simulation.

In the field test as presented by Venneker, et al. in [16], although lowered $\mathrm{NO}_{\mathrm{X}}$ emissions were obtained with flue gas recirculation, there were still above 700 $\mathrm{mg} / \mathrm{m}_{0}^{3} @ 3 \% \mathrm{O}_{2}$. This effect could be attributed to the overestimated reduction of both, thermal $\mathrm{NO}_{\mathrm{x}}$ and fuel $\mathrm{NO}_{\mathrm{x}}$. Considering the fact that $\mathrm{ED}$ model is not likely to underestimate the peak temperature, it is concluded that the fuel nitrogen have contributed more in the $\mathrm{NO}_{\mathrm{x}}$ formation in field test than in simulation. Further decrease in flame peak temperature has no significant effect on fuel $\mathrm{NO}_{\mathrm{X}}$ reduction. 

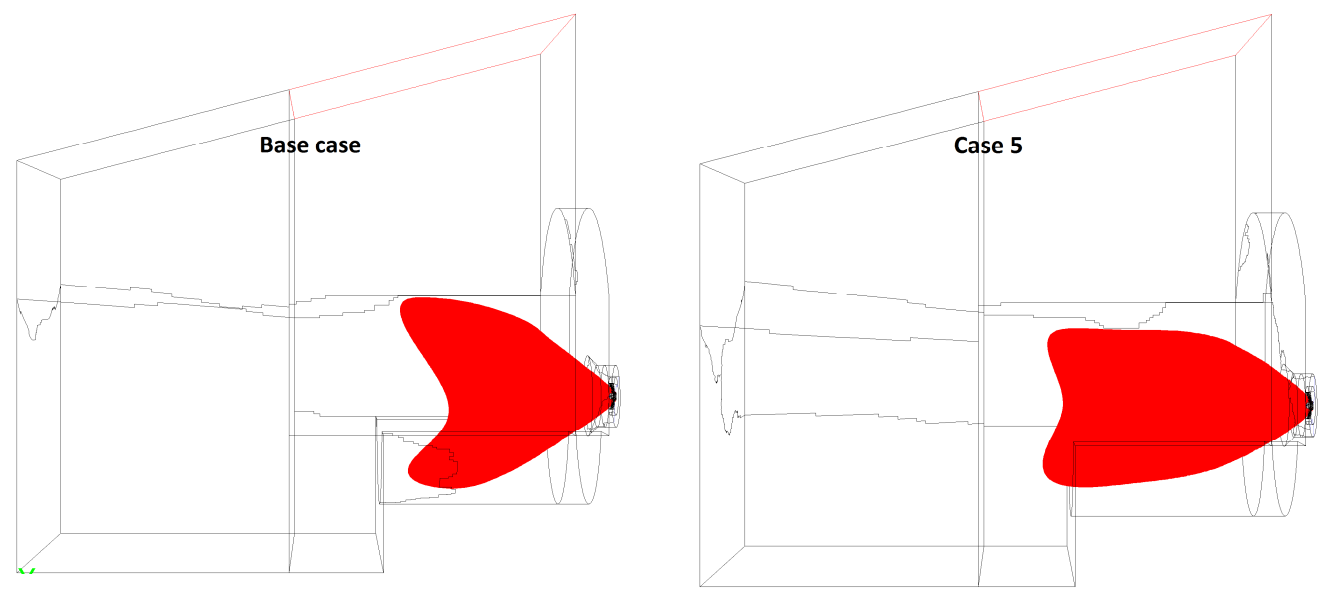

Fig.7 Regions with CO concentration above 500 ppm, dry. Base Case (left) vs Case 5 (right)

Fig.7 shows the regions with $\mathrm{CO}$ concentration above 500 ppm for Base Case and Case 5. Case 3 and Case 4 are similar to the Base Case, while Case 6 is alike to Case 5. This indicates that $\mathrm{CO}$ is formed and consumed in the combustion zone as shown in the temperature profiles. The flame's outer profiles can be described in this way, as well.

However, in order to obtain the flame volume as shown in chapter 3, both the external and internal boundaries of the flame are required. The oxidation mixture ratio [19], $R_{O}=\frac{m_{O}}{m_{O}+\sum_{c} S_{c} m_{F, c}}$ as introduced in chapter 2, has been employed.

With the flame external boundary defined as $R_{O}=0.99$ and the internal boundary as $R_{O}=0.01$, the flame volume can be calculated. 

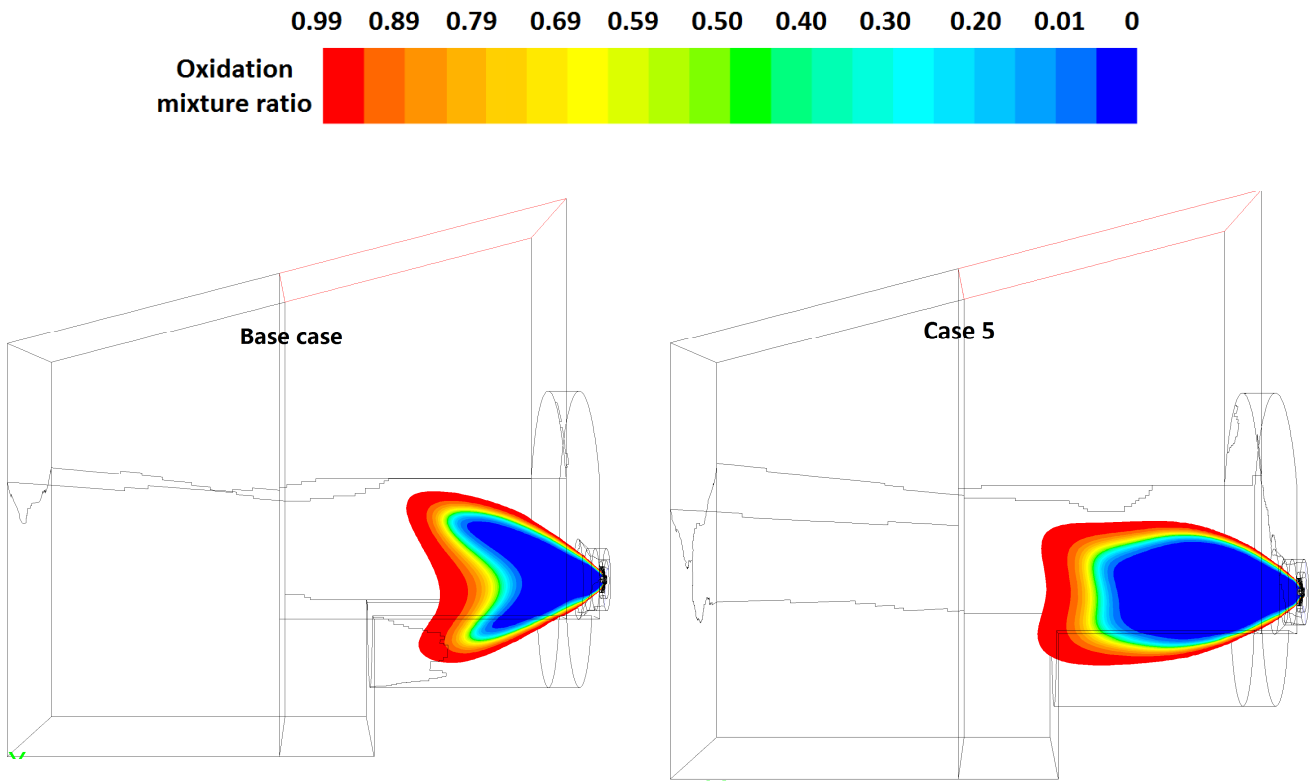

Fig. 8 Oxidation mixture ratio, $R_{O}$ in Base Case and Case 5

Fig. 8 presents that for Case 5 the fuel is distributed more uniformly over the active flame zone than in Base Case (see the distribution of the blue colored region). Since mixing of the fuel with low oxygen flue gas has been found the effective way to reduce thermal NOx, fuel staging with fuel injected to low oxygen content flue gas is then a potential way to further reduce thermal NOx. This has been verified by the field test results presented by Venneker, et al. in [16]. Two fuel oil injectors located above the DRB burner have been used to inject a portion of heavy oil into the boiler. The case with about $35 \%$ fuel staging had similar $\mathrm{NO}_{\mathrm{x}}$ emissions as the case with about $20 \%$ flue gas recirculation. With the combination of $44 \%$ fuel staging and $25 \%$ flue gas recirculation the $\mathrm{NO}_{\mathrm{x}}$ emissions have been reduced to the minimum measured value of about $560 \mathrm{mg} / \mathrm{m}_{0}^{3} @ 3 \% \mathrm{O}_{2}$. 


\subsection{Conclusions}

In the present study, the heavy fuel-oil combustion in a $9 \mathrm{MW}$ boiler was numerically investigated. The Euler-Lagrange method and the ED model with a twostep global reaction mechanism were employed. The standard k- $\varepsilon$ model is used for the turbulence, and an empirical droplet size distribution is used for the spray injected by a steam blast atomizer.

Simulation results with the existing burner showed that increasing of the temperature of the combustion air from $373 \mathrm{~K}$ to $746 \mathrm{~K}$ leads to a higher peak temperature from $2240 \mathrm{~K}$ to $2390 \mathrm{~K}$, while reducing $\mathrm{O}_{2}$ concentration of the combustion air from about $23.1 \mathrm{wt} \%$ to $11.5 \mathrm{wt} \%$ results in more uniform temperature distribution with a peak temperature of $1510 \mathrm{~K}$. Further investigation was done with recycling various ratios of flue gas into the primary and secondary air respectively to introduce various $\mathrm{O}_{2}$ concentration conditions for the combustion air flow. Four cases which are possible for application in the field test were then numerically studied and compared with the Base Case results. The case with the lowest $\mathrm{O}_{2}$ concentration in the primary air has the least peak temperature. It was shown that besides thermal $\mathrm{NO}_{\mathrm{x}}$, fuel bound nitrogen is also one of the dominant contributors to $\mathrm{NO}_{\mathrm{x}}$ formation in heavy fuel-oil combustion. By introducing flue gas recirculation, thermal NOx can be reduced to a low level, leaving the fuel NOx playing the dominant role. The interaction between soot and radiation also showed considerable influence on the NOx profiles. In the case with hot combustion air, the peak temperature was reduced by $140 \mathrm{~K}$ and the $\mathrm{NO}$ x emission was decreased to about a quarter. It should be noted that although the predicted $\mathrm{NO}_{\mathrm{x}}$ emissions in the Base Case resemble the measured data very well, the modeling should only be qualitatively used because many intermediate products and processes such as thermal cracking, coking, etc. were not included. More detailed reaction mechanism is required for further numerical study of heavy fuel oil combustion, especially under high temperature and low oxygen conditions.

For heavy fuel-oil combustion, a more uniform temperature distribution in the boiler can be achieved by diluting the primary and secondary air flow with flue gas recirculation. In this way the thermal $\mathrm{NO}_{\mathrm{x}}$ can be effectively reduced, while the remained fuel $\mathrm{NO}_{\mathrm{x}}$ formation is mainly dependent on the local combustion 
characteristics and the initial concentration of nitrogen-bound compounds. The contribution of fuel bound nitrogen to $\mathrm{NO}$ formation and its reduction requires further investigation supported by the detailed reaction mechanism.

Realization of HiTAC condition in heavy fuel-oil combustion depends on the possibility to guarantee a feasible and sufficiently high level of entrainment of flue gas into the evaporating spray jet. Fuel staging has a similar effect on NOx reduction since the combustion zone is enlarged when the fuel is injected into flue gas containing relatively low oxygen content. 


\section{References}

[1] R. Weber, J. P. Smart, W. vd Kamp, On the (MILD) combustion of gaseous, liquid, and solid fuels in high temperature preheated air, Proceedings of the Combustion Institute 30 (2005): 2623-2629.

[2] A.L. Verlaan, G. Deus Vazquez, M. Kösters, N. Lallemant, S. Orsino, R. Weber, Excess enthalpy combustion of light and heavy fuel oils, results of high temperature air combustion trials, IFRF Doc. No. F 46/y/2, 1999.

[3] R. Weber, S. Orsino, A.L. Verlaan, N. Lallemant, Combustion of light and heavy fuel oils in high temperature air, J. Inst. Energy 74 (2001): 38-47.

[4] S. Wu, W. Chang, J. Chiao, Low NOx heavy fuel oil combustion with high temperature air. Fuel 86 (2007): 820-828.

[5] J. B. Zeldovich, The oxidation of nitrogen in combustion and explosion, Acta Physicochimica, 21(1946): 577-628.

[6] C. T. Bowman, D. J. Seery, Emissions from continuous combustion systems, Plenum Press: New York, 1972.

[7] J. Warnatz, NOx formation in high temperature processes, University of Stuttgart, Germany, 2001.

[8] D. L. Baulch, C. J. Cobos, R. A. Cox, et al., Evaluated kinetic data for combustion modelling, Journal of Physical and Chemical Reference Data, 21 (1992): 411-734.

[9] C. K. Westbrook and F. L. Dryer, Chemical kinetic modelling of hydrocarbon combustion, Progress in Energy and Combustion Science, 10-1 (1984): 1-57.

[10] T. J. Houser, M. Hull, R. Alway, and T. Biftu. Int. Journal of Chem. Kinet., Vol. 12 (1980):569.

[11] G. G. De Soete, Overall reaction rates of no and $\mathrm{n}_{2}$ formation from fuel nitrogen, 15th Symp. (Int.) on Combustion, Vol.15 (1) (1975): 1093-1102.

[12] T. J. Houser, M. Hull, R. Alway, and T. Biftu. Int. Journal of Chem. Kinet., 12:579, 1980.

[13] P. A .Tesner, T. D. Smegiriova, and V. G. Knorre, Kinetics of dispersed carbon formation, Combustion and Flame, 17-2 (1971): 253-260. 
[14] B.F. Magnussen, B.H. Hjertager, On mathematical modelling of turbulent combustion with special emphasis on soot formation and combustion, 16th Symp. (Int.) on Combustion, 16-1 (1977): 719-729.

[15] S.J. Dijkstra, B.C.H. Venneker, M.A.F. Derksen, et al., Experiences with firing pyrolyis fuel oil on industrial scale, 25th Deutsche Flammentag, Karlsruhe, Germany (2011).

[16] B.C.H. Venneker, J.N.A. Koomen, M.P. Morskate, et al., Towards HiTAC conditions in a 9MW oil fired industrial boiler, Combura 2013 symposium, Kasteel Vaeshartelt, Maastricht, the Netherlands (2013).

[17] S. C. Hill, L. D. Smoot, Modeling of nitrogen oxides formation and destruction in combustion systems, Prog. Energ Combust, 26, 4-6 (2000): 417-458.

[18] P. F. Nelson, A. N. Buckley, and M. D. Kelly, Functional forms of nitrogen in coals and the release of coal nitrogen as NOx precursors $\left(\mathrm{HCN}\right.$ and $\left.\mathrm{NH}_{3}\right)$. In 24th Symposium (Int'l) on Combustion, The Combustion Institute (1992): 1259-1267.

[19] Yang, W. and Blasiak, W., Numerical study of fuel temperature influence on single gas jet combustion in highly preheated and oxygen deficient air, Energy, Vol.30 (2005): 385-398. 


\section{CHAPTER 6.}

\section{CONCLUSIONS AND}

\section{RECOMMENDATIONS}

In this chapter, the main conclusions and findings from the investigations on the methanol spray combustion in conventional conditions, ethanol spray combustion under various coflow conditions and heavy oil spray combustion in a 9MW boiler are summarized. Recommendations and perspectives based on the findings are made for future studies. 


\subsection{Main conclusions and model development}

In the present study we have investigated fuel oil spray combustion with two objectives in mind: to identify and specify the important parameters for achieving good model performance and to understand how HiTAC conditions can be achieved.

First in order to gain detailed knowledge regarding spray combustion, the NIST methanol spray flame under a conventional condition has been numerically studied. Models for turbulence, atomization, collision, coalescence and secondary breakup, evaporation, combustion, radiation, etc. were all included in the simulation and discussed. The main concussions are as follow:

- The simulation results showed good agreement with the experimental data. All observations found in the experiment, such as gaseous and droplet velocity components, droplet size distribution at various elevations, and measured temperature at the exit were captured by the models.

- For turbulence modelling, some previous numerical studies reported that the standard k- $\varepsilon$ model shows poor performance compared to other models, such as Realizable k- $\varepsilon$ model or Shear-Stress Transport (SST) k- $\omega$ model. However, good agreement with experimental data was achieved with the standard k- $\varepsilon$ model in the simulations carried out in the present study. The enhanced wall treatment was found a key factor in the simulation. This is based on the analysis of $y+$ value in the near-wall region in the numerical study.

- For spray calculations (droplet size and velocity distribution), experimental data have been analyzed and discussed, prior to modelling. A LISA model with a Rosin-Rammler distribution of droplets was used to mimic boundary conditions for droplet size and velocity distribution. Special attention was given to the analysis of the spray trajectory. The advantage of this method has been discussed in comparison to direct application of the measured data. It should be noted that the properties of fuel oil, such as viscosity, surface tension and saturation vapor pressure under various temperature conditions, were also used in the simulation in order to take into account their influence. 
- For evaporation modelling, the rate of vaporization was governed by gradient diffusion, with the flux of droplet vapor into the gas phase related to the difference in vapor concentration at the droplet surface and the bulk gas. For radiation, the discrete ordinate (DO) model with a variable absorption coefficient, weightedsum-of-gray-gases model (WSGGM) were used. They both have shown good results in various previous simulations carried out by the author and other researchers.

- For combustion assessment, a simple Eddy Dissipation (ED) model was deemed not suitable because it often overestimates temperature due to its inherent assumptions. Instead the laminar flamelet model with detailed reaction mechanism was employed showing good capability in simulation. This flamelet model could be improved and further developed based on the reaction mechanism and study of ignition and extinction processes of the specific fuel.

- The influence of the source term in the mixture fraction variance equation only occurs in the lower region while the combustion mainly occurs in the flame area. Therefore the combustion characteristics are not strongly influenced by the modelling of the variance equation.

Next, the investigation was further extended to spray combustion under HiTAC coflow conditions, i.e. with high temperature and low $\mathrm{O}_{2}$ concentration. Ethanol spray combustion under various co-flow conditions has been experimentally studied in the work of Rodrigues, et al. and HiTAC conditions have been achieved with the Delft Spray in Hot Co-flow (DSHC) burner. The same methods and models as used in the conventional spray combustion modelling were used for the simulation of DSHC flames. The main conclusions are summarized below:

- In the experiment the co-flow temperature and oxygen dilution cannot be varied independently. The atomization was markedly different under different co-flow conditions, thus the comparative numerical studies are crucial to investigate and understand details of spray combustion.

- In the comparative numerical studies it was found that a low $\mathrm{O}_{2}$ concentration is the key parameter for achieving HiTAC conditions. It leads to a low peak temperature in the flame and reduced consumption rate of the fuel. Both slow 
down the evaporation process of droplets. Thus the volume of the combustion zone increases creating a HiTAC-like condition.

- Although the increased temperature in the co-flow leads to a decrease in its density which then enlarges the flame zone, the increased enthalpy input still results in a high peak temperature in the flame. Thus more thermal $\mathrm{NO}_{\mathrm{X}}$ is produced. A high co-flow temperature also accelerates the evaporation of droplets along the spray trajectories, which has negative effect on the "delay" of combustion process and generation of HiTAC-like conditions. However, due to the enlarged flame zone, the temperature difference between the peak temperature and the co-flow temperature decreases with the increased co-flow temperature.

- Since the mixing process is more difficult to be optimized towards HiTAC conditions for heavy fuel oils than light fuel oils, suggestion is given that the optimization needs to be carried out based on the analysis of a specific fuel in order to create a HiTAC-like condition.

- For validation of spray combustion under various co-flow conditions, the numerical results of the cold co-flow case and the hot co-flow case were compared with the experimental data under similar co-flow conditions. Good match was shown on the flame profile, and the range and trend of SMD at various elevations. A further match improvement can be expected based on a more detailed analysis of spray. This has been discussed in the modelling of the NIST methanol spray combustion.

- Due to the effect of hot co-flow on the atomization process (including the atomizer) and limitations of the measuring device in the experiment, it becomes more difficult than in the conventional co-flow conditions, to obtain data of droplets, especially at low elevations which are essential for defining boundary conditions of droplets in simulation. Similarly the comparison between experimental data and predictions in the near nozzle region is not trivial. In the validation cases a conditional droplet injection model was introduced based on work of Ma et al. This model is tuned based on a large amount of measured data, and preliminary predictions of droplets from simulation to count for the droplets not captured in the experiment and evaporated at low elevations. 
- The analysis of spray and boundary conditions, and the validation of the implemented models and methods in multiple cases are required to obtain a convincing and transferable modeling approach.

Finally, heavy fuel-oil combustion in a 9MW boiler towards HiTAC conditions was numerically investigated. The standard $k-\varepsilon$ model was used for the turbulence modeling whereas an empirical droplet size distribution was applied to approximate the spray injected by a steam blast atomizer. The Euler-Lagrange method was employed for computations. Since detailed reaction mechanisms of heavy fuel oils are not available yet, the ED model with a two-step global reaction mechanism was used instead. The main conclusions are as follows:

- Due to the complexity of geometry and inlet conditions, i.e. staged supply of highly swirled combustion air, high velocity of steam assisting fuel oil injection, very small orifices through atomizer vs. a 3D large volume of boiler, etc., a method of staged simulation employing the second order upwind scheme was used.

- The results showed that a relatively uniform temperature distribution in the boiler can be achieved by diluting the primary and secondary air flow with flue gas recirculation. Also, the thermal $\mathrm{NOx}$ can be effectively reduced, while the remained fuel $\mathrm{NO}_{\mathrm{x}}$ formation is mainly dependent on the local combustion characteristics and the initial concentration of nitrogen-bound compounds. The contribution of fuel bound nitrogen to $\mathrm{NOx}$ formation and its reduction requires further investigation supported by the detailed reaction mechanism.

- The formation of soot should be taken into account since it reduces the peak temperature in the flame, and thus decreases the formation of thermal $\mathrm{NO}_{\mathrm{x}}$.

- With the ED model with a two-step global mechanism many intermediate products and processes such as thermal cracking, coking, etc. are not included. This leads to an overestimation of the temperature profile and underestimation of the soot formation. More detailed reaction mechanism is required for further numerical study of heavy fuel oil combustion, especially under high temperature and low oxygen conditions. 
- Realization of HiTAC-like conditions in heavy fuel-oil combustion depends on the possibility to guarantee a sufficiently high level of flue gas recirculation flow into the evaporating spray jet.

Spray flames can be considered as combustion with multiple (millions of) moving sources of fuel injection. The surrounding air/ $\mathrm{O}_{2}$ condition is changing due to droplet evaporation, chemical reactions, etc. For fuel gas combustion in HiTAC/flameless/MILD conditions fuel has to be mixed with low $\mathrm{O}_{2}$ concentration flue gas in order to reduce the peak temperature. For fuel oil spray combustion, it is the same case that the dilution/mixing with low $\mathrm{O}_{2}$ concentration flue gas to evaporated droplets is essential, and there are many ways for this purpose, but the reduced $\mathrm{O}_{2}$ concentration along the moving droplets leading to potential secondary cracking, soot formation and flame extinction for a specific fuel oil and operating conditions has to be taken into account.

\subsection{Recommendations and perspectives}

For modeling and validation of spray combustion:

- Analysis of boundary conditions from experiments and proper use of numerical models and methods is essential. In experiments there are often limitations and errors due to either inherent features of the setup or measuring methods, overlooked aspects or even mistakes. In simulations there are always model assumptions and simplification of boundary conditions. A good understanding of these limitations and errors in experiment helps modelers to define boundary conditions and validate the used models in a better way than focusing on the modelling itself. The knowledge of assumptions and simplifications in simulation is helpful to the experimenters to well define the crucial boundary conditions and influential parameters used in simulation, and to pay special attention to the data of concern for validation.

- Turbulence modelling is crucial in spray combustion simulation due to its strong coupling with other involved modeled processes. The grids and $\mathrm{y}+$ value require special attention for the proper use of near-wall treatment and discretization methods, and need to be analyzed according to the specific investigated geometry. 
- The used laminar flamelet model with tabulated chemistry method since it has been generated based on detailed reaction mechanism, is an effective way for spray combustion modeling and to account for strong coupling among involved processes. For methanol and ethanol fuels such reaction mechanisms are available, while for heavy oils, due to their complexity, they do not exist. Therefore future investigations should be focused on describing and establishing relatively detailed reactions able to mimic heavy fuel oil combustion.

- For an accurate prediction of ignition process and lift-off height in the near nozzle region, an application of a non-adiabatic FGM lookup table and LES potentially would capture more features of spray flames.

For spray combustion towards HiTAC conditions:

- The pressure-swirl atomizer was used in the investigated experimental flames (NIST and DSHC) because of its lower complexity compared to other atomizers, and the requirements for light oil atomization. From the point of view of creating HiTAC-like conditions, other two fluids atomizers possess more potential to generate fine droplets and a fuel-diluted environment than the pressure-swirl atomizer, especially for heavy oils. However, the atomization mechanism and the corresponding modelling and measuring methods require more future investigations.

- The enhanced Y-jet steam assisted atomizer shown in the current study can generate a spray with fine droplets by the high-speed steam flow. The droplets are diluted by steam and entrained flue gas before combustion occurs. Staged fuel injection has a similar effect.

- The applied ED model with two-step reaction mechanism can be further optimized by including more intermediate products. This could give better prediction of final temperature in the boilers. Besides, the experimental and numerical study of thermal cracking, formation and aggregation of char, etc., during evaporation for heavy oils and bio oils would lead to a better understanding of spray combustion and application of HiTAC conditions to these oils. 
- Since atomization and evaporation processes are related to the properties of fuel oil, change of the corresponding properties by various means, can be a potential way to tune the combustion characteristics.

- Due to the limitation of external flue gas recirculation, the maximum temperature of co-flow and oxygen in the co-flow is limited. An alternative way to achieve HiTAC-like conditions is to strengthen the internal flue gas recirculation by new concept of burners and create high temperature and low oxygen co-flow.

- In some premixed combustion applications, such as gas turbines, the combustion zone in the combustion chamber also provides a relatively low oxygen and high temperature conditions of flue gas, which can be used as co-flow for either gas or spray injection and create a HiTAC condition. Turn-down to a lower load can be achieved in this way. However, the position of the injector(s) and the corresponding fuel control needs more investigation. 


\section{Appendix A: Summary of models used in the current study}

\begin{tabular}{|c|c|c|c|}
\hline Item & $\begin{array}{c}\text { NIST } \\
\text { (Chapter 2) }\end{array}$ & $\begin{array}{c}\text { DSHC } \\
\text { (Chapter } 3 \& 4)\end{array}$ & $\begin{array}{l}\text { 9MW Boiler } \\
\text { (Chapter 5) }\end{array}$ \\
\hline Fuel oil & Methanol & Ethanol & Heavy oil $\left(\mathrm{C}_{19} \mathrm{H}_{30}\right)$ \\
\hline Computational & \multicolumn{2}{|c|}{$2 \mathrm{D}$ axisymmetric } & 3D (cold and hot states) \\
\hline domain & \multicolumn{3}{|c|}{ Second order upwind scheme } \\
\hline Turbulence model & \multicolumn{3}{|c|}{ Standard k-- $\varepsilon$ turbulence model with: } \\
\hline & \multicolumn{2}{|c|}{ Enhanced wall treatment } & Standard wall function \\
\hline Atomization model & \multicolumn{2}{|c|}{$\begin{array}{c}\text { Linearized Instability Sheet Atomization (LISA) } \\
\text { model (calculated Rosin- Rammler size } \\
\text { distribution) }\end{array}$} & $\begin{array}{l}\text { Droplets with a presumed } \\
\text { Rosin- Rammler size } \\
\text { distribution, a cone angle } \\
\text { and velocity according to } \\
\text { the empirical data of the } \\
\text { steam-blast atomizer }\end{array}$ \\
\hline $\begin{array}{c}\text { Secondary breakup } \\
\text { model }\end{array}$ & \multicolumn{2}{|c|}{ Taylor Analogy Breakup (TAB) model } & - \\
\hline $\begin{array}{c}\text { Collision and } \\
\text { coalescence model }\end{array}$ & \multicolumn{2}{|c|}{ Algorithm of O'Rourke } & - \\
\hline Evaporation model & \multicolumn{3}{|c|}{ Vapor-liquid Equilibrium (VLE) } \\
\hline Radiation model & \multicolumn{3}{|c|}{$\begin{array}{c}\text { Discrete Ordinates (DO) model with a variable absorption coefficient, } \\
\text { weighted-sum-of-gray-gases model (WSGGM) }\end{array}$} \\
\hline \multirow[t]{2}{*}{ Combustion model } & \multicolumn{2}{|c|}{$\begin{array}{l}\text { Steady laminar flamelet model with the detailed } \\
\text { reaction mechanism }\end{array}$} & Eddy Dissipation Model \\
\hline & $\begin{array}{c}32 \text { species and } 167 \text { reactions; } \\
\text { developed by Lindstedt and } \\
\text { Meyer [1] and provided by } \\
\text { Lindstedt and Chen [2] }\end{array}$ & $\begin{array}{l}57 \text { species and } \\
383 \text { reactions; } \\
\text { developed by } \\
\text { Marinov [3] }\end{array}$ & $\begin{array}{l}\text { (ED) with a two-step } \\
\text { global reaction mechanism } \\
\text { including CO }\end{array}$ \\
\hline $\mathrm{NO}_{\mathrm{x}}$ model & - & \multicolumn{2}{|c|}{$\begin{array}{c}\text { Thermal NOx: Extended Zeldovich } \\
\text { mechanism }[4,5]\end{array}$} \\
\hline
\end{tabular}




\begin{tabular}{|c|c|c|c|}
\hline & & - & $\begin{array}{c}\text { Fuel NOx: Intermediate } \\
\text { HCN as the primary } \\
\text { route [6] }\end{array}$ \\
\hline Soot model & - & - & $\begin{array}{c}\text { Two-step Tesner model } \\
{[7,8]}\end{array}$ \\
\hline
\end{tabular}

\section{References}

[1] Lindstedt, R.P. and Meyer, M.P., A dimensionally reduced reaction mechanism for methanol oxidation, in Proceedings of the Combustion Institute, 29(2002): 1395-1402.

[2] International workshop on measurement and computation of turbulent nonpremixed flames. http://www.sandia.gov/TNF/chemistry.html

[3] Marinov, N. M., Kinetic model for high temperature ethanol oxidation, Int. J. Chem. Kinet. 32 (1998): 183-220.

[4] J. B. Zeldovich, The oxidation of nitrogen in combustion and explosion, Acta Physicochimica, vol. 21 (1946): 577-628.

[5] C. T. Bowman, D. J. Seery, Emissions from continuous combustion systems, Plenum Press: New York, 1972.

[6] T. J. Houser, M. Hull, R. Alway, and T. Biftu. Int. Journal of Chem. Kinet., 12:579, 1980.

[7] P. A .Tesner, T. D. Smegiriova, and V. G. Knorre, Kinetics of dispersed carbon formation, Combustion and Flame, 17-2 (1971): 253-260.

[8] B.F. Magnussen, B.H. Hjertager, On mathematical modelling of turbulent combustion with special emphasis on soot formation and combustion, 16th Symp. (Int.) on Combustion, 16-1 (1977): 719-729. 


\section{Appendix B: Comparison of ED model vs. steady laminar flamelet model for the DSHC flame}

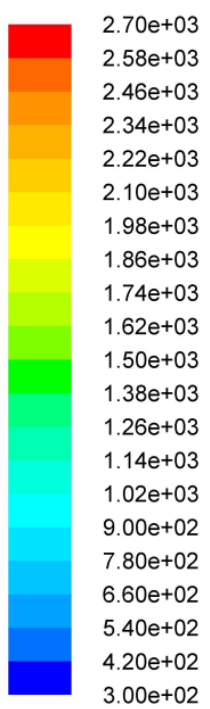

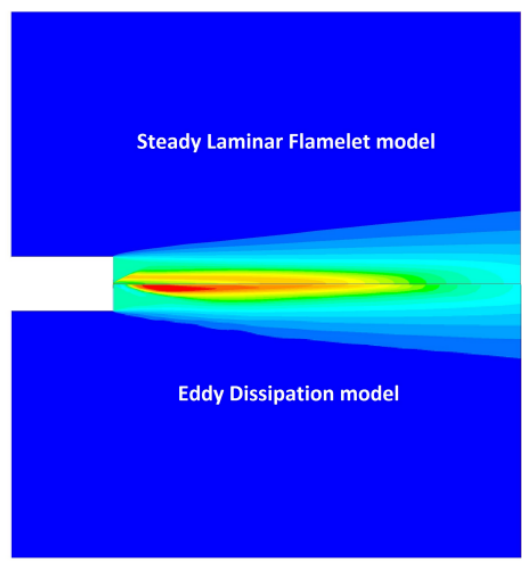

Contours of Static Temperature (k)

Fig.1 Mean temperature contours using the ED model and the Steady Laminar Flamelet model under $1200 \mathrm{~K}$ and $21 \mathrm{vol} \% \mathrm{O}_{2}$ co-flow condition

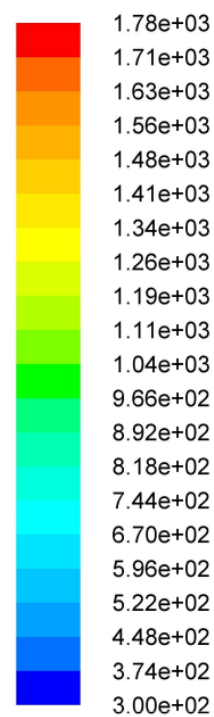

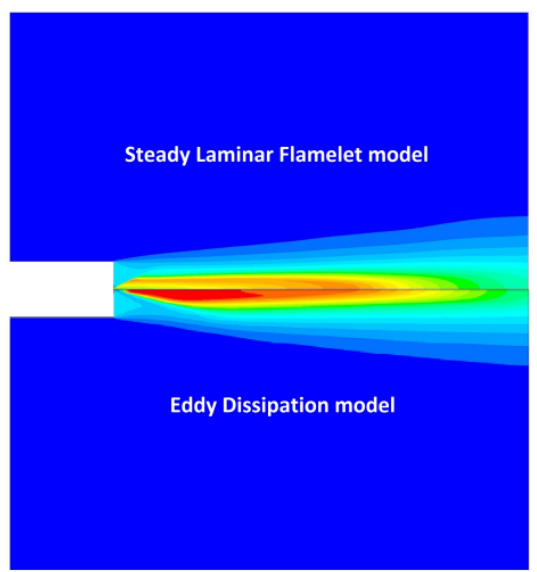

Contours of Static Temperature (k)

Fig.2 Mean temperature contours using the ED model and the Steady Laminar Flamelet model under $600 \mathrm{~K}$ and $12 \mathrm{vol} \% \mathrm{O}_{2}$ co-flow condition 
The predicted mean temperature contours of the DSHC flame using the ED model and the steady laminar flamelet model under two co-flow conditions (1200K and $21 \mathrm{vol} \%$ $\mathrm{O}_{2} ; 600 \mathrm{~K}$ and $12 \mathrm{vol}_{\%} \mathrm{O}_{2}$ ) are shown in Fig.1 and Fig.2, respectively.

The peak temperature for the steady laminar flamelet model is much lower than for the ED model in both conditions. This is due to the fact that with the global reaction mechanism the ED model does not take into account the formation of many intermediate and radical species, leading to overestimated peak temperature.

As shown in Fig.1 and Fig.2, the ED model predicts a peak temperature zone in the middle, while the high temperature exists at the side of the flame using the steady laminar flamelet model. The temperature profiles at height $\mathrm{z}=100 \mathrm{~mm}$ under $1200 \mathrm{~K}$ and 21 vol $\% \mathrm{O}_{2}$ co-flow condition are shown in Fig. 3 and Fig.4 shows those at $\mathrm{z}=700 \mathrm{~mm}$.

An interesting observation is that the flame lift-off height with the ED model is larger than that with the steady laminar flamelet model. This is found attributed to the high concentration of fuel in the near nozzle region with the ED model (more details see the work of A.W. van de Wolfshaar [1]). In this work it was also reported that by adjusting the empirical mixing rate constants, the ED model has the potential to obtain similar temperature predictions as the steady laminar flamelet model.

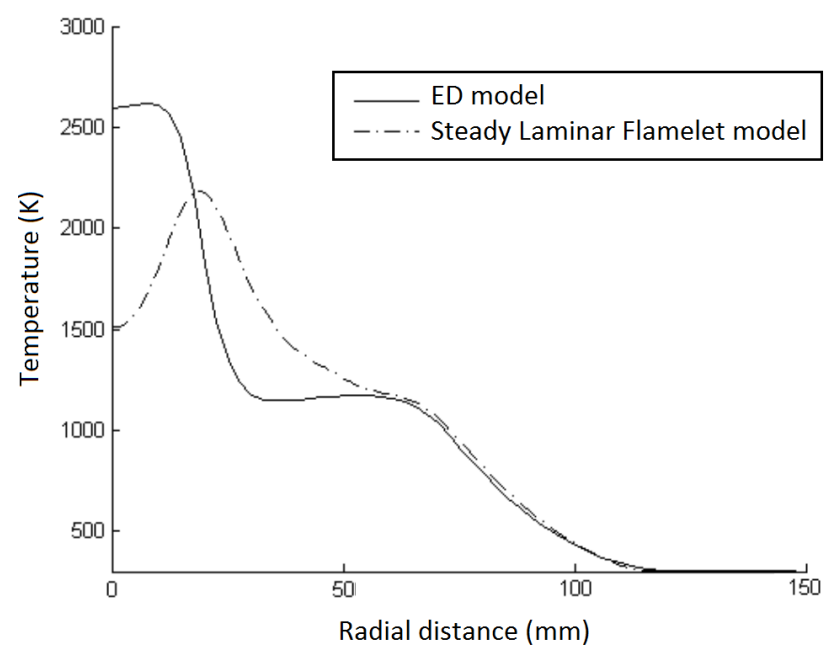

Fig. 3 Comparison of temperature profiles at height $\mathrm{z}=100 \mathrm{~mm}$ (under $1200 \mathrm{~K}$ and $21 \mathrm{vol} \% \mathrm{O}_{2}$ co-flow condition) 


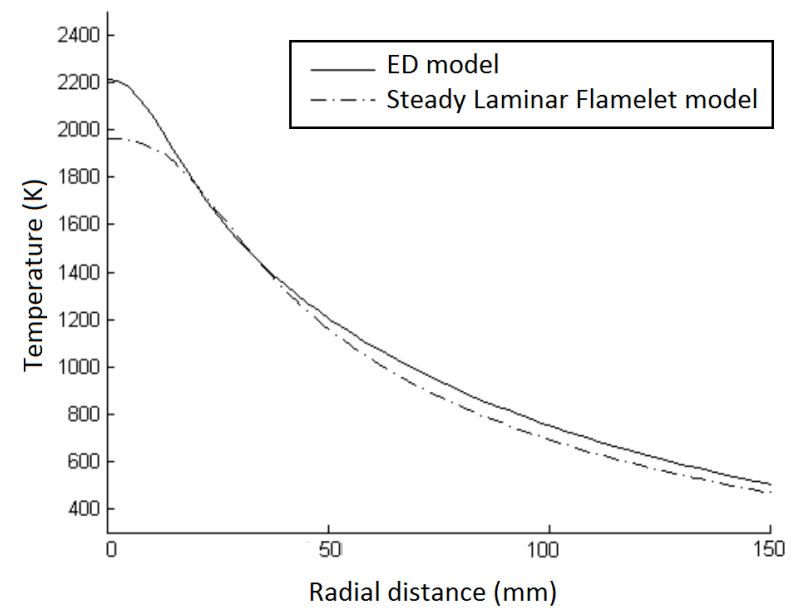

Fig.4 Comparison of temperature profiles at height $\mathrm{z}=700 \mathrm{~mm}$ (under $1200 \mathrm{~K}$ and $21 \mathrm{vol} \% \mathrm{O}_{2}$ co-flow condition)

\section{References}

[1] A.W. van de Wolfshaar, CFD modeling of an ethanol spray flame under HiTAC conditions, master thesis, University of Twente, 2012. 


\section{ABOUT THE AUTHOR}

Shanglong Zhu

Born on December 3rd, 1983

in Chaohu, Anhui, China

\section{4-2017 Combustion Engineer}

Product Manufacturing, Ansaldo Thomassen, the Netherlands

PhD researcher

2009-2013 Faculty of Thermal Engineering, University of Twente, the Netherlands

Supervision of master thesis: CFD modelling of an ethanol spray flame under HiTAC condition, Arjan van de Wolfshaar (Oct. 2010- Jan. 2012)

\section{Visiting researcher}

2010-2013 Faculty of Applied Sciences, Delft University of Technology

Faculty of Mechanical, Maritime and Material Sciences (3mE), Delft

University of Technology, the Netherlands

2006-2009 Thermal/combustion engineer, project manager

Shanghai Marine Diesel Engine Research Institute, China

2003-2006 Master in Engineering Thermophysics

Faculty of Mechanical Engineering, Tongji University, China

1999-2003 Bachelor in Heating, ventilating and air conditioning

Faculty of Environmental Engineering

\section{Bachelor in Computer Science and Technology}

Faculty of Electronics and Information Engineering,

Tianjin University, China 


\section{LIST OF PUBLICATIONS}

\section{Journal and conference papers}

\section{Publications from this thesis:}

- Shanglong Zhu, Artur Pozarlik, Dirk Roekaerts, Hugo Correia Rodrigues, Theo van der Meer, Numerical investigation towards HiTAC conditions in laboratory-scale ethanol spray combustion, Fuel, under review.

- Shanglong Zhu, Dirk Roekaerts, Artur Pozarlik, Theo van der Meer, Eulerian-Lagrangian RANS model simulations of the NIST turbulent methanol spray flame, Combustion Science and Technology, 2015, 187(7):1110-1138.

- Likun Ma, Shanglong Zhu, Hugo Rodrigues, Mark Tummers, Theo van der Meer, Dirk Roekaerts, Numerical investigation of ethanol spray-in-hot-coflow flame using steady flamelet model, The eighth Mediterranean Combustion Symposium, Izmir, Turkey, September 8-13, 2013.

- Shanglong Zhu, Bart Venneker, Dirk Roekaerts, Artur Pozarlik, Theo van der Meer, Numerical investigation towards a HiTAC condition in a 9MW heavy fuel-oil boiler, The Sixth European Combustion Meeting, Lund, Sweden, June $25-28,2013$.

- Shanglong Zhu, Dirk Roekaerts, Theo van der Meer, Numerical simulation of a turbulent methanol spray flame using the Euler-Lagrange method and the steady laminar flamelet model, The Seventh Mediterranean Combustion Symposium, Sardinia, Italy, September 11-15, 2011.

- Shanglong Zhu, Dirk Roekaerts, Theo van der Meer, Numerical study of a methanol spray flame, The Fifth European Combustion Meeting, Cardiff, UK, June 28- July 1, 2011.

\section{Other publications:}

- Jianping Kuang, Mingfen Yang, Shanglong Zhu, Jianzhou Liu, Shicheng Zhang, 
the Characteristic Analysis and Mathematical Simulation of Flow Field in Powdered Coal Gasifier, Proceeding of the 6th International Symposium on Coal Combustion, 2007:712-718.

- Shanglong Zhu, Xiangrong Sui, Wei Zheng, Application of Oxygen-Enriched Combustion Technology in Ladle Roaster, Industrial Furnace, 2007 Vol.29(4):21-23.

- Wei Zheng, Shanglong Zhu, Tong Zhu, Experimental Study on the Effect of Parameters of High Temperature Air Burner on NOx Emission, Dynamical Engineering, 2007, Vol.27(2):287-291.

- Tong Zhu, Shanglong Zhu, Zhenjun Cao, Peng Li, Liang Feng, Experimental Study on the $\mathrm{NO}_{\mathrm{x}}$ Emission of High Temperature Air Combustion, Journal of Engineering Thermophysics, 2006, Vol.27(5):894-896.

- Tong Zhu, Shanglong Zhu, Zhenjun Cao, Peng Li, Experimental Study on the Effect of Burner Structure and Operating Parameters of High Temperature Air Burner on $\mathrm{NO}_{\mathrm{X}}$ Emission, Proceeding of the 11th Chinese Engineering Thermophysics Academy Conference on Combustion, BeiJing, 2005:818-822.

- Shanglong Zhu, Li Chen, Tong Zhu, Jiazheng Wu, Effect of Length-Width Ratio of the Rectangular Air-Jet on NOx Emission in HTAC, Industrial Furnace, 2005 Vol.27(6):4-8.

\section{Conference abstracts}

- Th.H. van der Meer, S. Zhu, H. Rodrigues, E.H. van Veen, D.J.E.M. Roekaerts, M.J. Tummers, B.C.H.Venneker, HiTAC: Heavy Fuel-oil combustion in a HiTAC boiler, Combura Symposium, October 9-10, 2013, Maastricht, the Netherlands.

- Likun Ma, Shanglong Zhu, Hugo Rodrigues, Mark Tummers, Theo van der Meer, Dirk Roekaerts, Modeling of Delft ethanol Jet-in-Hot-Coflow flame with tabulated chemistry method, Combura Symposium, October 9-10, 2013, 
Maastricht, the Netherlands.

- Shanglong Zhu, Artur Pozarlik, Theo van der Meer, Hugo Rodrigues, Mark Tummers, Dirk Roekaerts, Bart Venneker, Heavy Fuel-oil combustion in a HiTAC boiler, Combura Symposium, October 3-4, 2012, Maastricht, the Netherlands.

- Shanglong Zhu, Dirk Roekaerts, Theo van der Meer, Initial simulations of an ethanol spray combustion under HiTAC condition, 2nd Workshop on Measurement and Computation of Turbulent Spray Combustion (TCS2), September 11, 2011, Sardinia, Italy.

- Th.H. van der Meer, S. Zhu, H. Rodrigues, D.J.E.M. Roekaerts, M.J. Tummers, B.C.H.Venneker, HiTAC: Heavy Fuel-oil combustion in a HiTAC boiler, Combura Symposium, October 10-11, 2011, Ede, the Netherlands.

- Shanglong Zhu, Jim. B.W. Kok, Theo. H. van der Meer, Numerical study of a methanol spray flame, 13th International Conference on Numerical Combustion, April 27-29, 2011, Corfu, Greece.

- Shanglong Zhu, Th.H. van der Meer, J.B.W. Kok, H. Rodrigues, D.J.E.M. Roekaerts, M.J. Tummers, Marco Derksen, Koen Steernberg, Heavy Fuel-oil combustion in a HiTAC boiler, Combura Symposium, October 12-13, 2010, Maastricht, the Netherlands.

\section{Presentations at conferences}

(Presenter indicated with underline)

- Th.H. van der Meer, $\underline{\text { S. Zhu }}, \underline{\text { H. Rodrigues }}$, E.H. van Veen, D.J.E.M. Roekaerts, M.J. Tummers, B.C.H.Venneker, HiTAC: Heavy Fuel-oil combustion in a HiTAC boiler, Combura Symposium, October 9-10, 2013, Maastricht, The Netherlands.

- Likun Ma, Shanglong Zhu, Hugo Rodrigues, Mark Tummers, Theo van der 
Meer, Dirk Roekaerts, Modeling of Delft ethanol Jet-in-Hot-Coflow flame with tabulated chemistry method, Combura Symposium, October 9-10, 2013, Maastricht, the Netherlands.

- Likun Ma, Shanglong Zhu, Hugo Rodrigues, Mark Tummers, Theo van der Meer, Dirk Roekaerts, Numerical investigation of ethanol spray-in-hot-coflow flame using steady flamelet model, The eighth Mediterranean Combustion Symposium, Izmir, Turkey, September 8-13, 2013.

- Shanglong Zhu, Bart Venneker, Dirk Roekaerts, Artur Pozarlik, Theo van der Meer, Numerical investigation towards a HiTAC condition in a 9MW heavy fuel-oil boiler, The Sixth European Combustion Meeting, Lund, Sweden, June 25-28, 2013.

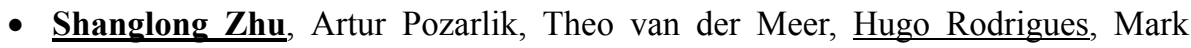
Tummers, Dirk Roekaerts, Bart Venneker, Heavy Fuel-oil combustion in a HiTAC boiler, Combura Symposium, October 3-4, 2012, Maastricht, the Netherlands.

- Shanglong Zhu, Artur Pozarlik, Theo van der Meer, Hugo Rodrigues, Mark Tummers, Dirk Roekaerts, Ethanol spray combustion under HiTAC condition, 34th International Symposium on Combustion, July 29- August 3, 2012, Warsaw, Poland.

- Th.H. van der Meer, $\underline{\text { S. Zhu }}$ H. Rodrigues, D.J.E.M. Roekaerts, M.J. Tummers, B.C.H.Venneker, HiTAC: Heavy Fuel-oil combustion in a HiTAC boiler, Combura Symposium, October 10-11, 2011, Ede, the Netherlands.

- Shanglong Zhu, Dirk Roekaerts, Theo van der Meer, Initial simulations of an ethanol spray combustion under HiTAC condition, 2nd Workshop on Measurement and Computation of Turbulent Spray Combustion (TCS2), September 11, 2011, Sardinia, Italy.

- Shanglong Zhu, Dirk Roekaerts, Theo van der Meer, Numerical simulation of a turbulent methanol spray flame using the Euler-Lagrange method and the steady laminar flamelet model, The Seventh Mediterranean Combustion Symposium, September 11-15, 2011, Sardinia, Italy. 
- Shanglong Zhu, Dirk Roekaerts, Theo van der Meer, Numerical study of a methanol spray flame, The Fifth European Combustion Meeting, June 28- July 1, 2011, Cardiff, UK.

- Shanglong Zhu, Jim. B.W. Kok, Theo. H. van der Meer, Numerical study of a methanol spray flame, 13th International Conference on Numerical Combustion, April 27-29, 2011, Corfu, Greece.

- Shanglong Zhu, Th.H. van der Meer, J.B.W. Kok, H. Rodrigues, D.J.E.M. Roekaerts, M.J. Tummers, Marco Derksen, Koen Steernberg, Heavy Fuel-oil combustion in a HiTAC boiler, Combura Symposium, October 12-13, 2010, Maastricht, The Netherlands.

- Shanglong Zhu, Th.H. van der Meer, J.B.W. Kok, H. Rodrigues, D.J.E.M. Roekaerts, M.J. Tummers, Marco Derksen, Koen Steernberg, Heavy fuel-oil combustion in a HiTAC boiler, Combura Symposium, October 16, 2009, Nieuwegein, the Netherlands. 


\section{ACKNOWLEDGEMENTS}

Undertaking this $\mathrm{PhD}$ has been a truly life-changing experience for me and it would not have been possible to do without the support and guidance that I received from many people.

First and foremost I would like to express my special appreciation and thanks to my supervisor, Professor dr.ir. T.H. Van der Meer. You have been a tremendous mentor to me, being supportive since the day I began with my $\mathrm{PhD}$ project. You always provide me constructive advice and guidance, while leaving space to me to explore the unknown, just like a kind but strict father to a child who is curious about the surrounding world. Besides, I want to say it again that you do live in an area looks like my unpolluted hometown which exists now only in my childhood memories.

I also would like to thank my co-supervisor, Professor dr. D.J.E.M. Roekaerts. Your academic instructions and innovative inspiration, with always a smiling face, have been encouraged me to go deep into my research and smile at difficulties. I gratefully acknowledge the opportunity you provided me to be a visiting researcher at TU Delft. The academic seminars and weekly discussions among doctoral and post-doctoral researchers have been my lifetime of wealth.

Many thanks also to my co-supervisor, Dr.ir. A.K. Pozarlik. You have been always providing attentive and meticulous support and guidance, with insightful comments and great patience. Without your precious support, the writing of the thesis would take more time due to my availability for discussions mainly at nights and during weekends.

My gratitude is also extended to my co-supervisor in the first year, Dr.ir. J.B.W. Kok, who possesses immense knowledge of combustion. Your strict attitude towards research has been always motivating me to keep learning.

My sincere thanks also goes to my thesis committee members: Dr.ir. B.C.H. Venneker, Prof.dr.ir. G. Brem, Dr.ir. A.R. Thornton, Prof.dr.ir. S.A. Klein and Dr.ir. L.M.T. Somers, for insightful comments and encouragement, and for the hard questions, which incented me to widen my research from various perspectives. 
I want to express my deep thanks to Dr. Cary Presser at NIST for the discussion of the details of the NIST flame. I also thank Dr. Jeroen Vancoillie and Reni de Meester from Gent University, Dr. Michael Stoelllinger from TUDelft, for the discussions of chemical reaction mechanisms. I appreciate also the support from Wouter Den Breeijen at Twente University for using the cluster, UDF coding and contacting ANSYS Service Center.

I would also like to give my special thanks to Dr. Hugo C.Rodrigues for the efforts on the experimental data of the DHSC flames, and to Joris Koomen for the testing of the heavy oil boiler. I also thank Dr. Likun Ma for your work on the numerical validation of the DHSC flames using multiple methods. We had many discussions and your fruitful results answered many questions of mine and verified some of my inferences.

In addition, thanks to Technology Foundation STW for financial support of my project.

I thank all the members in the laboratory of thermal engineering at Twente University and Process \& Energy Department at TUDelft (too many to list here but you know who you are!), for providing support and friendship that I need. My thanks also goes to Ansaldo Thomassen for the opportunity to further investigate premixed combustion, work with experienced colleagues and apply my knowledge into practice on GT's.

I also thank my friends, Lixian Xu, Hongping Luo, Weihua Zhou, Qiwei He, Jie Zhao, Yali Zhang, Meng Wang, Hao Wen, Jing Hu, etc. for the sharing of experience from life and work, cook, and all the fun we had together.

Of course no acknowledgments would be complete without giving thanks to my parents. Without you there would be no me. You have taught me a lot. Especially my mom, you taught me how to be a good person, and the truth of "one good return deserves another".

Thanks to Teacher, Zedong Mao, for the better understanding of this world and the significance of Philosophy. You and your works belong to the whole world.

Last, but certainly not least, I must acknowledge with deep love my wife, Wei Zheng, and my daughter, Luna Zhu. No matter how tied I get, I become enlightened the moment I see you two. Wei, you have been always there supporting me, for better, for worse, for richer, for poorer, in sickness and in health. Your complete and unconditional love carries me through always. I love you. 